\title{
MATHEUS SCHMidT SOARES
}

Avaliação da hemodinâmica cerebral através da técnica de ultrassonografia Doppler e suas correlações com as variações da pressão intracraniana em um modelo animal de hipertensão intracraniana

Tese apresentada à Faculdade de Medicina da Universidade de São Paulo para obtenção do título de Doutor em Ciências

Programa de Neurologia

Orientador: Prof Dr Wellingson Silva Paiva

(Versão corrigida. Resolução CoPGr 6018/11, de 1 de novembro de 2011. A versão original está disponível na Biblioteca da FMUSP) 
Dados Internacionais de Catalogação na Publicação (CIP)

Preparada pela Biblioteca da

Faculdade de Medicina da Universidade de São Paulo

Creprodução autorizada pelo autor

Soares, Matheus Schmidt

Avaliação da hemodinâmica cerebral através da técnica de ultrassonografia Doppler e suas

correlações com as variações da pressão intracraniana

em um modelo animal de hipertensão intracraniana /

Matheus Schmidt Soares. -- São Paulo, 2018.

Tese(doutorado)--Faculdade de Medicina da

Universidade de São Paulo.

Programa de Neurologia.

Orientador: Wellingson Silva Paiva.

Descritores: 1.Pressão intracraniana

2. Hemorragia cerebral 3.Hipertensão intracraniana

4.Ultrassonografia Doppler 5.Velocidade do fluxo

sanguíneo 6. Modelos animais

$\mathrm{USP} / \mathrm{FM} / \mathrm{DBD}-014 / 18$ 
Podem queimar livros, mas não se queimam ideias; as chamas das fogueiras as superexcitam, em vez de extingui-las. Ademais, as ideias estão no ar, e não há Pirineus bastante elevados para detê-las; e quando é grande e generosa uma ideia, encontra milhares de corações dispostos a almejá-la. 


\section{DEDICATÓRIA}

À minha esposa Fernanda, minha fonte de inspiração, pela dedicação, incentivo e doçura.

Ao meu filho Davi, que faz tudo valer a pena e me ensinou a sentir o mais puro amor. 


\section{AGRADECIMENTOS}

A Deus, por todas as oportunidades de aprendizado.

Ao Prof. Dr. Manoel Jacobsen Teixeira, pelo exemplo de dedicação à Neurocirurgia brasileira, e pelos ensinamentos e apoio durante a minha formação como neurocirurgião.

Ao Prof Dr. Wellingson Silva Paiva, pela orientação desta tese, assim como pelos ensinamentos neurocirúrgicos e acadêmicos fornecidos durante a residência médica no HCFMUSP. Também agradeço pela amizade e parceria de sempre.

Ao Prof Dr. Almir Ferreira de Andrade, grande mestre em Neurotraumatologia, idealizador e incentivador deste trabalho.

Ao Prof. Dr. Jose Pinhata Otoch, pelo apoio desde o início do trabalho no LIM 26, permitindo a realização deste trabalho em seu laboratório.

Ao Prof Dr. Edson Bor Seng Shu, pelo auxílio na elaboração deste trabalho.

Ao Prof Dr. Eberval Gadelha Figueiredo, pelos ensinamentos em Neurocirurgia vascular e oportunidades profissionais.

Aos Drs. Ricardo Fontes, Robson Amorim e Wagner Tavares, pelos ensinamentos durante a residência médica e pelas importantes orientações no exame de qualificação.

Aos Drs. Marcelo Lima e Alessandro Belon, pelo auxílio na realização dos experimentos e discussão dos resultados.

Aos funcionários do Laboratório de Investigações Médicas 26, pela colaboração em suas instalações. 
Aos colegas de residência médica Dr. Felippe Saad e Dr. Eloy Rusafa Neto, pela amizade e companheirismo.

Ao Dr. Luiz Favaro, pelos ensinamentos e grandes oportunidades profissionais no início de minha carreira

Ao Dr. Mario Flavio Seixas e sua equipe de neuroanestesiologia, pelo profissionalismo e amizade.

Aos colegas neurocirurgiões e residentes do HCFMUSP, pelo companheirismo e auxilio no desenvolvimento deste trabalho.

Aos funcionários e à equipe de enfermagem da Divisão de Clínica Neurocirúrgica do HC-FMUSP e da Divisão de Neurocirurgia Funcional do IPQ-HCFMUSP, pelo apoio durante os anos de convívio.

Aos colegas médicos e funcionários da Santa Casa de Misericórdia de Passos, pelo comprometimento e competência em bem cuidar de nossos pacientes, e pela compreensão de minhas ausências para o desenvolvimento desta tese.

Ao meu pai Vivaldo e minha mãe Neuman, pelos exemplos de dedicação à família e à medicina. Também pela torcida e amor incondicionais à mim e ao meu irmão.

Ao meu irmão André e minha cunhada Larissa, pelo incentivo e companheirismo de sempre.

Aos familiares e amigos, por existirem. 
Esta tese está de acordo com as seguintes normas, em vigor no momento desta publicação:

Referências: adaptado de International Committee of Medical Journals Editors (Vancouver).

Universidade de São Paulo. Faculdade de Medicina. Serviço de Biblioteca e Documentação. Guia de apresentação de dissertações, teses e monografias.

Elaborado por Anneliese Carneiro da Cunha, Maria Julia de A. L. Freddi, Maria F. Crestana, Marinalva de Souza Aragão, Suely Campos Cardoso, Valéria Vilhena. $3^{a}$ ed. São Paulo: Divisão de Biblioteca e Documentações; 2011.

Abreviatura dos títulos dos periódicos de acordo com List of Journals Indexed in Index Medicus. 


\section{SUMÁRIO}

Lista de abreviaturas e siglas

Lista de figuras

Lista de tabelas

Lista de gráficos

Resumo

Abstract

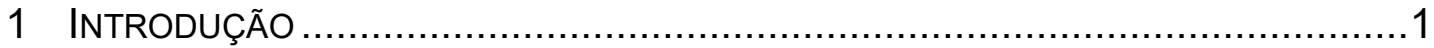

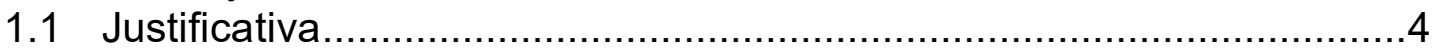

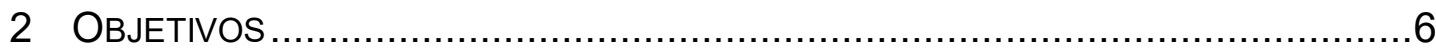

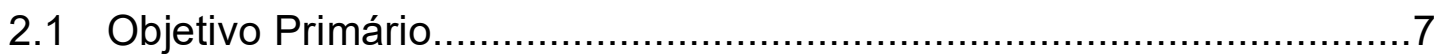

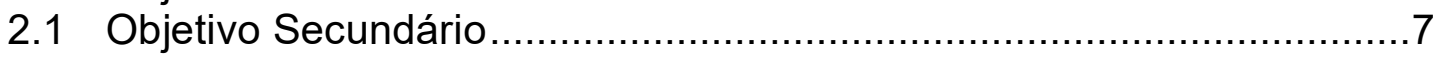

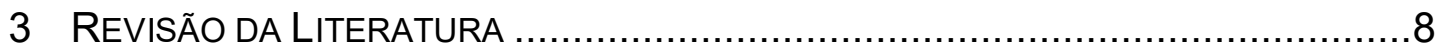

3.1 Pressão Intracraniana e Hipertensão Intracraniana ......................... 9

3.2 Análises Quantitativa e Qualitativa da PIC ......................................14

3.3 Pressão de Perfusão Cerebral e Autorregulação .............................17

3.4 Dispositivos para Monitoração Invasiva da Pressão Intracraniana .......................................................................... 19

3.5 Avaliação não Invasiva da PIC: Doppler Transcraniano ....................22

3.6 Medidas Clínicas para o Tratamento da Hipertensão lintracraniana ..............................................................................

3.7 Hematoma Intracerebral Espontâneo ............................................30

3.8 Modelos Experimentais de Hematoma Espontâneos.........................37

3.8.1 Modelo de injeção intracerebral de sangue autólogo .....................38

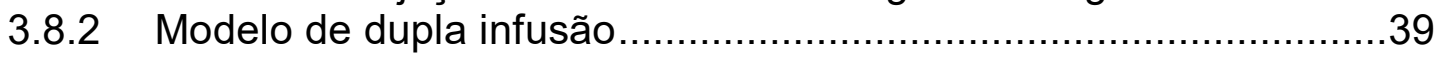

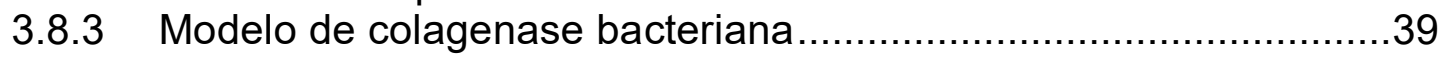

3.8.4 Modelo de avulsão dos vasos sanguíneos cerebrais....................40

3.8.5 Modelo de hematoma cerebral com balão ................................40

3.8.6 Modelos em animais girencéfalo .........................................42

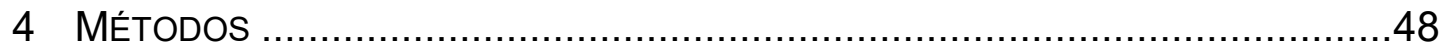

4.1 Aspectos Éticos.....................................................................49

4.2 Preparação do Animal: Anestesia e Monitoração ...............................50

4.3 Método de Monitoração da Pressão Intracraniana.............................53

4.4 Método de Avaliação da Hemodinâmica Cerebral com Ultrassonografia Doppler Craniano ..........................................55

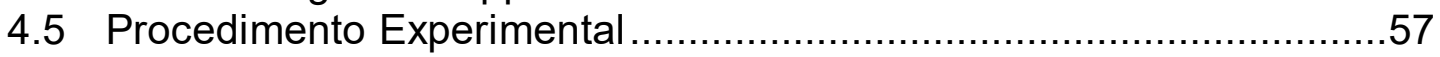

4.6 Instrumento de Coleta de Dados ....................................................63

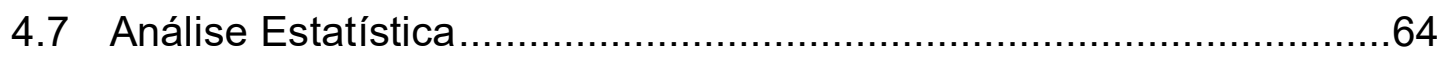

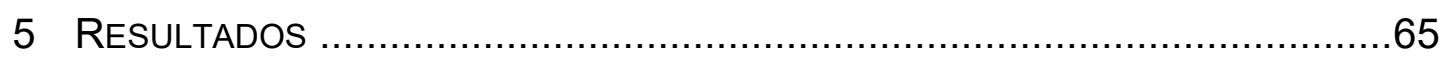

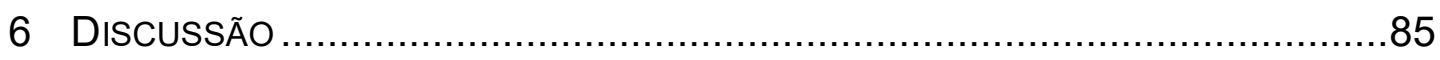


6.1 Considerações sobre o Modelo Animal de HIC

.86

6.2 Considerações sobre as Correlações da PIC com os Parâmetros do DTC

6.3 Efeito da Infusão de Solução Salina Hipertônica no Presente Modelo Experimental

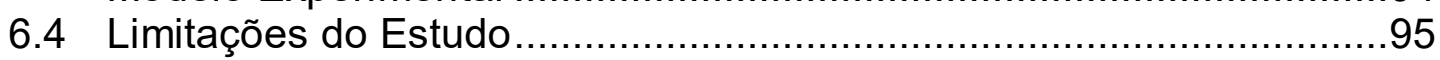

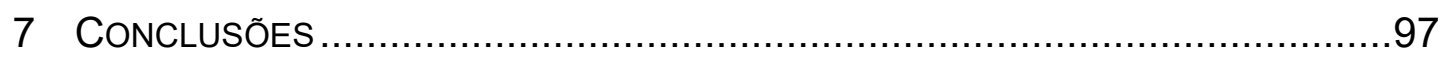

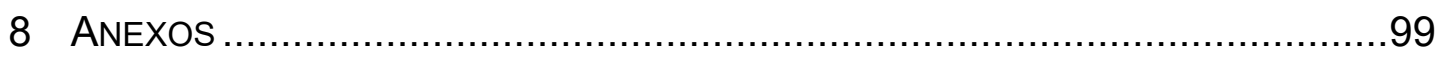

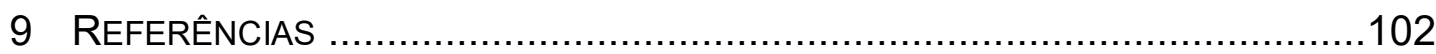




\section{LISTA DE ABREVIATURAS E SIGLAS}

AAS

AHA

AVE

CAPPesq

DTC

DVE

$\mathrm{EtCO}_{2}$

FAPESP

$\mathrm{FIO}_{2}$

FMUSP

FSC

GCS

HIC

HIE

IP

IV

LCR

LCS

LIM 26

MAV

PAD

PAM

PAS

PEEP

PIC

PPC

PRx

RCV
- Ácido acetilsalicílico

- American Heart Association

- Acidente vascular encefálico

- Comissão de Ética para Análise de Projetos de Pesquisas

- Doppler transcraniano

- Derivação ventricular externa

- Dióxido de carbono expirado

- Fundação de Apoio a Pesquisa do Estado de São Paulo

- Fração inspirada de oxigênio

- Faculdade de Medicina da Universidade de São Paulo

- Fluxo sanguíneo cerebral

- Escala de Coma de Glasgow

- Hipertensão intracraniana

- Hematoma intracerebral espontâneo

- Índice de pulsatilidade

- Intra venosa

- Líquido cefalorraquidiano

- Lesões cerebrais secundárias

- Laboratório de Investigação Médica 26

- Malformações arteriovenosas

- Pressão arterial diastólica

- Pressão arterial média

- Pressão arterial sistólica

- Pressão positiva expiratória final

- Pressão intracraniana

- Pressão de perfusão cerebral

- Índice de reatividade pressórica cerebrovascular

- Resistência cerebrovascular 


$\begin{array}{ll}\text { RNM } & \text { - Ressonância magnética } \\ \text { rtPA } & \text { - Plasminogênio tecidual recombinante } \\ \text { SatO }_{2} & \text { - oximetria de pulso } \\ \text { SF } & \text { - Solução fisiológica (NaCl 0,9\%) } \\ \text { SH } & \text { - Solução salina hipertônica } \\ \text { SNC } & \text { - Sistema nervoso central } \\ \text { SSH } & \text { - Solução salina hipertônica } \\ \text { TC } & \text { - Tomografia computadorizada } \\ \text { TCE } & \text { - Traumatismo cranioencefálico } \\ \text { tPA } & \text { - Ativador de plasminogênio tecidual } \\ \text { USNG com Doppler } & \text { - Ultrassonografia Doppler } \\ \text { UTI } & \text { - Unidade de terapia intensiva } \\ \text { VC } & \text { - Volume corrente } \\ \text { VD } & - \text { Velocidade do fluxo sanguíneo cerebral diastólica } \\ \text { VM } & - \text { Velocidade média do fluxo sanguíneo cerebral } \\ \text { VS } & - \text { Velocidade do fluxo sanguíneo cerebral sistólica }\end{array}$




\section{LISTA DE FIGURAS}

Figura 1 - Curva de Langfitt.................................................... 12

Figura 2 - Morfologia normal da onda da PIC .......................................15

Figura 3 - Morfologia anormal da onda da PIC; complacência intracraniana reduzida ......................................................16

Figura 4 - Locais de inserção de cateteres para monitoração da PIC ...........20

Figura 5 - Curvas de velocidades do fluxo sanguíneo captados pela técnica de Doppler .........................................................25

Figura 6 - Fase inicial do experimento, incluindo transporte em condição adequada e indução pré-anestésica.

Figura 7 - Procedimento de intubação orotraqueal realizado pelo veterinário anestesista ...................................................52

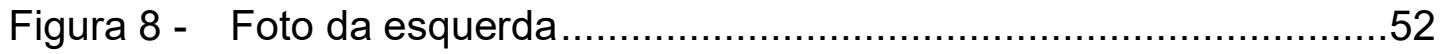

Figura 9 - Aspecto final após cistostomia (na incisão mediana) e cateterismo da artéria femoral direita.

Figura 10 - Sistema de anestesia geral e monitoração sistêmica durante o experimento

Figura 11 - Cateter Neurovent $P^{\circledR}$ utilizado no experimento para aferição de PIC parenquimatosa..

Figura 12 - Doppler das artérias encefálicas. .56

Figura 13 - Ultrassonografia transcraniana mostrando balão insuflado $4 \mathrm{~mL}$ de SF 0,9\% no lobo frontal direito no suíno

Figura 14 - Equipamento de USNG utilizado nos experimentos

Figura 15- À esquerda imagem do experimento com destaque para o cateter monitor da PIC intraparenquimatosa, balão intracerebral e janela para o USNG com Doppler. À direita o transdutor do ultrassom sendo usado na trepanação temporal .

Figura 16 - Fluxograma do procedimento experimental .60

Figura 17 - Ressecção do encéfalo logo após sacrifício do animal. .63 


\section{LISTA DE TABELAS}

Tabela 1 - Distribuição dos suínos de acordo com os valores individuais de PAS, PAD e PAM (em mmHg) mensuradas em cada momento do estudo. São Paulo, 2013

Tabela 2 - Distribuição dos valores médios e desvios padrão dos parâmetros mensurados por Grupo e por Momento de avaliação. São Paulo, 2013

Tabela 3 - Comparações múltiplas da diferença da PIC entre os grupos $\mathrm{B}$ e $\mathrm{A}$ nos diferentes momentos do experimento. São Paulo, 2013

Tabela 4 - Comparações múltiplas da diferença de VS entre os grupos B e A nos diferentes momentos do experimento. São Paulo, 2013

Tabela 5 - Comparações múltiplas da diferença de VD entre os grupos B e A nos diferentes momentos do experimento. São Paulo, 2013

Tabela 6 - Comparações múltiplas da diferença de VM entre os grupos B e A nos diferentes momentos do experimento. São Paulo, 2013

Tabela 7 - Comparações múltiplas da diferença do IP entre os grupos $\mathrm{B}$ e $\mathrm{A}$ nos diferentes momentos do experimento (excluindo-se os suínos 15 e 16). São Paulo, 2013

Tabela 8 - Correlação de Spearman entre PIC e IP em todos os momentos (excluindo-se os suínos 15 e 16). São Paulo, 2013

Tabela 9 - Correlação de Spearman entre PIC e VD em todos os momentos. São Paulo, 2013.

Tabela 10 - Correlação de Spearman entre PIC e VM em todos os momentos. São Paulo, 2013.

Tabela 11 - Correlação de Spearman entre PIC e VS em todos os momentos 


\section{LISTA DE GRÁFICOS}

Gráfico 1 - Distribuição do perfil individual de PIC para cada suíno ...........70

Gráfico 2 - Distribuição do perfil médio de PIC por Grupo...........................71

Gráfico 3 - Distribuição do perfil individual de VS para cada suíno ............73

Gráfico 4 - Distribuição do perfil médio de VS por Grupo ...........................73

Gráfico 5 - Distribuição do perfil individual de VD para cada suíno,

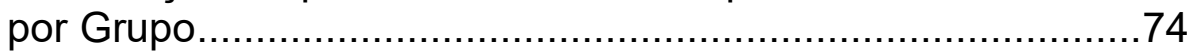

Gráfico 6 - Distribuição do perfil médio de VD por Grupo...........................75

Gráfico 7 - Distribuição do perfil individual de VM para cada suíno,

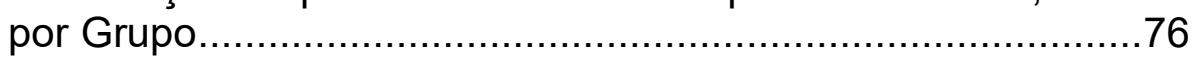

Gráfico 8 - Distribuição do perfil médio de VM por Grupo ……………......76

Gráfico 9 - Distribuição do perfil individual de IP (em escala logarítmica) dos suínos, por grupo........................................78

Gráfico 10 - Distribuição do perfil individual de IP dos suínos, por grupo (excluindo-se os suínos 15 e 16)

Gráfico 11 - Distribuição do perfil médio de IP por grupo (eccluindose os suínos 15 e 16)...........................................................

Gráfico 12 - Dispersão entre PIC e IP em cada momento, sem os suínos 15 e 16

Gráfico 13 - Dispersão entre PIC e VD em cada momento

Gráfico 14 - Dispersão entre PIC e VM em cada momento

Gráfico 15 - Dispersão entre PIC e VS em cada momento 


\section{RESUMO}

Soares MS. Avaliação da hemodinâmica cerebral através da técnica de ultrassonografia Doppler e suas correlações com as variações da pressão intracraniana em um modelo animal de hipertensão intracraniana [tese]. São Paulo: Faculdade de Medicina, Universidade de São Paulo; 2018.

Introdução: $O$ aumento da pressão intracraniana (PIC) é um problema comum na prática neurocirúrgica, e a monitoração invasiva deste parâmetro faz parte da rotina de unidades de terapia intensiva. O Doppler transcraniano vem sendo testado na avaliação da hemodinâmica cerebral como parâmetro de avaliação não invasiva da PIC, porém há controvérsias na literatura sobre seu real benefício e utilidade nesta situação. Este estudo objetivou correlacionar os dados de avaliação do fluxo sanguíneo cerebral através da técnica de Doppler com as variações da monitoração invasiva da PIC na fase aguda de hipertensão intracraniana em um modelo animal. Métodos: Trata-se de um estudo experimental realizado em suínos. O experimento constou de dois grupos de animais (A e B) com hipertensão intracraniana gerada por insuflação com soro fisiológico de um balão no parênquima cerebral, sendo o grupo A com $4 \mathrm{~mL}$ e o grupo B com $7 \mathrm{~mL}$. Nos dois grupos houve uma intervenção clínica com infusão de solução salina a 3\% e uma simulação de intervenção cirúrgica (desinsuflação do balão). Em todos os momentos de insuflação do balão e das intervenções foram registrados os valores dos monitores de PIC e do Doppler: velocidades sistólica (VS), diastólica (VD), média (VM) do fluxo sanguíneo cerebral e índice de pulsatilidade (IP). Foram realizadas comparações do comportamento dos parâmetros avaliados pela ultrassonografia Doppler craniana (VS, VD, VM e IP) em relação às variações da PIC intraparenquimatosa. Resultados: Foram estudados 20 suínos sendo 10 no grupo A e 10 no grupo B. Um animal do grupo $B$ foi excluído do estudo, pois foi a óbito antes do término do 
experimento. Após a insuflação do balão, como era de se esperar, a PIC no grupo $B$ foi superior à do grupo $A$ em todos os momentos, até a desinsuflação do mesmo. Realizada a correlação de Spearman observou-se correlação significativa entre IP e PIC, principalmente logo após insuflação do balão, ou seja, na elevação abrupta da PIC. Não houve correlação entre a PIC e os parâmetros VS, VD e VM. Também não houve variação significativa da PIC após infusão endovenosa de solução salina hipertônica. Conclusão: Este resultado demonstra o potencial do IP como bom parâmetro de avaliação de pacientes com suspeita de elevação hiperaguda e recente da PIC. Não se conseguiu demonstrar os mesmos resultados de correlação entre a PIC e as demais variáveis VS, VD e VM. Diante destes achados, adicionados aos dados conflitantes da literatura disponível até o momento, não se recomenda, por enquanto, a utilização desses parâmetros isoladamente como substitutos da monitoração invasiva da PIC, evidenciando a necessidade de mais estudos clínicos e experimentais.

Descritores: pressão intracraniana; hemorragia cerebral; hipertensão intracraniana; ultrassonografia Doppler; velocidade do fluxo sanguíneo; modelos animais 


\begin{abstract}
Soares MS. Evaluation of cerebral hemodynamics using the Doppler ultrasonography technique and its correlations with variations of intracranial pressure in an animal model of intracranial hypertension [thesis]. São Paulo:“Faculdade de Medicina, Universidade de São Paulo”; 2018.
\end{abstract}

Introduction: Increased intracranial pressure (ICP) is a common problem in neurosurgical practice. Invasive monitoring of ICP in these cases is part of the intensive care unit routine. Transcranial Doppler has been tested in the evaluation of cerebral hemodynamics as a non-invasive evaluation of ICP, but there are controversies in the literature about its real benefit and usefulness in this situation. Thus, this study aimed to correlate the data of cerebral blood flow assessment using the Doppler technique and the invasive monitoring of ICP in the acute phase of intracranial hypertension in an animal model. Methods: This is an experimental study in pigs. During the experiment, an intracerebral expansive mass with an inflatable balloon was simulated. The experiment consisted of two groups ( $A$ and $B$ ) of animals with intracranial hypertension generated by a ballon inflation inside the cerebral parenchima, group A with $4 \mathrm{~mL}$ and group B with $7 \mathrm{~mL}$. In both groups there was a clinical intervention with infusion of $3 \%$ saline solution and a simulation of surgical intervention (balloon drain out). The values of ICP and Doppler parameters (systolic $(\mathrm{FVs})$, diastolic $(\mathrm{FVd})$, and mean $(\mathrm{FVm})$ cerebral blood flow velocities) were collected at all moments of balloon inflation and interventions, as well as the pulsatility index (PI). Comparisons of the behavior of the parameters evaluated by Doppler ultrasound (FVs, FVd, FVm and $\mathrm{PI}$ ) were performed in relation to intraparenchymal ICP. Results: Twenty pigs were studied, 10 in group A and 10 in group B. One pig died in group B and it was excluded. After balloon inflation, as expected, ICP in group $B$ was higher than in group $A$ at all times, until the ballon was empty again. 
Significant correlation between PI and ICP was obtained when Spearman correlation was performed, mainly shortly after balloon inflation, that is, in the abrupt elevation of ICP. There was no correlation between ICP and FVs, FVd or FVm. There was also no significant change in ICP after intravenous infusion of hypertonic saline solution. Conclusion: These results demonstrate the potential of $\mathrm{PI}$ as a good parameter for the evaluation of patients with suspected ICP elevation. It was not possible to demonstrate the same correlation results between the ICP and FVs, FVd or FVm. Due to these results and also to the literature conflicting data to date, the use of these parameters alone as substitutes for the invasive monitoring of ICP is not recommended until now, which shows the need for further clinical and experimental studies.

Descriptors: intracranial pressure; cerebral hemorrhage; intracranial hypertension; ultrasonography, doppler; blood flow velocity; Models, Animal 
1 INTRODUÇÃO 
A hipertensão intracraniana (HIC) é uma condição clínica desafiadora no manejo dos pacientes com lesões intracranianas agudas. Muitas são as situações que podem elevar de forma abrupta a pressão intracraniana (PIC), dentre as quais se pode citar o traumatismo cranioencefálico (TCE), acidentes vasculares encefálicos (AVE), que incluem os hematomas intracerebrais espontâneos (HIE), hidrocefalia, processos infecciosos ou inflamatórios, trombose de veias ou seios venosos intracranianos e lesões expansivas neoplásicas. Há também situações, não menos comuns, em que a HIC pode ocorrer de forma crônica, instalando-se insidiosamente, em alguns tipos de hidrocefalia, hematomas crônicos, processos infecciosos crônicos, tumores de crescimento lento, além de formas de origem idiopática.

Os conhecimentos acumulados ao longo dos séculos, mais intensamente a partir do Século XIX, de anatomia e fisiologia relacionados ao conteúdo intracraniano, permitiram o desenvolvimento da noção da existência da PIC propriamente dita, assim como de situações patológicas em que ela se eleva e da possibilidade de sua monitoração. Muitas tentativas foram feitas e muitos sistemas foram elaborados até que se chegasse aos modelos atuais de monitores de PIC, que atualmente têm seu padrão ouro representados pelo cateter intraventricular e pelo cateter intraparenquimatoso de monitoração da PIC. Outros locais possíveis de instalação destes monitores, mas menos utilizados, são os espaços intracranianos subdural, epidural e subaracnóideo. 
Desde a década de 1980 a monitoração invasiva da PIC em pacientes com suspeita de HIC se difundiu e tornou-se peça chave no seu manejo em unidades de terapia intensiva (UTI). Existem pesquisadores e estudos que questionam o real benefício da monitoração invasiva da PIC na melhora do prognóstico destes pacientes. Porém, devido ao devastador efeito da HIC, o seu uso se manteve recomendado pelos atuais protocolos dos principais grupos de estudiosos destas condições clínicas (Carney et al., 2017; Chesnut et al., 2012).

Ao longo destes anos vários parâmetros estudados foram adicionados na monitoração destes pacientes como os conceitos de pressão de perfusão cerebral (PPC), fluxo sanguíneo cerebral (FSC), oxigenação cerebral tecidual, o eletroencefalograma contínuo, estudo de metabólitos cerebrais (microdiálise), entre outros, criando-se o conceito de monitoração multimodal ou multiparamétrica.

Como já citado, os cateteres intraventriculares e intraparenquimatosos continuam sendo o método padrão ouro para monitoração da PIC, porém, como são técnicas invasivas, apresentam diversas possíveis complicações como hematomas e infecções. Por isso, há atualmente diversos estudos que buscam métodos não invasivos para monitorar a PIC, dentre eles o Doppler transcraniano (DTC).

O desenvolvimento do DTC permitiu a avaliação não invasiva do fluxo sanguíneo cerebral, tornando-se também importante na avaliação dos pacientes neurocríticos. É uma ferramenta portátil, não invasiva, que pode ser usada na beira do leito. Recentemente este método vem sendo testado e 
estudado para monitoração não invasiva da PIC em pacientes com potencial HIC de diversas origens. Para tal, utiliza-se os valores de velocidades do fluxo sanguíneo cerebral sistólica (VS) e diastólica (VD) obtidos pelo DTC, além de parâmetros calculados a partir destas, como velocidade média do fluxo sanguíneo cerebral (VM) e índice de pulsatilidade (IP). Porém há resultados conflitantes na literatura a respeito deste método, e consequentemente as polêmicas geradas em torno de suas indicações e impactos no prognósticos dos doentes evidenciam a necessidade de mais estudos sobre o tema, inclusive em animais, para estabelecimento de quais parâmetros do DTC são realmente válidos na monitoração de pacientes com HIC.

Diante dessas considerações, o grupo de pesquisa do Laboratório de Investigação Médica 26 (LIM 26) da Faculdade de Medicina da Universidade de São Paulo (FMUSP) desenvolveu um modelo animal de HIC controlada e reversível (Andrade et al., 2013) possibilitando o desenvolvimento do atual estudo.

\subsection{Justificativa}

A monitoração invasiva da PIC nos pacientes com potencial de estarem ou de desenvolverem HIC ainda tem um papel importante no seu manejo, apesar de haver questionamentos por alguns trabalhos já citados. Como os métodos invasivos "padrão ouro" (cateteres intraventriculares e intraparenquimatosos) podem ter complicações e em algumas situações clínicas serem contra-indicados, tornam-se necessários os esforços para se desenvolver métodos não invasivos para aferição da PIC. 
Há muitos estudos realizados sobre hipertensão intracraniana e monitoração multimodal, tanto experimentais como em humanos. A maioria dos modelos experimentais de hipertensão intracraniana já publicados, descrevem métodos de lesão cerebral irreversíveis do ponto de vista anatômico, o que impossibilita, nestes modelos, o estudo de parâmetros após a reversão da HIC. Estudos da hemodinâmica cerebral em fases hiperagudas de hemorragia são difíceis de realizar, principalmente em seres humanos, devido ao tempo de transporte dos pacientes até o hospital de referência.

Um método não invasivo de aferição da PIC que vem sendo muito estudado é o DTC. Trata-se de um método barato, de fácil realização e disponível na maioria das UTIs. Porém, há resultados conflitantes do uso dos parâmetros do DTC para aferição não invasiva da PIC.

Assim, é essencial um estudo experimental em que se tenha um modelo animal de HIC reversível, onde se possa avaliar a hemodinâmica cerebral com a técnica de Doppler na fase aguda da HIC e comparar seus parâmetros à monitoração invasiva da PIC através de um cateter intraparenquimatoso. 


\section{OBjetivos}




\subsection{Objetivo Primário}

Correlacionar os dados de avaliação do fluxo sanguíneo cerebral através da técnica de Doppler (IP, VS, VD e VM) com as variações da PIC, medida por cateter intraparenquimatoso na fase aguda de HIC em um modelo animal.

\subsection{Objetivo Secundário}

Confirmar o modelo animal de HIC usado no presente estudo como modelo de efetiva HIC.

Estudar o efeito da infusão endovenosa de solução salina hipertônica a $3 \%$ na HIC. 
3 REVISÃo DA LITERATURA 


\subsection{Pressão Intracraniana e Hipertensão Intracraniana}

A PIC é a pressão dentro da calota craniana, relativa à pressão atmosférica, exercida pelo conteúdo intracraniano (sangue, encéfalo, líquido cefalorraquidiano [LCR]). Apesar de haverem relatos de observações e teorias das pulsações cerebrais anteriores ao Século XVIII, que remontam à antiguidade, as primeiras noções de PIC, e os fundamentos para explicar suas variações, foram estudados e definidos pelo anatomista escocês Alexander Monro, em 1783. Anos mais tarde, em 1824, foi completada pelos estudos do cirurgião e também escocês George Kellie (Andrews e Citerio, 2004; Steiner e Andrews, 2006). Estes fundamentos foram denominados de doutrina de Monro-Kellie e consistem nos seguintes princípios, desde que as fontanelas e suturas estejam fechadas: (I) o cérebro é envolto por uma estrutura rígida não expansível; (II) o cérebro não é compressível; (III) portanto, o volume de sangue na cavidade craniana é praticamente constante; (IV) um escoamento constante de sangue venoso é necessário para dar espaço ao suprimento arterial. Como se pode observar, um componente importante do espaço intracraniano na fisiologia da PIC, que é o LCR, não foi considerado pelos dois eminentes estudiosos para elaboração de sua doutrina. Isto se deve ao desconhecimento na época da exata importância do mesmo (Mokri et al., 2001; Andrews e Citerio, 2004). 
Em 1842 o fisiologista francês François Magendie, através de punções da cisterna magna em experimentos animais, descreveu a anatomia e fisiologia do líquido cefalorraquidiano (Torack, 1982). Este conhecimento abriu caminho para posteriores observações do médico inglês George Burrows, que propôs a existência de um equilíbrio entre o volume de LCR e de sangue no espaço intracraniano, de modo que o aumento do volume de um proporcionaria a diminuição do outro, incorporando este importante conceito à doutrina de Monro-Kellie (Andrews e Citerio, 2004). No início do século passado, o pioneiro neurocirurgião norte-americano Harvey Cushing associou todo o conhecimento da época sobre o assunto para modificar a doutrina de Monro-Kellie, dando-lhe os moldes nos quais se conhece hoje: com um crânio intacto, os volumes do cérebro, sangue e LCR são constantes. O aumento em um componente irá causar diminuição de um ou ambos os outros componentes (Cushing, 1903).

Todos estes conceitos relativos à fisiologia da PIC permitiram que no final do Século XIX e, ao longo do Século $X X$, se desenvolvessem mecanismos e sistemas capazes de mensurar e monitorar as variações da PIC. Na década de 1890 o médico alemão Heinrich Quincke publicou os primeiros estudos sobre a técnica de punção lombar (antigamente conhecida pelo epônimo de punção de Quincke) e estudos do LCR como propedêutica diagnóstica para doenças neurológicas. Ele determinou que uma pipeta de vidro deveria ser afixada na agulha de punção, e através do mecanismo de coluna de água era possível que a pressão do LCR pudesse ser medida. Esta técnica de medição repetida da pressão do LCR como uma avaliação da PIC tornou-se amplamente utilizada, tornando-se o primeiro método clínico de aferição da mesma (Andrews e Citerio, 2004; Torack, 1982). 
Em 1964 o neurocirurgião da Universidade da Pennsylvania, Thomas Langfitt, demonstrou que uma punção lombar poderia induzir compressão do tronco encefálico devido a hérnia cerebral transtentorial ou herniação das amígdalas cerebelares através do forame magno e que, além disso, quando o sistema ventricular não se comunica, a pressão da coluna vertebral não é um reflexo preciso da PIC. Assim, a aferição da PIC em doentes neurocrítico por punção lombar com manometria caiu em desuso, e os pesquisadores começaram a realizar aferição hidrostática diretamente do sistema ventricular. Conceitos importantes expressados pela curva de Langfitt (curva pressão $\mathrm{x}$ volume) são a elastância e a complacência cerebrais. A complacência cerebral é a variação do volume $(\Delta V)$ para cada unidade de pressão variada $(\Delta P)$, e representa o inverso da elastância (Figura 1) (Andrews e Citerio, 2004; Langfitt et al., 1964).

Em 1951, Guillaume e Janny realizaram a primeira aferição contínua da PIC intraventricular. Eles idealizaram uma técnica em que se introduzia uma agulha no ventrículo cerebral e a mesma era conectada a um sistema eletromagnético capaz de aferir continuamente a PIC. O neurocirurgião sueco Nils Lundberg publicou um trabalho clássico em 1960, consolidando o método de aferição da PIC intraventricular. Através de um cateter inserido no ventrículo cerebral (cateter ventricular externo), conectado a um manômetro na beira do leito, a PIC era aferida e gravada continuamente. Este método provou ser preciso e confiável, além de permitir a drenagem terapêutica de LCR (Lundberg, 1960). 


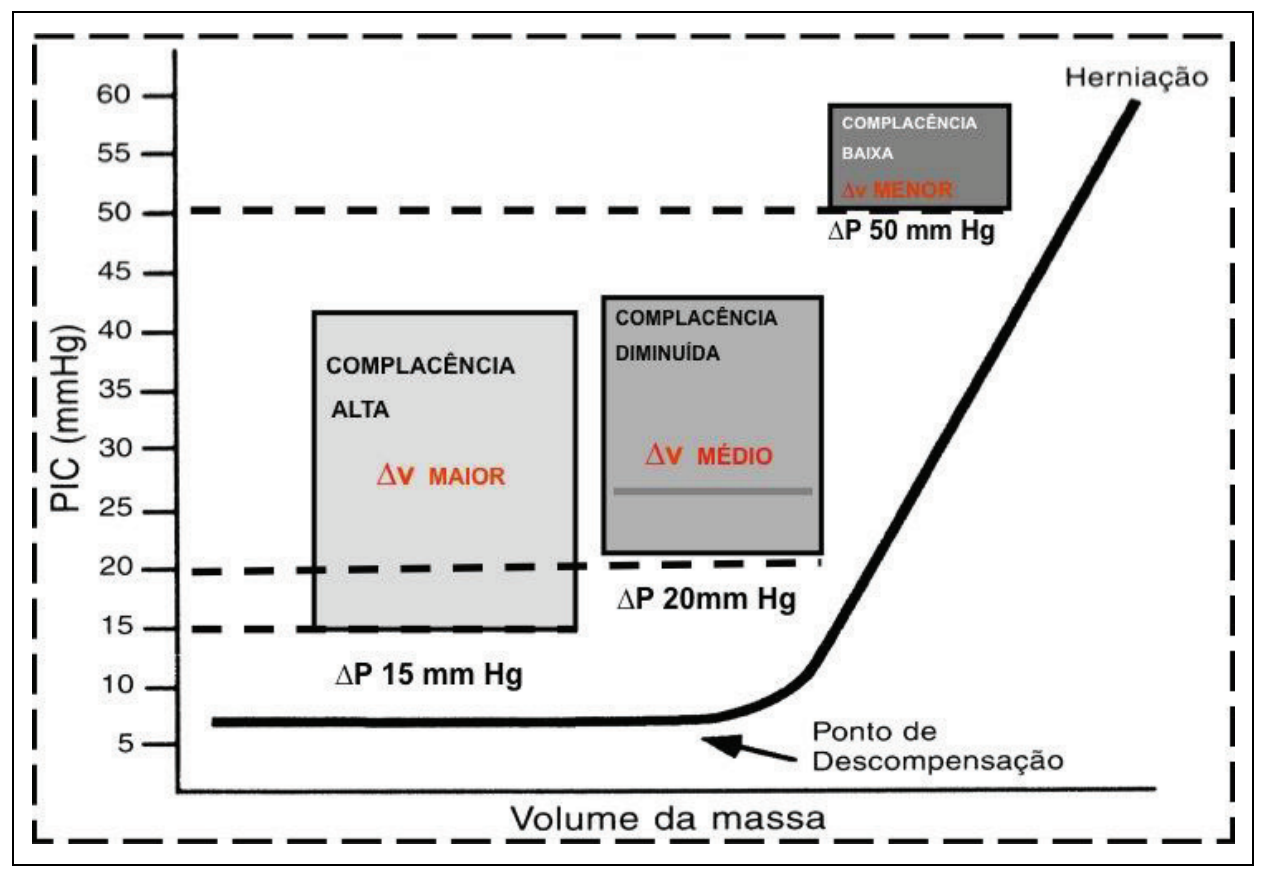

Figura 1 - Curva de Langfitt. Evidencia graficamente o comportamento da variação da PIC em relação à variação de volume do conteúdo intracraniano. Inicialmente alta complacência e baixa elastância e, após exauridos mecanismos compensatórios, baixa complacência e alta elastância [Fonte: Paiva, 2014]

Contudo, na prática clínica, os sistemas de monitoração ventricular por cateter não foram aplicados de forma sistemática até meados da década 1970. Nas UTIs entre as décadas de 1960 e 1980, e nas poucas UTIs neurológicas da época (voltadas principalmente aos pacientes em pósoperatório neurocirúrgico), haviam disponíveis parâmetros de monitoração sistêmicos como saturação sanguínea de oxigênio, frequências respiratória e cardíaca, pressão arterial e pressão venosa central. Os pacientes neurocríticos, com provável HIC, eram avaliados através de exame neurológico seriado e alterações dos parâmetros sistêmicos monitorados já citados. Raros centros se utilizavam, na época, de monitoração direta da PIC, sendo que, muitas vezes, quando a HIC alterava parâmetros sistêmicos ou ocasionava alterações no exame neurológico, o dano cerebral já era irreversível (Wartenberg et al., 2007). 
Em 1977, Becker et al. relataram dados de monitoração contínua da PIC, usando cateteres ventriculares em 160 pacientes com traumatismo cranioencefálico. Eles demonstraram uma clara evidência de bons resultados entre os pacientes nos quais a elevação da PIC poderia ser rapidamente reconhecida e posteriormente tratada, o que contribuiu para divulgação do método.

Entre as décadas de 1980 e 2000 a monitoração da PIC se difundiu, embora que, mesmo nos dias atuais, esteja longe de ser uma prática de uso rotineiro em todas as UTIs (Wartenberg et al., 2007).

Atualmente a monitoração da PIC é parâmetro central no manejo do paciente com lesão cerebral aguda, sendo que ela se eleva após exauridos os mecanismos de compensação (alterações na dinâmica da circulação liquórica, do fluxo sanguíneo cerebral e do volume sanguíneo cerebral) (Bhatia e Gupta, 2007). Mesmo que amplamente aceito como parâmetro de tratamento nestes pacientes, o uso da monitoração da PIC ainda gera controvérsias, devido a trabalhos com resultados conflitantes em relação ao real benifício da aferição da PIC no prognóstico destes doentes (Cremer et al., 2005; Chesnut et al., 2012). O polêmico Trial Best Trip, executado na Bolívia e Equador, mostrou resultados em que o grupo com monitoração da PIC, com um objetivo de mantê-la abaixo de 20 mmHg, não obteve melhor prognóstico em relação ao grupo controle (tratamento intensivo padrão baseado em parâmetros clínicos e exames de neuroimagem seriados) (Chesnut et al., 2012). Porém, este mesmo estudo mostrou um tratamento mais eficaz e rigoroso no grupo em que a PIC foi monitorada. Outras críticas foram feitas ao estudo como a não utilização de cateteres ventriculares para drenagem de LCR e sim apenas cateteres 
intraparenquimatosos (Talving et al., 2013; Sagher, 2013). Como elevações da PIC são classicamente tidas como preditores de mortalidade (Badri et al., 2012), o seu monitoramento se manteve recomendado pelos principais grupos de estudiosos para grupos específicos de pacientes. Sendo assim os guidelines da Brain Trauma Foundation (Carney et al., 2017) e do consenso internacional multidisciplinar de monitoramento multimodal do paciente neurocrítico (Le Roux et al., 2014) fazem recomendações para monitoração da PIC em pacientes com lesões cerebrais agudas ou TCE. Estas recomendações incluem pacientes com pontuação menor ou igual a 8 na Escala de Coma de Glasgow (GCS) que apresentem exames de neuroimagem com lesões que justifiquem elevação da PIC, ou ainda aqueles pacientes que estejam sendo tratados empiricamente para uma possível PIC elevada. Existe ainda um grupo de pacientes com TCE e GCS menor ou igual a oito que, mesmo com exames de neuroimagem normais, têm indicação de implante de um cateter para medir a PIC. São aqueles maiores de 40 anos, ou pacientes com pressão arterial média menor que $90 \mathrm{mmHg}$, ou manifestando posturas neurológicas patológicas.

\subsection{Análises Quantitativa e Qualitativa da PIC}

O valor normal da PIC varia de acordo com a idade e com a posição corporal. Em um adulto em decúbito dorsal horizontal ela varia de $7 \mathrm{mmHg}$ a $15 \mathrm{mmHg}$. Quando em posição vertical esta pressão é negativa tendo em média -10mmHg, sem exceder -15 mmHg (Czosnyka e Pickard, 2004). Em neonatos varia de $1,5 \mathrm{mmHg}$ a $6 \mathrm{mmHg}$ e em crianças maiores varia de 3 $\mathrm{mmHg}$ a $7 \mathrm{mmHg}$ (Dunn, 2002). 
Embora haja falta de dados robustos que determinem um limite superior exato da PIC desejável no doente neurocrítico, o tratamento padrão dos principais guidelines é aceitar valores de PIC entre $20 \mathrm{mmHg}$ e 25 mmHg (Le Roux et al., 2014; Carney et al., 2017). Níveis de PIC acima de 20 $\mathrm{mmHg}$, refratários a tratamento clínico intensivo, principalmente nas primeiras 48 horas, são preditores de mortalidade (Treggiari et al., 2007; Badri et al., 2012).

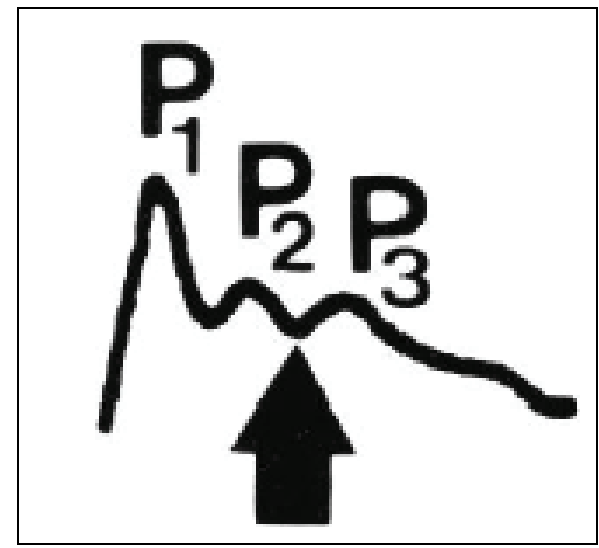

Figura 2 - Morfologia normal da onda da PIC [Fonte: Paiva, 2014]

A forma de onda da PIC consiste em três componentes que se sobrepõem, são denominados P1, P2 e P3, e podem ser analisados no domínio da frequência (Figura 2). Esta forma de onda tem componentes harmônicos, dos quais o componente fundamental tem uma frequência sincrônica à frequência cardíaca. Em condições fisiológicas normais, a morfologia da onda da PIC segue um padrão em que: P1 > P2 > P3. O componente $\mathrm{P} 1$ (onda de percussão) reflete a ejeção de sangue do coração transmitida através das artérias intracranianas e plexo coroide; o componente P2 (onda de repercussão) reflete a complacência cerebral; e o 
componente P3 (onda dicrótica) reflete o fechamento da válvula aórtica. Alterações na morfologia da onda de pressão intracraniana demonstram alterações na complacência cerebral, em que $P_{1}>P_{2}$ demonstra complacência normal e $P_{2}>P_{1}$ evidencia complacência reduzida (Figura 3) (Lundberg, 1960; Steiner e Andrews, 2006).

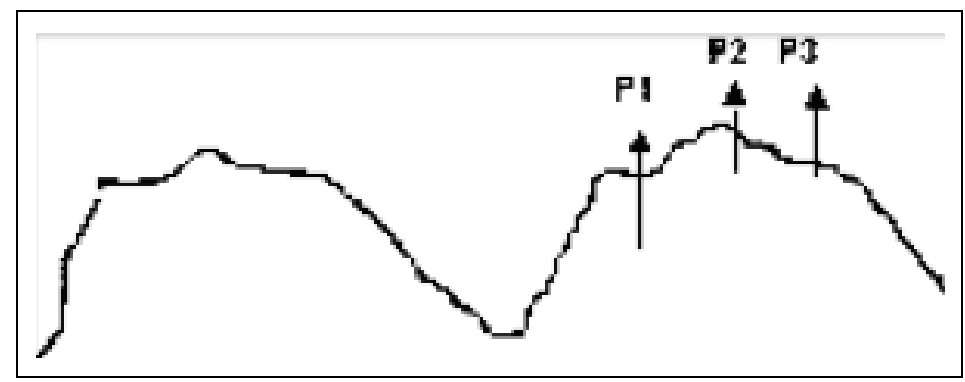

Figura 3 - Morfologia anormal da onda da PIC; complacência intracraniana reduzida

Quando a PIC é monitorada e gravada continuamente pode-se traçar em um gráfico uma curva contínua das suas variações ao longo tempo. Estas ondas podem ser analisadas de acordo com a classificação proposta por Lundberg (1960), em que ele descreve três tipos de padrões de ondas, denominadas A, B e C: as ondas "A" ou ondas em platô compreendem um íngreme aumento da PIC a partir de valores próximos dos normais até 40 $\mathrm{mmHg}$ ou mais, persistindo desta maneira durante 5 a 20 minutos. As ondas "A" de Lundberg são sempre patológicas e ocorrem em pacientes com autorregulação intacta e complacência intracraniana reduzida. As ondas "B" representam oscilações que duram de 0,5 a 2 minutos. A PIC pode aumentar $20 \mathrm{mmHg}$ acima da linha de base normal. Estas ondas são provavelmente relacionadas com alterações no tônus vascular e refletem a influência do ciclo respiratório sobre a PIC. São consideradas sinal de alerta porque demonstram 
algum grau de prejuízo da complacência cerebral. Lundberg também descreveu as ondas ' $C$ ' como oscilações que ocorrem com uma frequência de quatro a oito oscilações por minutos. Estas ondas são provavelmente de pouco significado patológico (Lundberg, 1960; Steiner e Andrews, 2006).

\subsection{Pressão de Perfusão Cerebral e Autorregulação}

A pressão de perfusão cerebral é definida como a diferença entre a pressão arterial média (PAM) e a PIC (PAM - PIC = PPC). Para que o cálculo seja fidedigno é necessário que a PAM seja medida através de método invasivo por cateter introduzido em artéria periférica, e os transdutores de pressão tanto do monitor de PIC quanto da PAM invasiva sejam posicionados na altura do meato acústico externo (tragus); mas esta prática varia entre os diversos centros de tratamento de pacientes neurocríticos, o que dificulta a comparação de dados (Kosty et al., 2013). Em condições fisiológicas normais, a PAM entre $80 \mathrm{mmHg}$ e $100 \mathrm{mmHg}$ e a PIC entre $5 \mathrm{mmHg}$ e $10 \mathrm{mmHG}$ geram uma PPC de $75 \mathrm{mmHg}$ a $80 \mathrm{mmHG}$ (Wartenberg et al., 2007). A PPC alvo para pacientes com lesões cerebrais recomendada pela Brain Trauma Foundation (Carney et al., 2017) é de $60 \mathrm{mmHg}$ a $70 \mathrm{mmHG}$, pois há evidências de pior prognóstico em pacientes com níveis abaixo deste valor. Este controle da PPC na UTI é atingido com elevações da PAM e otimização das medidas para baixar a PIC, sendo um esforço para manter adequado FSC. Há muito a PPC vem sendo usada como um marcador substituto do FSC, pois o FSC depende da PPC e da resistência cerebrovascular $(\mathrm{RCV})$, donde $\mathrm{FSC}=\mathrm{PPC}-\mathrm{RCV}$ (Roh e Park, 2016). 
Pacientes com lesões cerebrais podem perder os mecanismos de autorregulação, incluindo a RCV. A perda da proteção do sistema nervoso central (SNC) em relação à pressão arterial pode gerar lesões cerebrais secundárias devido a hipóxia em situações de hipotensão arterial ou por hiperemia em situações opostas de elevação excessiva da PAM. Recentes evidências sugerem que pacientes neurocríticos mesmo com PPC ótima em torno de $60 \mathrm{mmHg}$ e controle da PIC abaixo de $20 \mathrm{mmHg}$, podem ainda estar em situações de hipóxia cerebral, o que pode piorar seus prognósticos (Eriksson et al., 2012). Isto vem estimulando estudos de novas interpretações da PIC e de valores de PPC ótima influenciadas pelos mecanismos de autorregulação.

A reatividade vascular prejudicada e a perda da complacência intracraniana levam a alterações da PIC conforme a flutuação da PAM, conceito refletido pelo índice de reatividade pressórica cerebrovascular (PRx). Se ocorre um PRx positivo isso significa que há uma relação linear positiva entre a variação da PAM e a PIC, evidenciando mecanismos de autorregulação cerebrovasculares prejudicados. O PRx consiste na aferição de 40 medidas (a cada 6 a 10 segundos) de valores de pressão arterial média e pressão intracraniana estabelecendo uma correlação de Pearson entre estas variáveis. Valores menores que $-0,2$ representam boa reatividade cerebrovascular, enquanto valores maiores que 0,2 refletem uma reatividade cerebrovascular comprometida (Czosnyka et al., 2009; Roh e Park, 2016).

Hematomas intraparenquimatosos espontâneos inicialmente causam elevação abrupta da PIC que leva à perda da autorregulação do FSC. Como 
nessa situação a PPC também está reduzida, recomenda-se baixar a PAM lentamente para se evitar queda ainda maior do FSC e lesões isquêmicas secundárias. As cascatas inflamatórias locais desencadeadas pelo contato direto do HIE com o parênquima cerebral e vasos prejudica ainda mais a autorregulação (Nakagawa et al., 2011; Xiao et al., 2017).

\subsection{Dispositivos para Monitoração Invasiva da Pressão Intracraniana}

A PIC pode ser mensurada por cateteres introduzidos em diferentes locais do espaço intracraniano. Atualmente os dispositivos recomendados para monitoração invasiva da PIC são os intraventriculares e os intraparenquimatosos (Roh e Park, 2016), sendo que os subdurais, epidurais e subaracnóideos ficam em segundo plano por apresentarem acurácia de aferição inferior (Figura 4). Pacientes com suspeita de HIC ou com lesões intracranianas não devem ser submetidos a punções lombares para aferição da PIC, devido ao risco de compressão do tronco encefálico por herniação cerebral, e também pelo fato de a aferição não ter boa acurácia devido ao bloqueio da coluna liquórica, que pode ocorrer nestes casos, entre o crânio e a coluna vertebral (Steiner e Andrews, 2006; Roh e Park, 2016). 


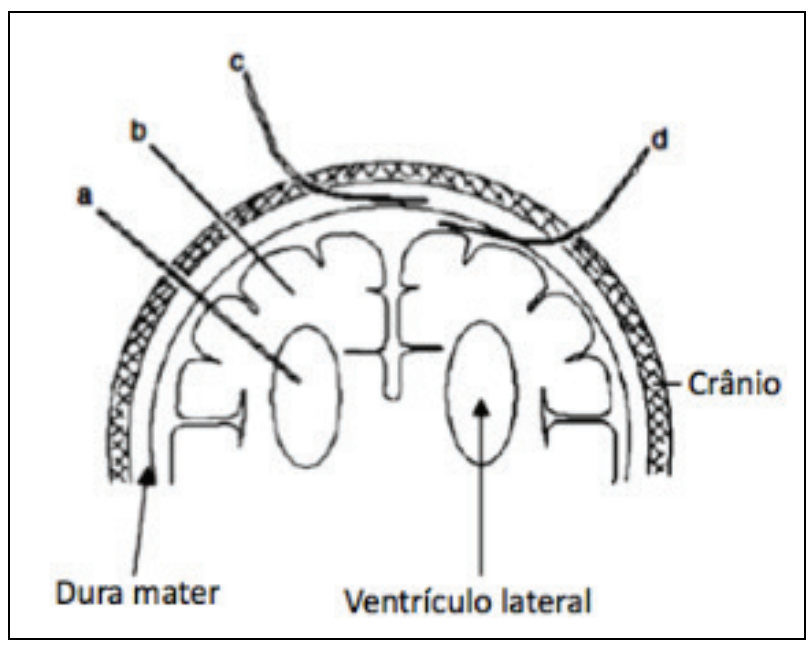

Figura 4-Locais de inserção de cateteres para monitoração da PIC. a: intraventricular; b: intraparenquimatoso; c: epidural; d: subdural [Fonte: adaptado de Steiner e Andrews, 2006]

Tanto os cateteres intraparenquimatosos quanto os intraventriculares são introduzidos através de uma trepanação no crânio e tem baixas taxas de complicações, se introduzidos por neurocirurgiões experientes (Bauer et al., 2011).

O cateter intraventricular, introduzido em um dos ventrículos laterais e conectado a um transdutor pressórico externo e a um sistema coletor externo de LCR (derivação ventricular externa [DVE]) é considerado o "padrão-ouro" para monitoração da PIC (Bhatia e Gupta, 2006; Steiner e Andrews, 2006; Cremer, 2008). O forame de Monro ou, para fins práticos, o meato acústico externo, são considerados os pontos de referência para "zerar" o transdutor, sendo que este sistema tem a vantagem de poder ser "zerado" repetidas vezes após a introdução do cateter. Outra importante vantagem da DVE é permitir a drenagem terapêutica de LCR para auxiliar no controle da HIC (Bhatia e Gupta, 2006; Steiner e Andrews, 2006). A principal desvantagem do método é o risco de infecção, que aumenta com o passar 
dos dias após a instalação do cateter, variando de $1 \%$ a $11 \%$ dos casos (Andrade et al., 2011 e 2014).

Em pacientes com inchaço cerebral e, consequentemente, ventrículos pequenos, pode ser difícil a introdução do cateter intraventricular. A melhor alternativa a este método é o cateter de PIC intraparenquimatoso. Após introduzido no parênquima cerebral através da trepanação, ele pode ser fixado no crânio por um parafuso específico (do inglês bolt) ou tuneilizado pelo subcutâneo. Estes cateteres são equipados em suas extremidades com dois tipos de sistema: um microsensor medidor de tensão (Codman ${ }^{\circledR} \mathrm{e}$ Raumedic Neurovent- $\mathrm{P}^{\circledR}$ ) ou um cateter de fibra óptica (Camino ${ }^{\circledR}$ ). No primeiro, alterações da PIC causam alterações de resistência e no segundo causam alterações na reflexão da luz. Existe ainda um terceiro sistema para aferição da PIC, que pode ser usado tanto nos espaços intraventricular, intraparenquimatoso, subdural ou epidural. São os sensores pneumáticos Spiegelberg, que utilizam um pequeno balão na extremidade distal do cateter , que é preenchido por líquido através de um sistema fechado, registrando as alterações na pressão quantitativamente. Este sistema é pouco utilizado na prática clínica (Bhatia e Gupta, 2007).

Estes cateteres têm baixas taxas de infecção. Porém desvantagens do sistema incluem a impossibilidade de novas calibragens após introduzido o cateter e pequenos desvios de acurácia com o passar do tempo de instalação. Também há o problema da compartimentalização da monitoração da PIC, sendo recomendado a introdução do cateter ipsilateral ao hemisfério cerebral mais acometido (Bhatia e Gupta, 2006; Steiner e Andrews, 2006; Roh e Park 
2016). Apesar destas diferenças tanto os cateteres intraventriculares quanto os parenquimatosos têm acurácias de medição comparáveis e confiáveis (Lescot et al., 2011).

Devido às potenciais complicações já citadas dos métodos invasivos, vêm-se estudando e se desenvolvendo métodos não invasivos para estimativa da PIC e da hemodinâmica cerebral. As tecnologias atualmente disponíveis para tal visam avaliar alterações morfológicas causadas pela HIC (ressonância magnética, tomografia computadorizada, avaliação da bainha do nervo óptico por ultrassonografia), ou alterações fisiológicas (Doppler transcraniano, elentroencefalograma, potencial visual evocado, timpanometria, entre outros), porém todos esses métodos ainda necessitam mais estudos para testarem seu real valor na monitoração não invasiva da PIC (Cardim et al., 2016b; Robba et al., 2016 e 2017).

\subsection{Avaliação não Invasiva da PIC: Doppler Transcraniano}

Quando uma fonte de som emite ondas de ultrassom e estas são refletidas por um objeto em movimento, a frequência do sinal refletido se desloca em proporção direta à sua velocidade. Em 1842 o físico austríaco Christian Doppler apresentou a descoberta deste fenômeno que é conhecido como "efeito Doppler", e constitui a base para o DTC (Rajamani e Gorman, 2001). Por muitos anos tentou-se avaliar a vasculatura cerebral com transdutores que emitem frequências de som de $4 \mathrm{MHz}$ a $10 \mathrm{MHz}$, porém sem sucesso, pois a barreira óssea do crânio atenuava essas ondas. Em 1982 o médico norueguês Rune Aaslid desenvolveu um transdutor de 
Doppler de $2 \mathrm{MHz}$ que se mostrou eficaz na avaliação dos vasos cerebrais através do crânio intacto, conseguindo registrar as velocidades de fluxo sanguíneo nos vasos intracranianos, introduzindo a técnica de DTC (Aaslid et al., 1982). Um transdutor de ondas de pulso emite as ondas insonantes, $\mathrm{e}$ recebe de volta a onda refletida pela superfície das hemácias do interior dos vasos cerebrais. Rapidamente um computador calcula e apresenta a frequência da onda refletida.

O DTC mede a velocidade do fluxo sanguíneo nas artérias basais do cérebro e não diretamente o FSC. Existe uma relação linear entre o FSC e velocidade média de VM em que FSC $=\mathrm{VM} x$ área do vaso insonado $\mathrm{x}$ cosseno do ângulo de insonação. Mas esta relação somente está presente se o diâmetro do vaso insonado e o ângulo de insonação se mantiverem constantes durante o exame. Este pré-requisito é provavelmente cumprido na maioria das situações dos exames realizados, com a possível exceção dos casos de hemorragia subaracnoide, onde pode haver vasoespasmo. Examinando a razão entre a velocidade de fluxo sanguíneo da artéria carótida interna e a velocidade do fluxo sanguíneo da artéria cerebral média pode-se diferenciar o vasoespasmo das situações de aumento do FSC (índice de Lindegaard). O DTC já é utilizado para avaliação de vasoespasmo em hemorragias subaracnoides há vários anos (Aaslid et al., 1984; Steiner e Andrews, 2006).

Para a interpretação de um estudo de DTC utiliza-se parâmetros que são medidos diretamente, como a VS e a VD. São também avaliadas a direção do fluxo sanguíneo e as características das formas das ondas. Além 
disso, são estudados os parâmetros derivados de VS e VD, que incluem a VM e o IP. O IP é uma medida comum para se descrever a forma da onda, e o seu cálculo é feito pela diferença entre VS e VD, dividida por VM (IP = (VS - VD) / VM) (Gosling e King, 1974). Este índice é um reflexo da resistência a fluir a jusante do ponto de insonação, e como é uma razão tem a vantagem de independer do angulo de insonação (Rajamani e Gorman, 2001).

A elevação da PIC e diminuição do fluxo sanguíneo cerebral alteram as características das curvas do DTC, como velocidades do fluxo sanguíneo cerebral e consequentemente o IP, podendo ser estudado e testado para monitoramento da hemodinâmica encefálica e monitoramento não invasivo das variações da PIC (Robba et al., 2016; Ursino et al., 1998) (Figura 5). O IP é um parâmetro do DTC muito estudado para aferição não invasiva da PIC. Alguns autores demonstraram uma forte correlação entre o IP e elevações da PIC acima de $20 \mathrm{mmHg}$ em pacientes com HIC, independentemente da patologia de base (Bellner et al., 2004; Cardim et al., 2017). Já outros trabalhos encontraram uma fraca correlação entre PIC e IP, concluindo ser este um método limitado para tal fim (Behrens et al., 2010; Cardim et al., 2016c; Morgalla e Magunia et al., 2016; Zweifel et al., 2012;). Devido a esses resultados conflitantes ainda não há consenso sobre a utilização dos parâmetros do DTC para avaliação não invasiva da PIC. 


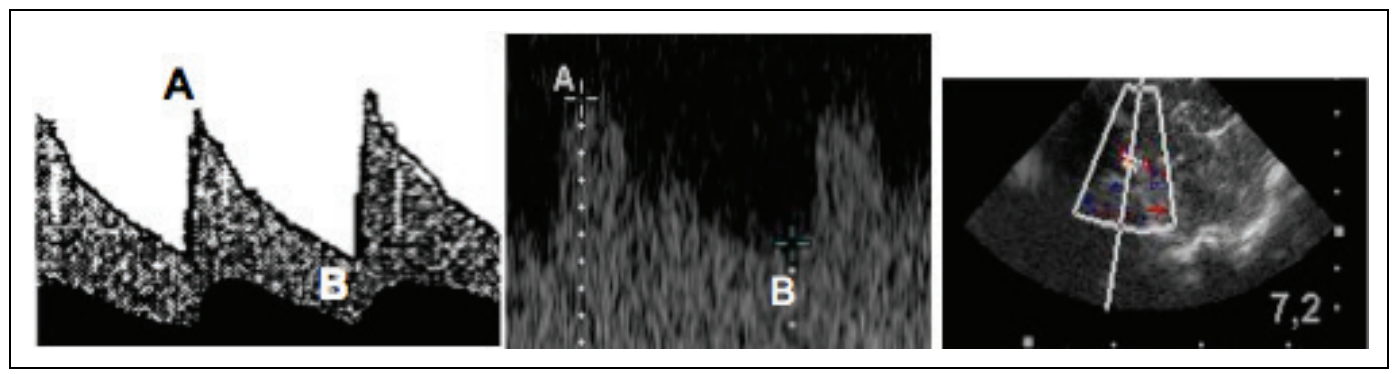

Figura 5 - Curvas de velocidades do fluxo sanguíneo captados pela técnica de Doppler, onde A é a velocidade sistólica e B é a velocidade diastólica (desenho esquemático na imagem à esquerda e exame real na imagem do centro); imagem da direita mostra o fluxo na artéria estudada em técnica de color flow

\subsection{Medidas Clínicas para o Tratamento da Hipertensão Intracraniana}

Apesar dos grandes avanços atuais no tratamento cirúrgico e clínico das lesões cerebrais agudas, muitas vezes o insulto inicial causa efeitos irreversíveis no cérebro. Sendo assim o diagnóstico precoce e a prevenção das lesões cerebrais secundárias (LCS) tornam-se o foco do tratamento neurointensivo, sendo o controle da HIC e a minimização dos seus danos uma preocupação constante (Roh e Park, 2016). As principais LCS são decorrentes de hipoperfusão cerebral causada por elevações da PIC, hipóxia tecidual, hipoglicemia tecidual, ou ainda por lesões causadas por crises epilépticas (Ko, 2013).

A proteção cerebral pode ser preventiva ou ser alcançada pelo tratamento durante ou depois da isquemia, sendo então uma medida para minimizar a lesão tecidual inicial ou melhorar a lesão secundária resultante da isquemia. Aumentando-se a PPC na área isquêmica é possível aumentar o FSC regional. A reanimação ou ressuscitação cerebral em isquemia cerebral global por hipertensão intracraniana envolve intervenção semelhante à proteção cerebral, sendo aplicada após a ocorrência da lesão 
isquêmica, como um processo de limitação da lesão. A neuroproteção pode ser definida como uma intervenção, não necessariamente farmacológica, para interferir diretamente nos mecanismos intracelulares da cascata isquêmica, visando o resgate da área de penumbra - definida como área de hipoperfusão, ainda viável, circunjacente ao infarto (Andrade et al., 2009).

Em 1977 o trabalho de Becker et al., que evidenciou a utilidade clínica da monitoração da PIC, mostrou também a importância do tratamento precoce da HIC e de lesões intracranianas agudas expansivas, alterando favoravelmente mortalidade e morbidade, resultados corroborados por outros estudos mais recentes (Becker et al.,1977; Schreckinger e Marion, 2009).

As medidas clínicas para tratamento da HIC em UTI iniciam-se com medidas preventivas como: elevação do cabeceira a $30^{\circ}$ do plano horizontal e manutenção da posição neutra do pescoço; manutenção de vias aéreas pérvias e ventiladas para boa difusão de $\mathrm{O}_{2}$ pulmonar. Como intervenções medicamentosas inicialmente pode-se realizar sedação e relaxamento muscular. Infusão de manitol a $20 \%$ pode ser usado em situações de elevação aguda da PIC, mas não de maneira contínua. Deve-se monitorar a temperatura corporal e manter normotermia. $\mathrm{Na}$ falha terapêutica dessas medidas, preconiza-se sedação com barbitúricos para induzir o coma e também hipotermia leve $\left(34^{\circ} \mathrm{C}\right.$ a $\left.35^{\circ} \mathrm{C}\right)$. A febre deve ser tratada imediatamente em pacientes com suspeita de HIC. A hiperventilação leve (pressão parcial de $\mathrm{CO}_{2}-\mathrm{PaCO}_{2}-$ de $30 \mathrm{mmHg}$ a $35 \mathrm{mmHg}$ ) controlada pode ser eficaz em curto prazo para reduzir a PIC por diminuição do FSC e do volume sanguíneo cerebral. Quando a $\mathrm{PaCO}_{2}$ diminui, os vasos cerebrais 
se contraem até a ocorrência da vasoconstrição. Mas se a $\mathrm{PaCO}_{2}$ diminui abaixo de $18 \mathrm{mmHg}$ a $20 \mathrm{mmHg}$, pode ocorrer isquemia. Na vigência de vasoespasmo ou de oliguemia, não se deve realizar hiperventilação. Devido aos resultados controversos e ao risco de isquemia, a hiperventilação não deve ser usada como rotina para controle da PIC (Schreckinger e Marion, 2009; Sorani et al., 2008).

O coma barbitúrico, quando necessário, deve ser ajustado por meio de registro eletrencefalográfico até a ocorrência de supressão da atividade elétrica cerebral, devendo ser evitada a isoeletricidade durante a infusão (Bor-Seng-Shu et al., 2012).

A terapia hiperosmolar, utilizando infusões de manitol ou solução salina hipertônica $(\mathrm{SH})$ é frequentemente administrada para reduzir a PIC. Atualmente, o manitol (20\%) é considerado o agente hiperosmolar padrãoouro e é de longe o mais bem estudado. No entanto, a $\mathrm{SH}$, que vem em uma variedade de concentrações, é cada vez mais utilizada neste contexto (Boone et al., 2015; Harutjunyan et al., 2005; Ichai et al., 2009; RangelCastillo e Robertson, 2006; Sorani et al., 2008).

Uma redução da PIC pode ocorrer dentro de cinco minutos após a infusão de manitol, embora o efeito de pico seja geralmente de 20 a 60 minutos e meia vida de uma a seis horas (Hartl et al., 1997). O manitol provoca a expansão intravascular por retirar osmoticamente água livre dos tecidos (incluindo o cérebro), o que resulta numa diminuição da viscosidade do sangue e melhor perfusão cerebral. Se a autorregulação cerebral está intacta, essas alterações hemodinâmicas resultam em vasoconstrição e uma 
diminuição do volume sanguíneo cerebral e PIC (Muizelaar et al., 1984). A vasoconstrição é um efeito adicional à desidratação cerebral resultante do uso do agente osmótico para reduzir a PIC (Narayan et al., 1982).

A SH age através de mecanismos osmóticos, o mesmo do manitol. Também agem através de mecanismos de ação secundários como redução da viscosidade sanguínea, aumento da tonicidade do plasma, aumento da perfusão tecidual regional do cérebro, aumento do débito cardíaco e da PAM, recuperação dos potenciais de membrana normais, redução do volume pulmonar extravascular e redução da produção do líquor (Suarez, 2004). A alteração induzida na PIC por SH pode ser explicada principalmente por uma redução no volume do cérebro através de uma ação osmótica direta (Harutjunyan et al., 2005; Francony et al., 2008). Estudos com uso de solução salina a $3 \%$ tiveram bons resultados no controle do valor da PIC em pacientes com TCE (Harukuni et al., 2002; Muizelaar Shahlaine, 2009).

Ao se decidir administrar um agente hiperosmolar deve-se levar em conta seus potenciais efeitos colaterais. O manitol é um diurético potente que pode aumentar o risco de lesão renal em pacientes com hipovolemia. Embora o manitol induza uma diurese osmótica, o rápido aumento inicial no volume intravascular pode paradoxalmente causar hipervolemia aguda (que poderia precipitar insuficiência cardíaca ou edema pulmonar em pacientes suscetíveis). A SH por sua vez pode causar um rápido aumento nas concentrações séricas de sódio, aumentando a preocupação para mielinolise pontina central. Felizmente, esta condição devastadora foi raramente observada neste cenário. Além disso, a SH é um expansor do volume 
intravascular, o que pode precipitar sobrecarga de volume (Boone et al., 2015). Alguns autores argumentam em favor da superioridade da SH em relação ao manitol no tratamento da HIC, no entanto ainda não existem atualmente dados suficientes para aconselhar o uso de um ao invés do outro. Além disso, em relação à SH ainda não há um protocolo padronizado quanto à melhor dosagem, tempo de uso, melhor método de infusão e melhor concentração da solução. Se a SH é superior ao manitol para o controle da HIC, isso ainda é uma questão controversa (Oddo et al., 2009).

Uma revisão sistemática e metanálise foi realizada em 2015 comparando estudos de pacientes com HIC por TCE que foram tratados com manitol $20 \%$ e SH em diferentes concentrações. Este estudo demonstrou melhor resultado do controle da PIC nos pacientes que receberam SH em relação aos que receberam manitol. Porém houveram algumas limitações do trabalho, como pequeno número de pacientes incluídos, concentrações das soluções diferiram entre os estudos e as complicações não foram avaliadas (Li et al., 2015). Por outro lado, outra revisão sistemática de estudos randomizados controlados, realizada em 2016, não mostrou diferença nos resultados e nas complicações de pacientes tratados com $\mathrm{SH}$ quando comparados com os que receberam manitol. As concentrações utilizadas também diferiram entre os estudos. Justifica-se, portanto, ainda não haver consenso sobre as melhores solução e concentração de SH a serem utilizadas no controle da HIC (Burgess et al., 2016) 


\subsection{Hematoma Intracerebral Espontâneo}

O aumento da PIC pode surgir como consequência de lesões intracranianas com efeito expansivo, como nos casos de HIE (Bor-Seng-Shu et al., 2012). Estes hematomas apresentam uma incidência média de 24,6 casos por 100000 mil habitantes-ano (van Asch et al., 2010), sendo que representam 10\% a 15\% dos AVE (Querish et al., 2001). Os demais casos são distribuídos entre acidentes vasculares encefálicos isquêmicos (75\%), hemorragia subaracnóidea (5\%) e em eventos indeterminados ou não classificados (5\%) (Thrift et al., 2001). A HIC é verificada em muitos pacientes com hematomas cerebrais, sendo frequentemente a causa de morte.

A mortalidade global dos HIE chega a 50\% em 30 dias (Broderick et al., 1993; Fogelholm et al., 2005), e aproximadamente metade das mortes ocorre nas primeiras 24 horas do ictus inicial (Hemphill et al., 2001). O prognóstico funcional dos sobreviventes também não é bom, sendo que apenas $20 \%$ destes estará funcionalmente independente em 6 meses (Broderick et al., 2007). Em até $40 \%$ dos casos a hemorragia se estende aos ventrículos, podendo ocasionar hidrocefalia obstrutiva, o que piora o prognóstico (Mayer e Rincon, 2005). Outros fatores que pioram prognóstico são volumes grandes de hematoma, localização na fossa posterior, idade avançada e pressão arterial de entrada maior que $130 \mathrm{mmHg}$ (Fogelholm et al., 2005; Hemphill et al., 2001 e 2015).

A hipertensão arterial, tratada ou não tratada, é um importante fator de risco (Woo et al., 2004). Mais de $85 \%$ dos HIE são causados por roturas de pequenas artérias perfurantes e arteríolas danificadas pela hipertensão 
arterial crônica ou angiopatia amiloide. Sessenta a $70 \%$ dos HIE são relacionados a hipertensão arterial e 10 a 15\% são relacionados a angiopatia amiloide, sendo que esta corresponde a mais de $50 \%$ dos casos em idosos, associadas ou não a doença de Alzheimer ou a síndromes da apolipoproteína (Querish et al., 2001). Outros fatores de risco, não modificáveis, são: gênero masculino, idade, etnias africanas e asiáticas (Ariesen et al., 2003). O uso do anticoagulante oral warfarina é associado a elevação do risco de HIE em seis a oito vezes (Fang et al., 2007; Rosand et al., 2004). O uso do antiagregante plaquetário ácido acetilsalicílico (AAS) como profilaxia para eventos cardiovasculares eleva pouco, mas estatisticamente significante o risco de HIE (Gorelick e Weisman, 2005), e também elevada mortalidade se observa em pacientes que faziam uso do AAS antes do HIE, provavelmente devido a maior chance de re-expansão do hematoma (Saloheimo et al., 2006; Toyada et al., 2005). O abuso crônico de álcool (mais que $60 \mathrm{mg} / \mathrm{dia}$ ) ou até mesmo o uso agudo de grandes quantidades aumenta o risco do HIE em até duas vezes (Feldmann et al., 2005; Thrift et al., 2001). Baixos níveis séricos de colesterol e triglicérides apesar de protegerem contra outros tipos de acidente vascular encefálico parecem ter um efeito contrário nos HIEs, sendo que atuam como fator de risco para tal (Segal et al., 1999; Sturgeon et al., 2007). Também são fatores de risco o uso de cocaína e de medicações simpatomiméticas, como a anfetamina. Os efeitos do tabagismo e da prática de atividade física sobre a incidência destes hematomas são incertos (Ariesen et al., 2003; Feldmann et al., 2005). 
Os HIE são normalmente classificados de acordo com a sua localização. A localização é dividida em profunda (gânglios da base), lobar, tronco encefálico ou cerebelar. Aproximadamente metade se localizam profundamente nos gânglios da base, um terço são lobares, e o restante localizado na fossa posterior do crânio (tronco encefálico e cerebelo). Podese inferir se o hematoma é primário ou secundário dependendo de sua localização. Causas secundárias são aneurismas cerebrais, cavernomas, tumores, coagulopatias, trombose venosa, angiopatia amiloide (Mayer e Rincon, 2005). Na maioria dos casos os mecanismos fisiopatológicos envolvidos na origem do HIE são as alterações crônicas na vasculatura cerebral. Hipertensão arterial crônica leva a alterações nas paredes de arteríolas cerebrais de pequeno e médio diâmetro, incluindo degeneração da musculatura lisa dos vasos e desenvolvimento de aneurismas arteriolares (conhecidos como aneurismas de Charcot-Bouchard) associados a microhemorragias e tromboses, além de hialinização da camada íntima dos vasos distais ou em bifurcações (Rincon e Mayer, 2004; Sutherland e Auer, 2006). Estas alterações ocorrem principalmente nas estruturas profundas do encéfalo como tálamo, gânglios da base, ponte e cerebelo. Angiopatia amiloide cerebral é resultado de alterações em vasos pequenos e médios decorrentes do depósito de proteína B-amiloide nas camadas média e adventícia dos mesmos. Estas alterações são associadas com os genótipos Ee2 e Ee4 da apolipoproteína (Skidmore e Andrefsky, 2002).

A apresentação clínica é variável e depende da localização e volume do hematoma. Uma rápida instalação de déficit neurológico focal com 
sintomas de hipertensão intracraniana como vômitos, cefaleia e alteração de consciência são sugestivos de HIE. Em pacientes conscientes os sintomas dependem principalmente da localização do hematoma (Hemphill et al., 2001). O HIE era inicialmente considerado um evento único, mas atualmente sabe-se que é complexo e dinâmico, com três fases distintas: hemorragia inicial, expansão do hematoma e edema perilesional (Brott et al.,1997; Mayer et al., 1998). Após o sangramento inicial o ressangramento é comum, ocorrendo em aproximadamente um terço dos casos nas primeiras 24 horas, sendo que alguns trabalhos mostram este crescimento em até 3 horas após o ictus inicial. A expansão do hematoma ainda causa grande deterioração neurológica devido à súbita elevação da PIC (Broderick et al., 2007; Brott et al., 1997). O edema perilesional ocorre precocemente e é a principal causa de piora neurológica após as primeiras 24 horas do sangramento. É causado pela liberação de trombina pelo hematoma e outros produtos finais da coagulação, além de mediadores citotóxicos e quebra da barreira hematoencefálica (Hua et al., 2007; Xi et al., 2004).

O HIE não pode ser diferenciado clinicamente de um evento isquêmico. A tomografia computadorizada (TC) de crânio confirma o diagnóstico, permite cálculo do volume da lesão e sua possível extensão intraventricular, e ainda o extravasamento de contraste na lesão pode indicar sangramento ativo (Goldstein e Simel, 2005; Murai et al., 2007). A ressonância magnética (RNM) de encéfalo tem a mesma sensibilidade para mostrar hematomas agudos, porém maior sensibilidade para evidenciar edema perilesional. Ela é mais utilizada no seguimento da investigação de 
causas secundárias como malformações arteriovenosas (MAV), angiopatia amiloide ou neoplasias associadas (Kidwell et al., 2004).

O HIE é uma emergência médica e atrasos no tratamento pioram o prognóstico. O manejo inicial deve priorizar estabilização dos parâmetros cardiorrespiratórios e tratamento das complicações intracranianas, como derivação ventricular nos casos de hidrocefalia (Mayer e Rincon, 2005; Morgenstern et al., 2010). Tanto o tratamento conservador quanto as medidas cirúrgicas para o HIE não apresentam melhoras significativas no prognóstico e na taxa de mortalidade, o que torna o HIE uma doença grave de difícil tratamento (Mendelow et al., 2005; Juvela et al., 1989). O tratamento do edema perilesional é feito com soluções hiperosmolares, sendo que o manitol é a mais usada, apesar de não haver consenso no benefício do prognóstico funcional após o uso deste tratamento em pacientes com HIE (Misra et al., 2007). Soluções salinas hipertônicas vem sendo usadas como tratamento promissor de edema cerebral, entretanto a dose ideal, concentração, momento ideal da administração são incertos (Muizelaar e Shahlaine, 2009). A expansão da lesão nas primeiras 24 horas por ressangramento é uma complicação grave e piora o prognóstico. Ela está relacionada a picos elevados da pressão arterial sistólica (PAS). Por isso a atual recomendação é que, salvo não haja contraindicação clínica, tenha-se a PAS inferior a $140 \mathrm{mmHg}$ como alvo do tratamento na fase aguda do HIE (Hemphill et al., 2015).

Como o HIE é uma lesão dinâmica, podendo haver ressangramentos, inundações hemorrágicas ventriculares súbitas e piora do edema cerebral 
com consequente elevação da PIC, torna-se necessário o desenvolvimento de técnicas para acompanhamento da evolução deste hematoma e do comportamento do encéfalo frente a estas mudanças, tanto do ponto de vista anatômico quanto funcional. A realização de TC de crânio seriadas é uma opção para monitorar o aumento do volume do hematoma. Porém, às vezes, o transporte à sala de exame de um doente crítico é difícil, além de a TC ser um exame estático. A monitoração contínua da PIC através de um cateter intraventricular ou intraprenquimatoso é uma opção. Apesar de controversa, ela mostra variações dinâmicas da PIC instantaneamente, o que permite ao neurointensivista tomar decisões imediatas (Schmidt et al., 1997 e 2001). Segundo o consenso da American Heart Association (AHA) a indicação de monitoração da PIC em pacientes com HIE incluem pontuação menor que 8 na escala de coma de Glasgow, com sinais clínicos ou tomográficos de herniação transtentorial, ou inundação hemorrágica ventricular com sinais de hidrocefalia. Já o uso do ativador do plasminogênio tecidual recombinante (rtPA) intraventricular, através de um cateter de DVE, ainda tem eficácia e segurança incertas (Hemphill et al., 2015).

De acordo com o mesmo consenso as recomendações de indicação de remoção cirúrgica dos HIEs ainda são controversas. Em hematomas de fossa posterior recomenda-se ressecção cirúrgica quando o diâmetro for maior que 3 $\mathrm{cm}$ ou se houver compressão do tronco encefálico, ou ainda se houver hidrocefalia por compressão do IV ventrículo. Nestas situações não se recomenda DVE antes de remover o hematoma (Hemphill et al., 2015). O trial STICH (Mendelow et al., 2005) que comparou a resseção precoce de HIEs 
supratentoriais versus tratamento clínico não encontrou melhor resultado no grupo cirúrgico. Neste estudo foram excluídos pacientes com hematomas de diâmetro menor que $2 \mathrm{~cm}$, ou com extensão para o tronco encefálico, ou escala de coma de Glasgow menor que 5, ou suspeita de aneurismas cerebrais, tumores ou trauma como causas dos hematomas. O volume dos hematomas variou de $4 \mathrm{~mL}$ a $210 \mathrm{~mL}$. No estudo STICH II (Mendelow et al., 2013) comparou-se cirurgia versus tratamento clínico apenas no subgrupo de hematomas lobares que estivessem a $1 \mathrm{~cm}$ da superfície cortical, com volume de $10 \mathrm{~mm}^{3}$ a $100 \mathrm{~mm}^{3}$, sem hemorragia intraventricular. Também não houve diferença de resultados entre os dois grupos. Porém há críticas aos dois estudos, como exclusão de muitos pacientes com herniação encefálica, além de elevado crossover de pacientes do grupo clínico para o grupo cirúrgico ao longo dos estudos, além de enfoque na cirurgia precoce, o que mantém em aberto o real papel da remoção cirúrgica nos HIEs supratentoriais. Baseado nisso o consenso atual da AHA faz algumas recomendações sobre cirurgias nos HIEs supratentoriais. A maioria dos pacientes com estes hematomas não se beneficia das ressecções cirúrgicas, com poucas exceções. Também não há evidência de que resseções precoces do hematoma sejam melhores que resseção tardia após deterioração neurológica. Quando ocorre piora neurológica importante do paciente, deve-se considerar remoção cirúrgica do HIE supratentorial. Já a craniectomia descompressiva, ampla e unilateral, com ou sem remoção do HIE, pode reduzir a mortalidade em pacientes com HIEs supratentoriais que estejam em coma, com TC de crânio evidenciando desvio das estruturas da linha mediana, ou com HIC refratária a medidas clínicas. As 
remoções cirúrgicas do HIE realizadas com técnicas minimamente invasivas, como estereotaxia ou endoscopia, com ou sem o uso de trombolíticos, ainda não tem bons resultados comprovados (Hemphill et al., 2015).

Como já citado, a ultrassonografia Doppler (USNG com Doppler), ou duplex, é um método não invasivo que pode ser feito na beira do leito (a ultrassonografia para avaliar anatomia e a técnica de DTC para avaliar hemodinâmica). A elevação da PIC e diminuição do fluxo sanguíneo cerebral podem alterar as características das ondas do DTC, e a ultrassonografia pode medir expansões do hematoma, sendo um método em estudo para o monitoramento da hemodinâmica encefálica e do efeito de massa do HIE (Pérez et al., 2009; Ursino et al., 1998). Um estudo prospectivo encontrou correlação entre parâmetros do DTC e volume de hematomas medidos por TC. Quanto maior o volume do HIE maior foi o IP e menor foi o VD (MartíFàbregas et al., 2015). Mas ainda não há clareza na literatura sobre a eficácia do uso USNG com Doppler na avaliação de HIEs.

\subsection{Modelos Experimentais de Hematoma Espontâneos}

O diagnóstico correto e precoce da hipertensão intracraniana associada ao HIE é essencial para definir medidas de intervenção e neuroproteção, desde o surgimento da lesão cerebral primária até o seguimento pós-operatório em uma unidade de terapia intensiva. Assim, os métodos de monitorização da PIC e hemodinâmica cerebral adotadas no manejo clínico de condições de hipertensão intracraniana causada por hematomas cerebrais tem uma grande relevância. O surgimento de novas 
intervenções são de grande importância na atual fase de conhecimento sobre estas lesões, o que leva a necessidade de experimentação animal para se conhecer aspectos das condições hemodinâmicas encefálicas, assim como o impacto de novas medicações e intervenções na fase aguda da hipertensão intracraniana. Modelos animais de hemorragia intracerebral contribuem grandemente para um entendimento avançado de fisiopatologia da doença. Na revisão a seguir serão discutidos os principais modelos descritos na literatura ressaltando vantagens e desvantagens.

\subsubsection{Modelo de injeção intracerebral de sangue autólogo}

Modelos experimentais de hematomas cerebrais foram descritos desde a década de 1960 e, normalmente, envolvem a injeção intracerebral de sangue autólogo, que é uma técnica simples e eficaz para a produção de hematoma parenquimatoso cerebral. Este tipo de modelo tem sido desenvolvido em animais maiores (cães, gatos, suínos e macacos) (Whisnant et al., 1963; Sussman et al., 1974; Takasugi et al., 1985; Wagner et al., 1996; Pourcyrous et al., 1997), por meio da injecão de sangue no lobo frontal. Para animais menores (ratos e camundongos) o sangue é injetado no núcleo caudado (Bullock et al., 1984; Yang et al., 1994; Xi et al., 1998a e 1998b; Hua et al., 2000; Nakamura et al., 2003; Xi et al., 2001). Este método não reproduz a ruptura do vaso arterial presente em hematomas cerebrais humanos, mas podem ser úteis para o estudo dos efeitos fisiopatológicos e bioquímicos em pacientes com hematomas cerebrais agudos com hipertensão intracraniana. 


\subsubsection{Modelo de dupla infusão}

O modelo de injeção de sangue foi desenvolvido como uma única injeção intracerebral, mas muitas vezes produz resultados inconsistentes devido ao refluxo de sangue ao longo da agulha (Yang et al., 1994). Para minimizar esta complicação, um método de injeção dupla foi desenvolvido, na qual uma pequena quantidade de sangue é injetado logo acima da área alvo do cérebro, seguido por uma segunda injeção de sangue para os gânglios da base, sendo que o sangue coagulado da primeira injeção impede o retorno do sangue ao longo da agulha (Rohde et al., 2002). Este modelo reproduz um hematoma em rápido desenvolvimento, mas não induz a ruptura real de vasos sanguíneos cerebrais. Uma grande vantagem do modelo de injeção de sangue autólogo é que não há fatores de confusão, tais como proteínas exógenas, que podem ser utilizadas para induzir HIC.

\subsubsection{Modelo de colagenase bacteriana}

A injeção de colagenase bacteriana nos gânglios da base em modelo murino, levando à desagregação da lâmina basal dos vasos sanguíneos foi introduzido pela primeira vez no início de 1990 (Rosenberg et al., 1990; Clark et al., 1998). Este modelo gera um sangramento intracerebral espontâneo que se desenvolve ao longo de várias horas, conforme exibido em cerca de $30 \%$ dos pacientes com HIC. A colagenase bacteriana é uma protease que lesa a matriz extracelular em torno dos capilares cerebrais e os enfraquece, causando ruptura do vaso e consequente extravasamento de sangue. Este modelo é geralmente utilizado para investigar os mecanismos 
de aumento do hematoma, bem como para desenvolver tratamentos potenciais que afetam a homeostase. No entanto, a colagenase bacteriana pode amplificar a resposta inflamatória e apresentar efeitos neurotóxicos em doses elevadas. Além disso, os sangramentos extensos consequentes à injeção intracerebral de colagenase podem produzir uma lesão cerebral isquêmica não planejada (Lei et al., 2014).

\subsubsection{Modelo de avulsão dos vasos sanguíneos cerebrais}

Neste modelo, veias corticais podem ser expostas através de uma craniotomia e lesadas usando uma agulha curva, resultando em hemorragias corticais (Funnell et al., 1990; Xue e Del Bigio, 2003). Este modelo foi muito pouco utilizado em estudos mais atuais, pois apresenta uma variabilidade muito grande da lesão cerebral criada, o que limita a confiabilidade dos resultados da experimentação.

\subsubsection{Modelo de hematoma cerebral com balão}

O uso de modelo de hipertensão intracraniana com balão não é novo. Sinar et al. (1987) desenvolveu um modelo em camundongos feito com inserção de microbalão em ratos como um modo para estudar os efeitos de massa de HIC. Um microbalão montado em uma agulha 25 Fr era inserida no núcleo caudado direito através de um orifício de trepanação no crânio do animal. O microbalão era inflado para $0,05 \mathrm{~mL}$ ao longo de um período de 20 segundos, sendo mantido durante 10 minutos inflado e após intervenção era esvaziado. No final do estudo, os autores analisaram a histologia do cérebro, 
a pressão intracraniana e o fluxo sanguíneo cerebral. Eles concluíram que o modelo com microbalão produziu uma lesão cerebral eficaz, com redução do fluxo sanguíneo cerebral e um aumento na pressão intracraniana no local da lesão. Em 1997 foi publicado um estudo em um modelo animal de HIC desenvolvido em gatos (Nagai et al., 1997). Um balão era insuflado no espaço epidural parietal do gato através de pequena trepanação. A PIC era monitorada por cateter epidural ipsilateral e realizou-se avaliação não invasiva por Doppler transorbital. Neste trabalho houve correlação estatisticamente significante da elevação do IP com elevação da PIC.

Em 2010, Shi et al. desenvolveram um modelo suíno de HIE que tinha em uma das etapas a insuflação de um balão no encéfalo do animal, porém também havia injeção de sangue autólogo diretamente no parênquima. Andrade et al. (2013) também desenvolveram um modelo de HIE experimental em suínos, com insuflação de balão no parênquima cerebral (sonda vesical pediátrica), capaz de simular os efeitos agudos sobre a pressão intracraniana, semelhante aos de hematomas cerebrais. O modelo de balão parece suficiente para gerar as condições de oscilações da pressão intracraniana e seus impactos sobre as condições hemodinâmicas enecefálicas. A principal desvantagem deste modelo é que não é possível avaliar o papel do sangue e seus produtos de degradação em lesões relacionadas ao HIE, mas é valioso para estudar os efeitos de danos mecânicos no tecido cerebral e dos efeitos pressóricos e hemodinâmicos (Kirkman et al., 2011). Também um modelo de simulação de hematoma epidural em coelhos, em que se monitorava a PIC e se realizava DTC foi publicado em 2014 (Kasapas et al., 2014). 


\subsubsection{Modelos em animais girencéfalo}

Analisando os modelos experimentais descritos na literatura, busca-se um modelo simples e eficiente. O uso de suínos parece interessante, considerando que o cérebro destes animais apresenta substância branca bem desenvolvida, estado de saúde mais uniforme, um custo relativamente baixo, sem maiores dificuldades com sociedades protetoras de animais. Assim se torna um excelente modelo animal para estudos de hipertensão intracraniana e de hematoma cerebral. A possibilidade de usar volumes de hematoma 20 a 30 vezes maiores neste modelo, em comparação com espécies de roedores, permite a remoção do hematoma (desinsuflação do balão), além de propiciar a simulação de ressangramentos. A insuflação de balão na substância branca subcortical, ao invés de sangue injetado na massa cinzenta dos gânglios basais, resulta em volumes de hematoma mais reprodutíveis e uniformes. Isto facilita a extrapolação de resultados para seres humanos. Além disso, o maior volume de substancia branca em animais de grande porte permite desencadear edema adjacente ao hematoma. Este modelo é clinicamente relevante, uma vez que as informacões sobre a PIC podem ser extrapoladas para os modelos clínicos de tratamento (Rojas et al., 2008).

Wagner et al. (1996) desenvolveram um modelo de hemorragia lobar em suínos, onde $1,7 \mathrm{~mL}$ de sangue arterial autólogo eram lentamente injetadas na substância branca frontal usando uma bomba de infusão. A injeção lenta reduzia a probabilidade de ruptura ventricular ou vazamento de sangue ao longo do trajeto da agulha. Em comparação com infusões rápidas 
em altas pressões, este método parece ser mais fidedigno aos hematomas profundos em humanos, onde o sangramento geralmente se origina a partir de pequenas artérias intraparenquimatosas. Modelo semelhante foi publicado no ano seguinte (Pourcyrous et al., 1997). Nesses modelos não era possível a remoção completa do hematoma por procedimento cirúrgico, uma vez que o sangue era infundido diretamente no tecido cerebral. Em outro estudo, liderado por Rohde et al. (2002), os autores modificaram este modelo em um procedimento de dupla injeção (com uma injeção principal de $2 \mathrm{~mL}$ a $3 \mathrm{~mL}$ de sangue venoso autólogo com reservatório de sangue) para melhor prevenir o refluxo pós-injeção.

O uso de suínos representa ainda um modelo útil de hipertensão intracraniana em decorrência da presença de giros corticais mais similares ao cérebro humano comparado com modelos murinos. Os modelos suínos de HIE com infusão autóloga têm sido utilizados para investigar a PIC, o FSC, o desenvolvimento de edema, metabolismo encefálico, fator de transcrição e expressão gênica para ativação inflamatória (Wagner et al., 1998, Wagner e Broderick, 2001; Wagner et al., 2002, 2003 e 2007). Também tem sido utilizada para estudar a possibilidade de lise de coágulos induzida pelo ativador de plasminogênio tecidual (tPA) (Wagner et al., 1999; Zuccarello et al., 2002). Também tem sido utilizado para testar os efeitos de lesão cerebral induzida na inibição da hemoxigenase (Wagner et al., 2000) e agentes quelantes de ferro com deferoxamina (Gu et al., 2009). Contudo, enquanto o uso de sangue autolólogo permite a avaliação dos efeitos bioquímicos do sangue sobre os neurônios, estes modelos não permitem 
avaliar de forma simples e direta os efeitos de uma eventual cirurgia para exérese do hematoma.

Os suínos também foram usados em modelos de injeção de colagenase. Foram realizadas infusões desta protease de $10 \mathrm{~mL}$ no córtex somato-sensorial direito, por bomba de microinfusão de 20 a 30 minutos, foram descritas por Mun-Bryce et al. (2001). Este estudo examinou a excitabilidade do tecido adjacente ao hematoma e avaliaram os resultados da lesão cerebral utilizando imagem por ressonância magnética além de eletro e magnetoencefalografia. O uso de colagenase liberado a partir de células lesadas, não aborda o fenômeno clinicamente relevante do edema vasogênico associado com hematoma cerebral e assim não oferece as condições ideais de estudos sobre pressão intracraniana. Os níveis de colagenase neste modelo suíno, no entanto, estão muito acima daqueles encontrados na lesão cerebral humana, o que dificulta qualquer correlação para extrapolar as informações para a prática clínica.

Fundamentado nos estudos clássicos de modelos animais com hipertensão intracraniana, Shi et al. (2010) publicaram um novo modelo experimental utilizando a insuflação de cateter vesical pediátrico com soro fisiológico para conseguir espaço anatômico e posteriormente infundir sangue autólogo. No entanto, não foram realizadas as análises da hemodinâmica cerebral e de suas variáveis. Apenas se avaliou o quadro clínico dos animais dias após a realização do procedimento cirúrgico que simulou um hematoma intracerebral profundo. Também pode-se considerar este modelo semelhante ao de injeção de sangue autólogo, pois o 
hematoma final, que induzia a HIC, era formado dessa maneira e não com a insuflação do balão.

Um modelo experimental de HIE em suínos foi desenvolvido na Faculdade de Medicina da Universidade de São Paulo (Andrade et al., 2013), conforme já citado. O modelo foi desenvolvido também usando-se insuflação de balão no parênquima cerebral. Utilizou-se um cateter vesical infantil de 8 French, adaptado, que era introduzido na substância branca do lobo frontal através de trepanação no osso frontal. Avaliou-se a variação da PIC através de cateter de monitorização intraparenquimatosa (introduzido por outra pequena trepanação frontal) e por cateter de monitorização epidural (introduzido no espaço epidural temporal através de pequena trepanação no osso temporal). Também foi possível a avaliação de velocidade de fluxo cerebral, nas diversas situações de elevação da PIC, utilizando-se o aparelho de ultrassonografia Doppler craniano através de outra pequena trepanação temporal. $\mathrm{O}$ balão foi insuflado lentamente com soro fisiológico ( $\mathrm{NaCl}$ 0,9\%) por bomba de infusão contínua, simulando diferentes volumes de HIE. Toda a homeostase do animal foi monitorizada, com exames de gasometria arterial seriadas, monitorização invasiva da pressão arterial e oximetria de pulso. Ao final do experimento foi possível a simulação da exérese cirúrgica do hematoma desinsuflando-se o balão. Este trabalho foi utilizado como projeto piloto para a atual pesquisa. O Quadro 1 mostra os principais modelos animais de HIE desenvolvidos ao longo do tempo. 
Outro estudo desenvolvido em suínos (Friess et al., 2011) tinha a intenção de simular uma lesão intracerebral difusa, com o método de aceleração e desaceleração rápida, comparando com o grupo controle. Nesse estudo foram analisados valores da PIC, no entanto é um modelo em que não é possível reverter a lesão cerebral através de procedimento cirúrgico e também não se aplica a modelos de hematoma intracerebral. 


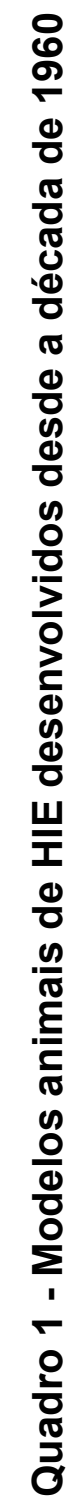

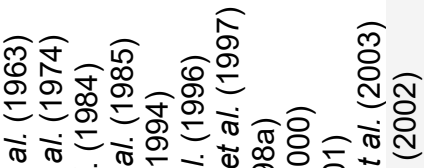

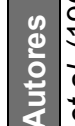

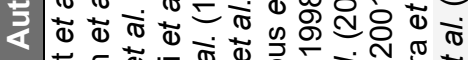

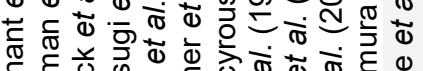

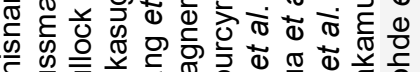

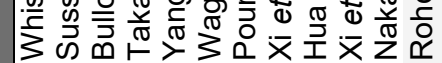

$\stackrel{\frac{\pi}{\pi}}{\frac{0}{6}}$

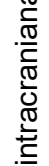

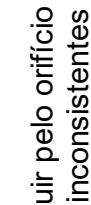

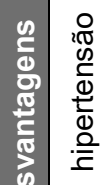

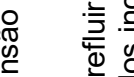

壱

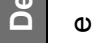

응

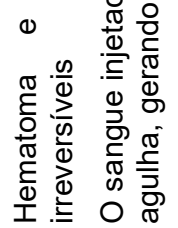

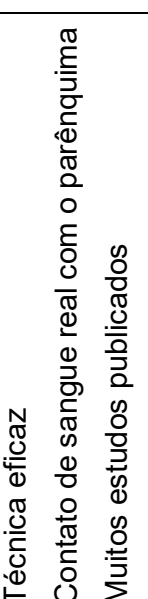
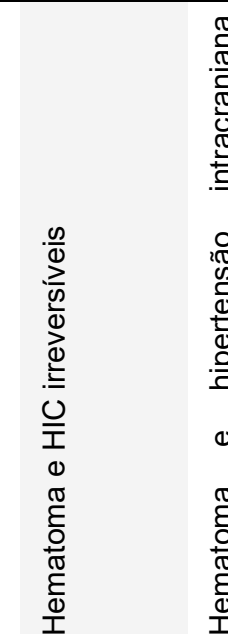

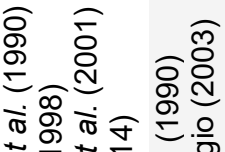

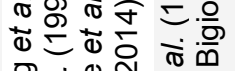

गें ब.

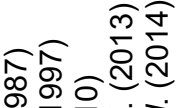

$=5 \dot{\sigma} \dot{\sigma}$

$\dot{\bar{\sigma}} \dot{\sigma} \dot{d} \widetilde{\Phi}$

蛋

竞

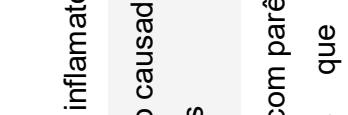

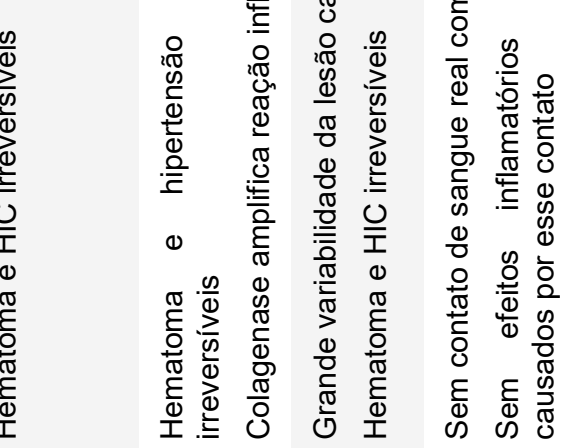

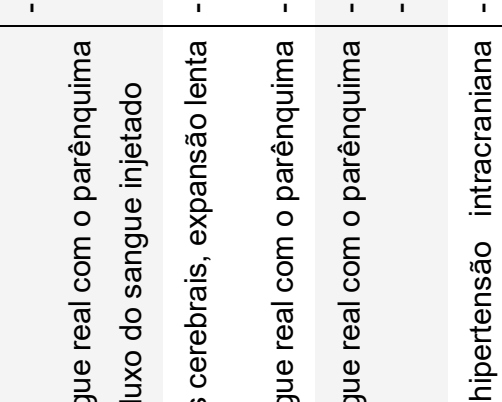

뜨응

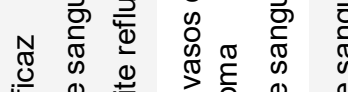

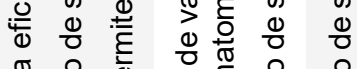

傡

胥

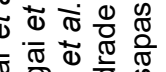

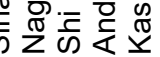

일

웅

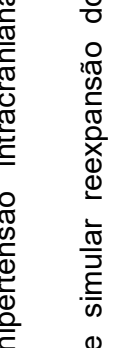

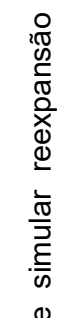

앙 क्

(n)

'

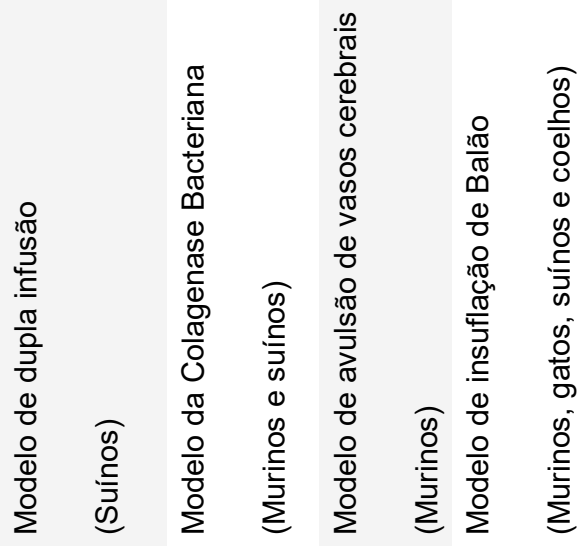


4 MÉtodos 
Este estudo é uma pesquisa experimental em modelo animal suíno, e foi realizado no LIM 26 da FMUSP, São Paulo, Brasil. Obteve-se fomento da Fundação de Apoio a Pesquisa do Estado de São Paulo (FAPESP), sob Processo n²013/01160-1.

\subsection{Aspectos Éticos}

Os experimentos foram feitos segundo diretrizes estabelecidas na Lei federal 11.794/08, que regula os procedimentos para uso científico de animais no Brasil. O estudo foi previamente aprovado pela Comissão de Ética para Análise de Projetos de Pesquisas (CAPPesq) do Hospital das Clínicas da FMUSP sob o número 0520/09, em reunião de 12 de março de 2013 (Anexo A). O presente projeto também foi aprovado em reunião do Departamento de Neurologia da FMUSP. Pode-se ressaltar que em nenhuma etapa da experimentação os animais foram submetidos a condições de sofrimento ou dor. 


\subsection{Preparação do Animal: Anestesia e Monitoração}

Os suínos foram submetidos a 12 horas de jejum com livre acesso à água, até 1 hora antes do experimento.

Sempre o mesmo médico veterinário, com vasta experiência, foi o responsável por anestesiar e acompanhar toda a homeostase do animal, durante todo o experimento. A técnica anestésica empregada em todos os animais incluiu administração de Quetamina (Ketamin-S ${ }^{\circledR}$, Cristália) na dose de $5 \mathrm{mg} / \mathrm{kg}$ e Midazolan (Dormire ${ }^{\circledR}$, Cristália) na dose de $0,25 \mathrm{mg} / \mathrm{kg}$, ambos colocados em mesma seringa e administrados pela via intramuscular, como medicação pré-anestésica (Figura 6). Decorridos quinze minutos a veia marginal da orelha foi cateterizada com cateter vascular de calibre 20 gauge ou 22 gauge (BD Insyte ${ }^{\circledR}$ ). Uma vez estabelecido o acesso venoso, realizouse a indução anestésica, que consistiu da aplicação de propofol (Provine ${ }^{\circledR}$ $1 \%$ - Cláris) na dose de $5 \mathrm{mg} / \mathrm{kg}$; receberam também um volume inicial de 20 $\mathrm{ml} / \mathrm{kg}$ de solução fisiológica $(\mathrm{NaCl}$ 0,9\%) (SF) para compensar a perda volêmica relativa ao jejum. Os animais foram submetidos a intubação orotraqueal com sonda endotraqueal de diâmetro 6 (Portex $\left.{ }^{\circledR}\right)$, sendo a manutenção anestésica feita com propofol (Provine ${ }^{\circledR} 1 \%$ - Cláris) na dose de $3 \mathrm{mg} / \mathrm{kg} / \mathrm{h}$ e a analgesia foi mantida com fentanil (Fentanest ${ }^{\circledR}$ - Cristália), por uma dose inicial de $5 \mu \mathrm{g} / \mathrm{kg}$ seguida de infusão contínua de $0,4 \mu \mathrm{g} / \mathrm{kg} / \mathrm{min}$ por via intra venosa (IV). O bloqueio neuromuscular foi obtido com a administração de pancurônio (Pancuron ${ }^{\circledR}$, Cristália), em bolus na dose de 0,1 $\mathrm{mg} / \mathrm{kg}$ IV seguida de infusão contínua deste agente na dose de 0,02 $\mathrm{mg} / \mathrm{kg} / \mathrm{h}$. 


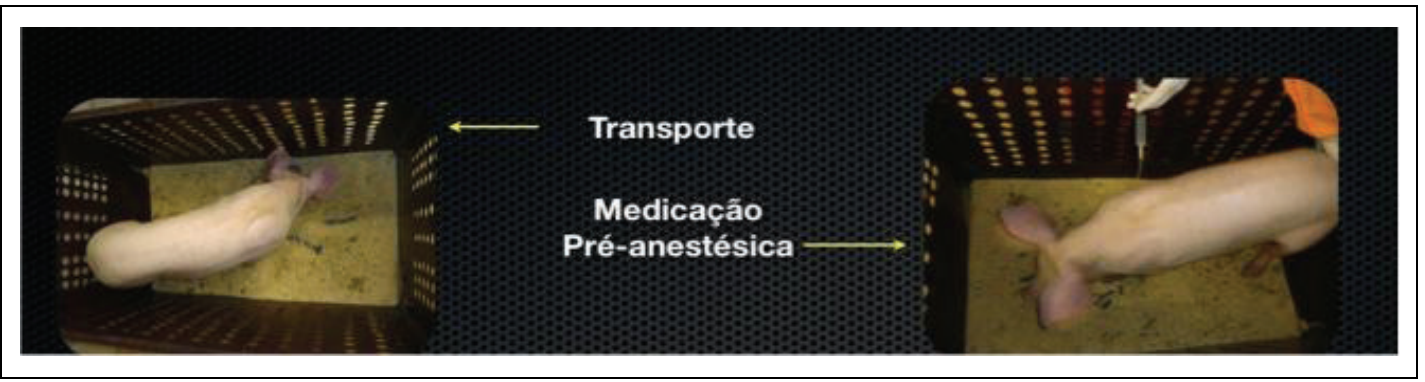

Figura 6 - Fase inicial do experimento, incluindo transporte em condição adequada e indução pré-anestésica

Após intubação orotraqueal os animais foram submetidos à ventilação mecânica controlada ciclada a volume (Ventilador Dixtal $\left.{ }^{\circledR} 5010\right)$, com volume corrente (VC) de $10 \mathrm{ml} / \mathrm{kg}$, fração inspirada de oxigênio $\left(\mathrm{FIO}_{2}\right)$ de 0,50 e pressão positiva expiratória final (PEEP) de $5 \mathrm{cmH}_{2} \mathrm{O}$ (Figura 7). Os parâmetros ventilatórios foram ajustados para manter a $\mathrm{PaCO}_{2}$ entre $35 \mathrm{~mm}$ Hg e $45 \mathrm{mmHg}$, a $\mathrm{PaO}_{2}$ entre $100 \mathrm{~mm} \mathrm{Hg}$ e 150 mm Hg e o pH entre 7,357,45. Para se avaliar a adequação da ventilação, foram mensurados continuamente tanto a pressão final de dióxido de carbono expirado $\left(\mathrm{EtCO}_{2}\right)$, quanto a saturação periférica da hemoglobina por meio de oximetria de pulso $\left(\mathrm{SatO}_{2}\right)$. Através de uma incisão mediana abdominal a bexiga urinária foi acessada e realizou-se cistostomia sob visão direta para controle da diurese do animal. A artéria femoral direita foi cateterizada e conectada a transdutor de pressão, em todos os animais para monitoração da pressão arterial média invasiva (Figuras 8 e 9). Foi realizada gasometria arterial com amostras $(0,3 \mathrm{~mL})$ no início do procedimento a fim de estabelecer os parâmetros ventilatórios e após intervenções para avaliar manutenção dos parâmetros fisiológicos. Ao total, foram realizadas quatro coletas de gasometria arterial durante cada procedimento. 


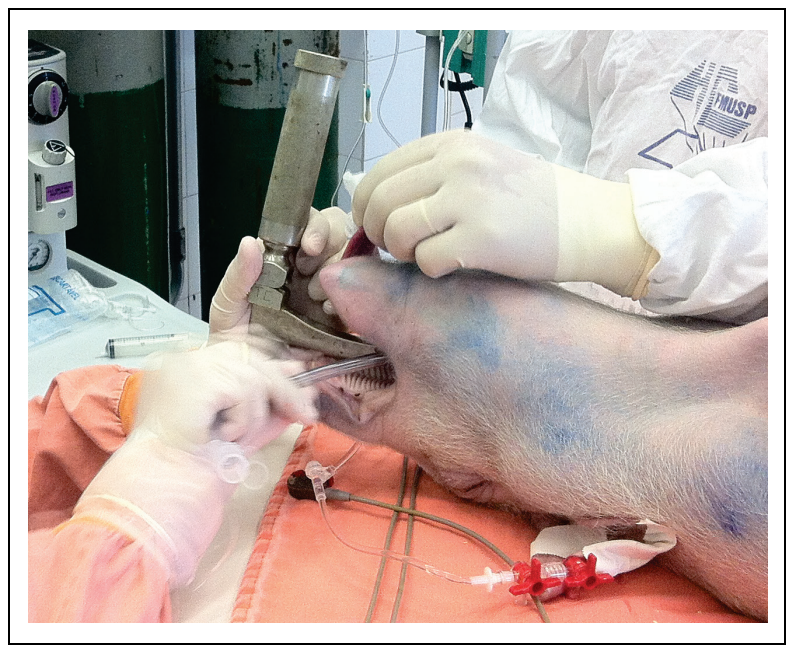

Figura 7 - Procedimento de intubação orotraqueal realizado pelo veterinário anestesista. Também observa-se orelha direita do animal com acesso venoso

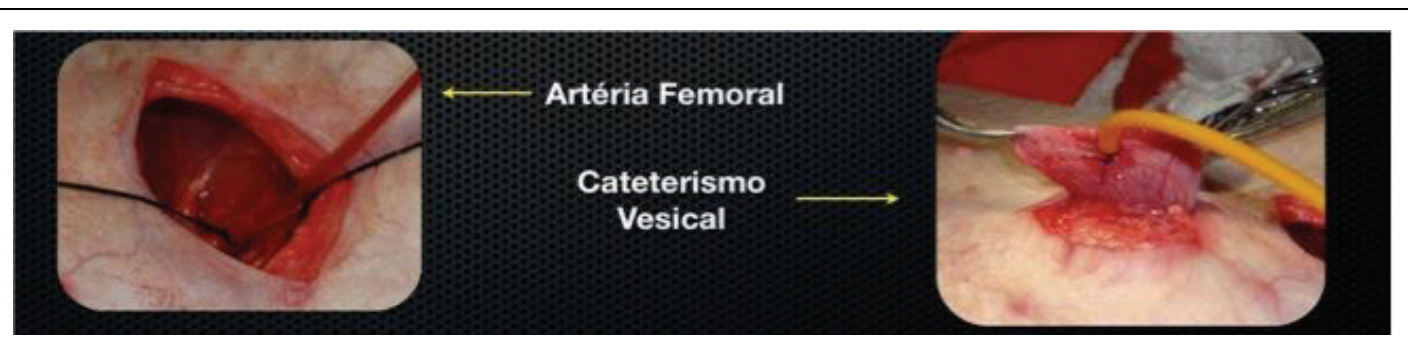

Figura 8 - Foto da esquerda: dissecção e cateterismo da artéria femoral direita para aferição da pressão arterial e invasiva; foto da direita: dissecção e cateterismo da bexiga vesical

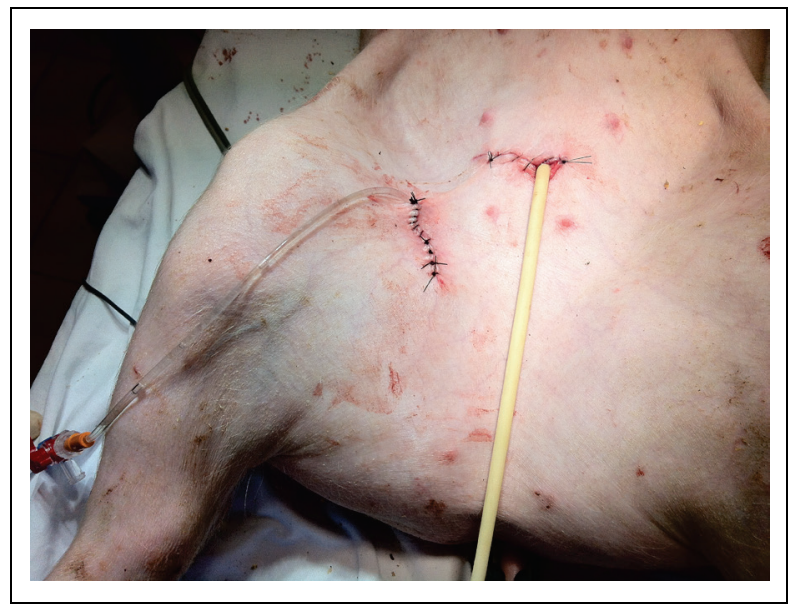

Figura 9 - Aspecto final após cistostomia (na incisão mediana) e cateterismo da artéria femoral direita 
Durante o procedimento os animais receberam fluidoterapia de suporte com SF de $5 \mathrm{~mL} / \mathrm{kg} /$ hora. Os dados hemodinâmicos foram mensurados através do monitor multiparâmetros (Monitor Portal DX 2020, Dixtal $^{\circledR}$, Dixtal Biomédica Ind Com Ltda., Brasil, 2003) (Figura 10).

A temperatura corporal foi medida continuamente com termômetro retal, e mantida entre $37^{\circ} \mathrm{C}$ e $38^{\circ} \mathrm{C}$ com a utilização de um colchão térmico e soluções de manutenção aquecidas previamente.

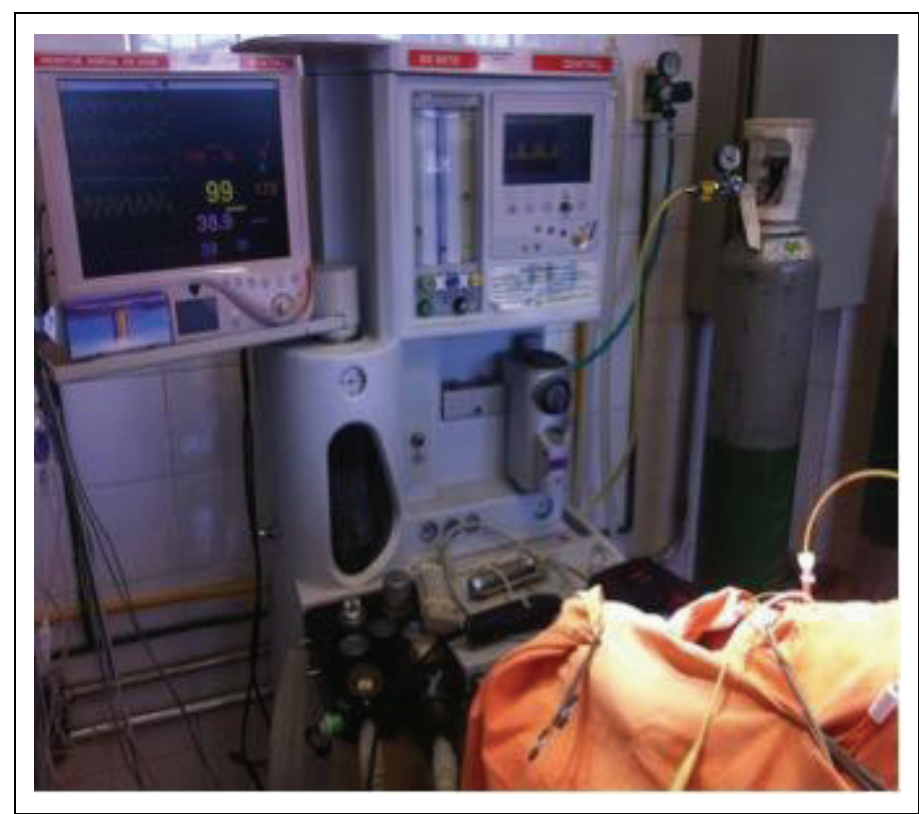

Figura 10 - Sistema de anestesia geral e monitoração sistêmica durante o experimento

\subsection{Método de Monitoração da Pressão Intracraniana}

Foi utilizado o sistema de monitoração da PIC parenquimatosa, como monitoração padrão, uma vez que a punção ventricular em suíno pode ser difícil por questões de anatomia. A técnica de instalação do cateter é detalhada abaixo na descrição do modelo animal. 
O sistema de aferição da PIC parenquimatosa escolhido foi 0 Neurovent-P (Raumedic ${ }^{\circledR}$, Munchberg, Alemanha), que consiste em uma sonda de pressão para uso parenquimatoso. Este sistema pode ser ligado a qualquer monitor, usando um pequeno simulador específico do ponto zero para o tipo de monitor de paciente. Mudanças no monitor durante a medição não resulta em perda de calibração. A ponta do sistema Neurovent-P® tem um diâmetro de cerca de 1,6 mm e sua função é baseada em um chip eletrônico na extremidade (Sahuquillo et al., 2008) (Figura 11). O chip é feito de silício e sua porção central é achatada, o que resulta em uma membrana fina. Esta membrana fica saliente em relação ao grau de pressão a que é exposta. A pressão é medida por determinação da deformidade de membrana usando o sistema piezoelétrico. A precisão de medição necessária e independência de variações de pressão de entrada são asseguradas por uma ponte de medição integrada ao chip. Erros de linearidade tomados isoladamente podem estar presentes, mas de pequeno valor, uma vez que eles são dados como um valor combinado. O máximo desse erro combinado é $0,5 \%$ (dados fornecidos pelo fabricante). 


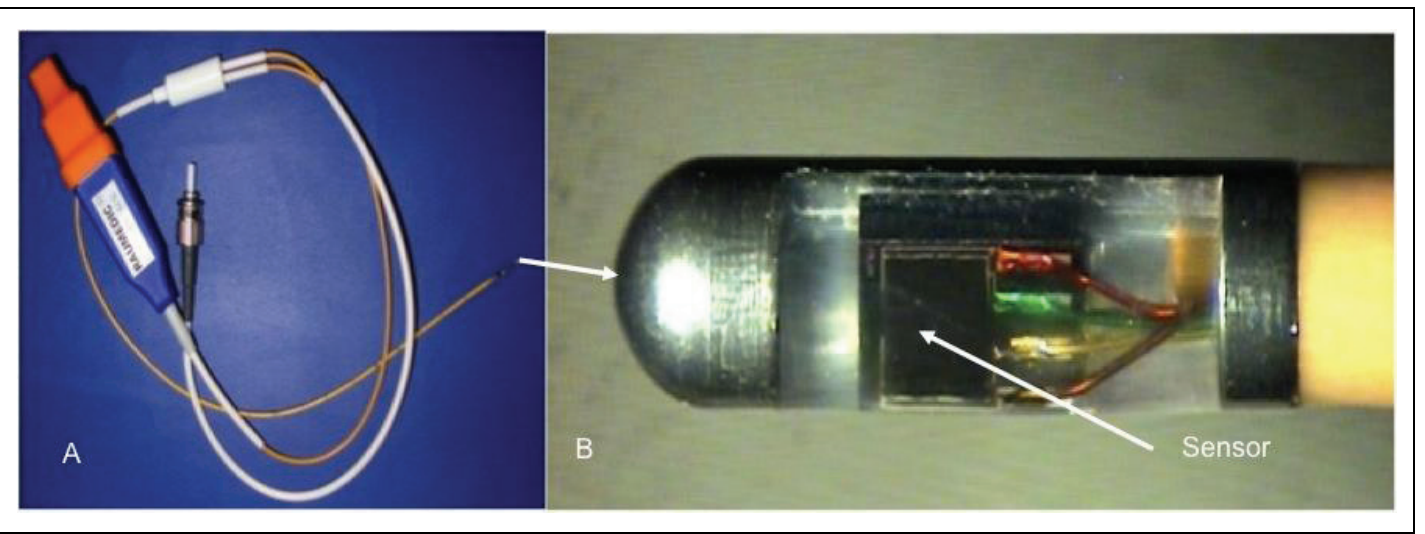

Figura 11 - Cateter Neurovent $P^{\circledR}$ utilizado no experimento para aferição de PIC parenquimatosa. Em A - Cateter completo e sistema para conexões. Em B - Imagem em maior aumento evidenciando sensor na extremidade com microcabos elétricos

\subsection{Método de Avaliação da Hemodinâmica Cerebral com Ultrassonografia Doppler Craniano}

A técnica empregada neste estudo foi a USNG com Doppler craniana e não apenas DTC, pois além da técnica de Doppler, que avalia as velocidades de fluxo sanguíneo, foi também utilizada o ultrassonografia para localizar as artérias (color flow) e para visualizar balão insuflado.

Mesmo em humanos, a principal limitação do uso da USNG com Doppler é a presença de janela acústica no osso temporal, que não está presente em algumas pessoas. Ao tentar realizar o exame no suíno deparou-se com essa dificuldade. Optou-se, portanto, pela realização de uma pequena trepanação no osso temporal ipsilateral à colocação do balão e o cateter, permitindo a realização do estudo com USNG com Doppler, utilizando transdutor setorial $(5 \mathrm{mHz}$ a $8 \mathrm{mHz})$. Foi possível a análise da velocidade de fluxo na artéria cerebral (sempre utilizada a artéria melhor 
visualizada com color flow do aparelho). Obteve-se então a VS, a VD (Figura 12), e destes calculou-se os parâmetros derivados: velocidade média do fluxo sanguíneo cerebral $[\mathrm{VM}=(\mathrm{VS}+2 \mathrm{xVD}) / 3)$ e o índice de pulsatilidade $(\mathrm{IP}=(\mathrm{VS}-\mathrm{VD}) / \mathrm{VM}]$. Estes parâmetros foram analisados posteriormente para avaliação do comportamento da pressão intracraniana e da hemodinâmica cerebral nas condições normais e de diferentes condições de hipertensão intracraniana. Além da mensuração das velocidades de fluxo sanguíneo, a ultrassonografia permitiu a visualização do balão insuflado no parênquima cerebral (conforme técnica descrita abaixo) e mensuração do volume do balão (Figura 13). Todos estes exames foram realizadados por um único neurossonologista, com vasta experiência em USNG com Doppler. O equipamento utilizado foi um ultrassom 2D (modelo Micromax ${ }^{\circledR}$, FUJIFILM SonoSite ${ }^{\circledR}$, Washington DC, Estados Unidos) com transdutores de baixa frequência (8 mHz a $4 \mathrm{mHz}$ ) para localização do balão inflado e realização do Doppler das artérias encefálicas que foram localizadas pela técnica de Doppler colorido (Figura 14).

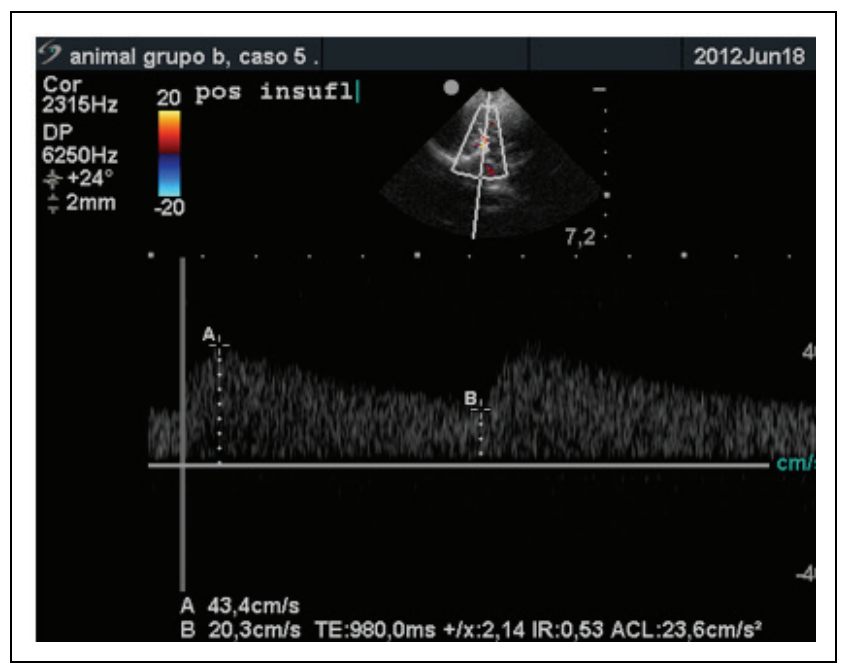

Figura 12 - Doppler das artérias encefálicas, sendo A a velocidade de fluxo na sístole e $B$ a velocidade de fluxo na diástole 


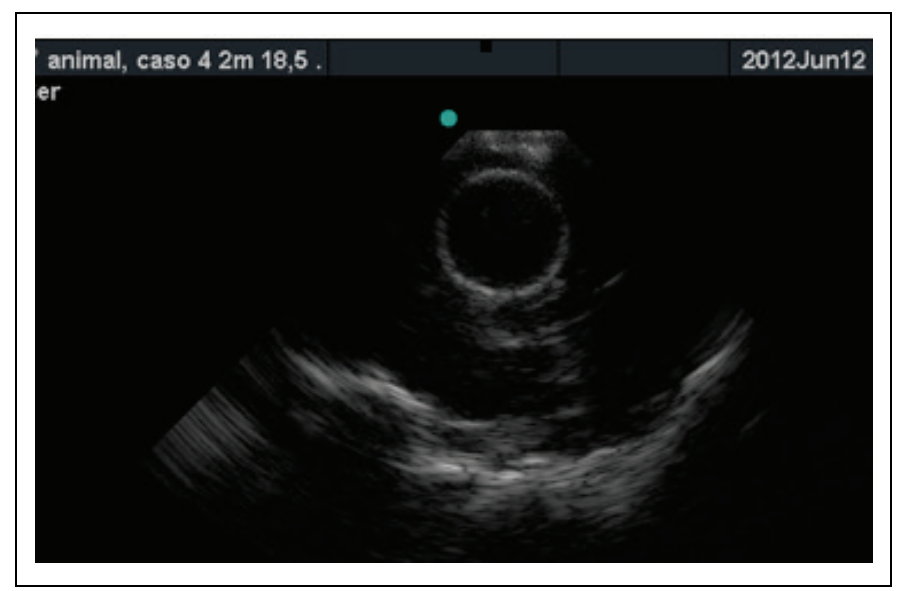

Figura 13 - Ultrassonografia transcraniana mostrando balão insuflado $4 \mathrm{~mL}$ de SF $0,9 \%$ no lobo frontal direito no suíno

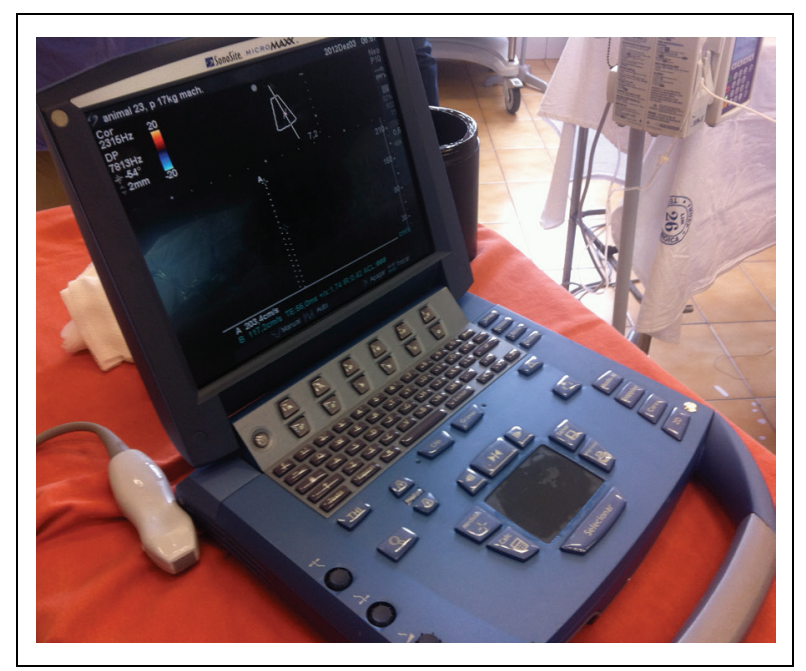

Figura 14 - Equipamento de USNG utilizado nos experimentos

\subsection{Procedimento Experimental}

O modelo experimental de hematoma espontâneo intracerebral desenvolvido e validado previamente pelo grupo de pesquisa do LIM 26 da FMUSP foi utilizado no presente estudo (Andrade et al., 2013). O modelo visa a simulação de um hematoma intracerebral frontal direito, realizado de maneira controlada. Foi realizada na cabeça de cada animal uma incisão fronto-temporal em forma de “ L” (Figura 15), na linha média e região 
temporal logo à frente da orelha, afim de expor as suturas coronária e sagital. Em seguida, foi feita uma trepanação óssea $1 \mathrm{~cm}$ lateral à sutura sagital e $1 \mathrm{~cm}$ anterior à sutura coronal, no hemicranio direito, por onde foi introduzido o cateter intraparenquimatoso (Neurovent-P ${ }^{\circledR}$, Raumedic ${ }^{\circledR}$, Munchberg, Alemanha), para monitoração da PIC, na substância branca do lobo frontal direito, em uma profundidade de $10 \mathrm{~mm}$. Uma trepanação óssea localizada $1 \mathrm{~cm}$ lateral à sutura sagital e $1 \mathrm{~cm}$ posterior à sutura coronária com diâmetro de $3 \mathrm{~mm}$ permitiu a introdução de cateter vesical pediátrico 8 Fr, com inclinação de 20 graus lateral e profundidade de $2 \mathrm{~cm}$, com o objetivo de atingir a substância branca subcortical frontal direita. A insuflação do balão foi realizada com infusão de soro fisiológico $(\mathrm{NaCl} \quad 0,9 \%)$, controlada com bomba de infusão (Infusomat ${ }^{\circledR}$ compact, B Braun ${ }^{\circledR}$, Melsungen, Alemanha), programada sempre para infusão em 15 minutos. Em cada experimento este sistema de fluidos foi previamente testado antes da sua instalação definitiva. Foi ainda realizada uma pequena trepanação temporal anterior para possibilitar a realização de USNG com Doppler (Figura 16) (SonoSite - Micromax, FUJIFILM SonoSite, Washington DC, Estados Unidos). A solução salina hipertônica utilizada no experimento foi a solução de $\mathrm{NaCl}$ a $3 \%$ e o cálculo para infusão foi de $5,3 \mathrm{ml} / \mathrm{kg}$, mesmo ainda não havendo consenso na literatura sobre a melhor concentração a ser utilizada, conforme citado na revisão bibliográfica. A Figura 16 mostra os passos do experimento de maneira esquemática. 


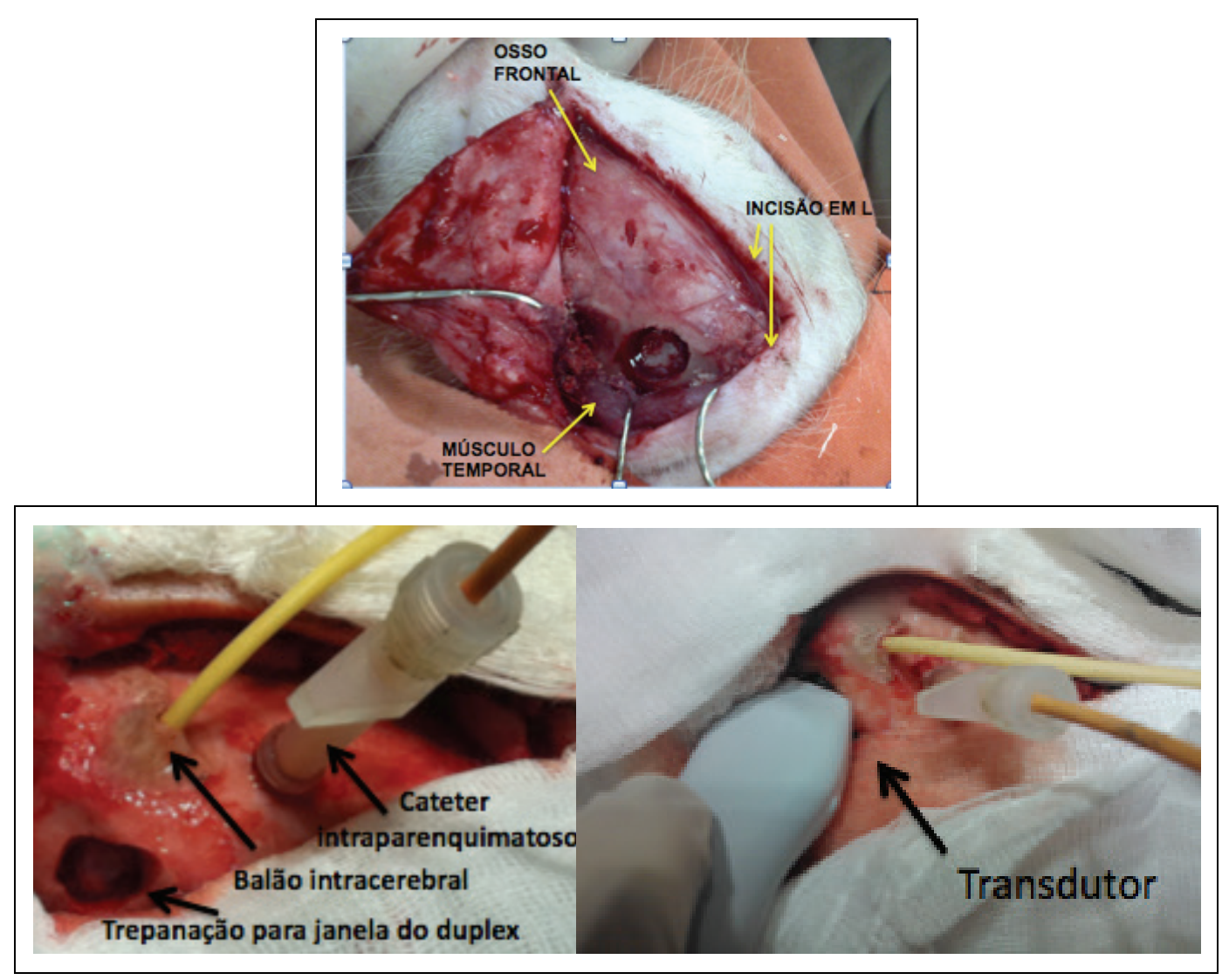

Figura 15- À esquerda imagem do experimento com destaque para o cateter monitor da PIC intraparenquimatosa, balão intracerebral e janela para o USNG com Doppler. À direita o transdutor do ultrassom sendo usado na trepanação temporal 


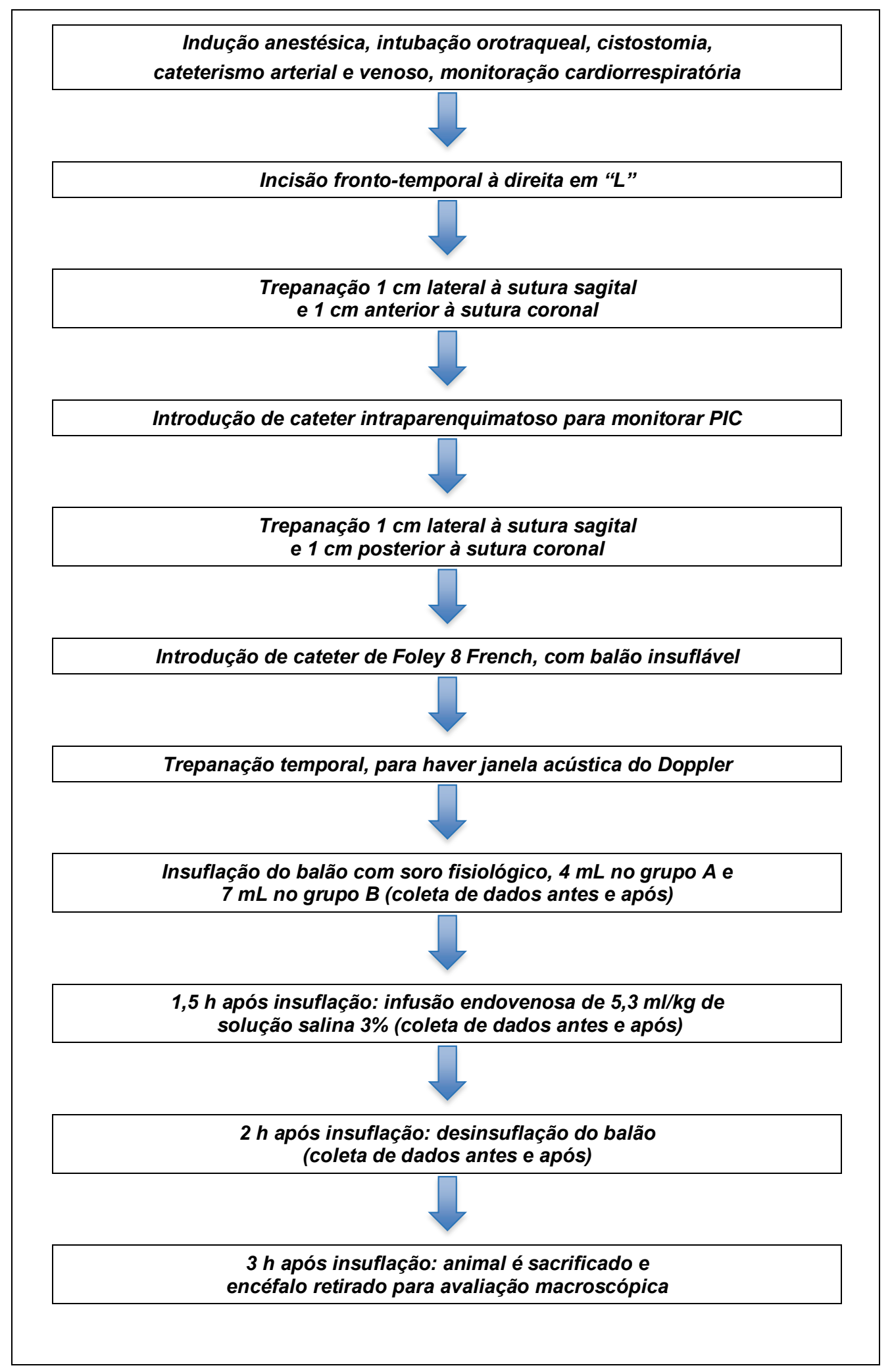

Figura 16 - Fluxograma do procedimento experimental 
Os animais foram divididos em dois grupos ( $A$ e $B$ ), sendo que em todos eles houve simulação de um HIE, porém cada grupo se diferenciou pelo volume do hematoma simulado, conforme descrito a seguir (Quadro 2). Em todos os grupos na primeira hora foram calibrados os parâmetros anestésicos da homeostase do animal. A PIC foi calibrada logo após instalação do sistema de monitoração.

Quadro 2 - Momentos do experimento nos diferentes grupos

\begin{tabular}{|c|c|c|c|c|c|}
\hline GRUPO & $0-1 \mathrm{~h}$ & $\begin{array}{c}1 \mathrm{~h} \\
\text { do início }\end{array}$ & $\begin{array}{c}2,5 \mathbf{h} \\
\text { do início }\end{array}$ & $\begin{array}{c}3 \mathbf{h} \\
\text { do início }\end{array}$ & $\begin{array}{c}\mathbf{4} \mathbf{h} \\
\text { do início }\end{array}$ \\
\hline A & Ajustes & $\begin{array}{c}\text { Balão } \\
4 \mathrm{~mL}\end{array}$ & SH 3\% & $\begin{array}{c}\text { Desinsuflação } \\
\text { do balão }\end{array}$ & FIM \\
B & Ajustes & $\begin{array}{c}\text { Balão } \\
7 \mathrm{~mL}\end{array}$ & SH 3\% & $\begin{array}{c}\text { Desinsuflação } \\
\text { do balão }\end{array}$ & FIM \\
\hline
\end{tabular}

No grupo A, após a primeira hora de monitoração e estabilização dos parâmetros cerebrais e hemodinâmicos, um HIE foi simulado com infusão de $4 \mathrm{~mL}$ de SF no balão já implantado na substância branca frontal, e logo após foram coletados os dados multiparamétricos, que incluem a PIC e a avaliação pela USNG com Doppler craniano. Este hematoma equivale a uma expansão de aproximadamente $80 \mathrm{ml}$ em um humano adulto. Essa equivalência deve-se à proporção do peso do cérebro do animal de 2 meses e $18 \mathrm{~kg}$ (média de $75 \mathrm{~g}$ ) em relação ao peso do cérebro do adulto normal (1500 g), com uma relação de 5\% (Andrade et al., 2013). Uma hora e 30 minutos após o início da insuflação do balão, foi realizada infusão endovenosa de $\mathrm{SH}(5,3 \mathrm{~mL} / \mathrm{kg})$. Após mais 30 minutos foi realizada reversão da HIC: balão desinsuflado. Antes e após as intervenções os dados da PIC e 
avaliação pela USNG com Doppler craniano foram novamente coletados, além de todos os parâmetros clínicos e gasométricos monitorados.

No grupo B, após a primeira hora de monitoração e estabilização dos parâmetros cerebrais e hemodinâmicos, um HIE foi simulado com infusão de 7 mL de SF no balão já implantado na substância branca frontal, equivalente a um volume de aproximadamente $140 \mathrm{~mL}$ em um humano adulto, e logo após foram coletados os dados multiparamétricos, que incluem a PIC e a avaliação pelo USNG com Doppler craniano. A solução salina hipertônica foi infundida 1 hora e 30 minutos depois do início da insuflação do balão. Após mais 30 minutos foi realizada a reversão da HIC: balão desinsuflado. Antes e após as intervenções, os dados da PIC e avaliação pelo USNG com Doppler craniano foram novamente coletados, além de todos os parâmetros clínicos e gasométricos monitorados.

Durante o experimento foi realizada uma monitoração neurológica através de parâmetros clínicos (pupilas), PAM invasiva, cateter de pressão intracraniana parenquimantosa; e avaliação não invasiva pelo USNG com Doppler craniano (VS, VD, VM e IP). Estes parâmetros foram obtidos antes e após todas as intervenções realizadas nos animais.

Ao final de cada experimento, os animais foram sacrificados através de uma dose intravenosa de propofol $(20 \mathrm{mg} / \mathrm{kg})$ e de fentanil $(10 \mathrm{mg} / \mathrm{kg})$, seguido de $40 \mathrm{~mL}$ de solução de cloreto de potássio a $19,1 \%$. O cérebro foi então removido e seccionado para avaliação macroscópica, de forma a excluir a possibilidade de hematomas cerebrais (Figura 17). Após o sacrifício, os animais foram colocados em sacos plásticos de biotério, com 
rótulos que identificavam claramente a origem, conteúdo e o pesquisador responsável. Eles foram, em seguida, transportados e incinerados, conforme protocolo rotineiro do LIM 26.

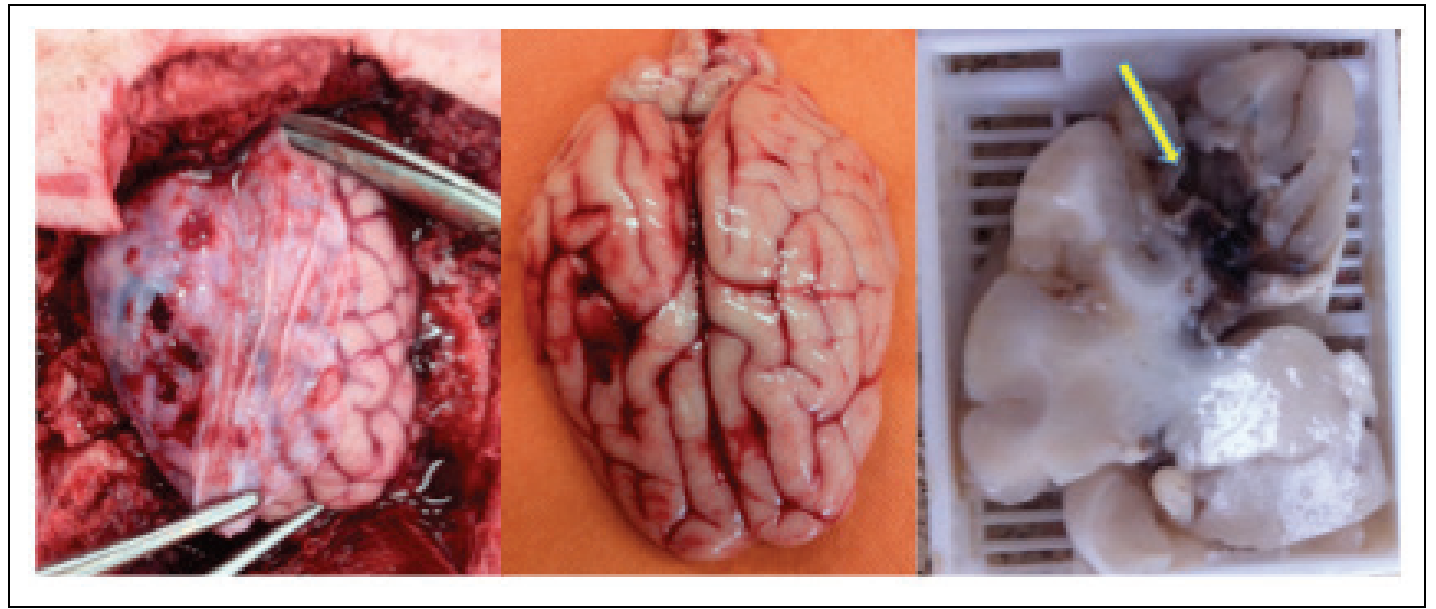

Figura 17 - Ressecção do encéfalo logo após sacrifício do animal (imagem a esquerda); visão superior do encéfalo ressecado, com morfologia normal dos giros corticais (imagem central); corte coronal do cérebro fixado com formol, evidenciando cavidade formada pelo balão (seta na imagem a direita)

\subsection{Instrumento de Coleta de Dados}

O instrumento de coleta de dados foi composto pelos seguintes itens que representam os diferentes momentos do estudo: basal, pós-insuflação, pré-salina, pós salina, pré-desinsuflação e pós-desinsuflação. Cada um destes itens foi prenchido para todos os animais, dividos nos grupos A e B.

Todos os dados referentes a estes momentos foram coletados para cada variável a ser estudada (VS, VD, VM e IP; PIC intraparenquimatosa). Também foram coletados os parâmetros da monitoração sistêmica (pressões arteriais sistólica, diastólica e média; saturação de oxigênio, 
temperatura retal, volume do balão medido pela ultrassonografia, dados da gasometria arterial), além dos pesos dos animais e do gênero dos mesmos (Anexo B).

\subsection{Análise Estatística}

A análise estatística foi apresentada por meio de médias e desvios padrão, além de gráficos de perfis individuais e médios. Para cada uma das medidas, inclusive a PIC, ajustaram-se modelos de regressão lineares mistos, considerando efeito aleatório no intercepto (do suíno) e distribuição normal para os efeitos aleatórios (Magalhães e Lima, 2000; Pinheiro e Bates, 2000). A análise gráfica indicou que o efeito aleatório do intercepto parecia diferente entre os grupos também, isto é, parecia que a variabilidade do efeito do experimento nos suínos do grupo B em geral era superior ao grupo A. Portanto, além de considerarmos um efeito aleatório do indivíduo, foi considerado que o efeito era distinto entre os grupos.

As análises foram realizadas utilizando o software $R 3.4 .0$ (R Core Team, 2017, Viena, Áustria). Os resultados foram interpretados utilizando um nível de significância de 5\%. 
5 Resultados 
Foram estudados 20 suínos híbridos das raças Landrace, Duroc e Pietrain, sendo 10 no grupo A (seis fêmeas e quatro machos) e 10 no grupo $B$ (seis fêmeas e quatro machos), com 2 meses de idade e peso médio de $18,46 \pm 1,12 \mathrm{~kg}$, sem variação entre os grupos. $\mathrm{O}$ animal número 20 do grupo B teve hipotensão arterial severa, irreversível e foi a óbito antes do término do experimento, sendo excluído da análise. Os animais foram submetidos a anestesia geral, devidamente assistidos com monitoração ventilatória e hemodinâmica, conforme citado nos métodos. A Tabela 1 mostra, para cada momento do experimento, os valores PAS, pressão arterial diastólica (PAD) e PAM. Houve estabilidade hemodinâmica dos animais, exceto animais 15 e 16 do grupo B, que apresentaram baixas medidas da PA em determinados momentos do estudo, o que influenciou nas medidas principalmente do IP, discutidas à frente. 
Tabela 1 - Distribuição dos suínos de acordo com os valores individuais de PAS, PAD e PAM (em $\mathrm{mmHg}$ ) mensuradas em cada momento do estudo. São Paulo, 2013

\begin{tabular}{|c|c|c|c|c|c|c|c|}
\hline \multicolumn{8}{|c|}{$\begin{array}{c}\text { PAS } \times \text { PAD } \\
\text { PAM }\end{array}$} \\
\hline \multirow{2}{*}{ Suíno } & \multirow{2}{*}{ Grupo } & \multirow{2}{*}{ Basal } & \multirow{2}{*}{$\begin{array}{c}\text { Insuflação } \\
\text { Pós }\end{array}$} & \multicolumn{2}{|c|}{ SH } & \multicolumn{2}{|c|}{ Desinfuflação } \\
\hline & & & & Pré & Pós & Pré & Pós \\
\hline 1 & A & $\begin{array}{c}125 \times 63 \\
83,67\end{array}$ & $\begin{array}{c}123 \times 62 \\
82,33\end{array}$ & $\begin{array}{c}108 \times 46 \\
66,66\end{array}$ & $\begin{array}{c}120 \times 57 \\
78\end{array}$ & $\begin{array}{c}133 \times 67 \\
89\end{array}$ & $\begin{array}{c}125 \times 56 \\
79\end{array}$ \\
\hline 2 & $A$ & $\begin{array}{c}128 \times 69 \\
88,6\end{array}$ & $\begin{array}{c}117 \times 60 \\
79\end{array}$ & $\begin{array}{c}107 \times 50 \\
69\end{array}$ & $\begin{array}{c}113 \times 61 \\
78,33\end{array}$ & $\begin{array}{c}113 \times 55 \\
74,33\end{array}$ & $\begin{array}{c}127 \times 64 \\
85\end{array}$ \\
\hline 3 & $A$ & $\begin{array}{c}131 \times 65 \\
87\end{array}$ & $\begin{array}{c}130 \times 65 \\
86,66\end{array}$ & $\begin{array}{c}136 \times 67 \\
90\end{array}$ & $\begin{array}{c}109 \times 81 \\
90,33\end{array}$ & $\begin{array}{c}143 \times 66 \\
91,66\end{array}$ & $\begin{array}{c}140 \times 65 \\
90\end{array}$ \\
\hline 4 & $A$ & $\begin{array}{c}114 \times 65 \\
81,33\end{array}$ & $\begin{array}{c}114 \times 65 \\
81,33\end{array}$ & $\begin{array}{c}117 \times 64 \\
81,66\end{array}$ & $\begin{array}{c}80 \times 62 \\
68\end{array}$ & $\begin{array}{c}112 \times 61 \\
78\end{array}$ & $\begin{array}{c}114 \times 64 \\
80,66\end{array}$ \\
\hline 5 & $A$ & $\begin{array}{c}118 \times 56 \\
76,67\end{array}$ & $\begin{array}{c}119 \times 60 \\
79,67\end{array}$ & $\begin{array}{c}126 \times 61 \\
82,66\end{array}$ & $\begin{array}{c}123 \times 56 \\
78,33\end{array}$ & $\begin{array}{c}125 \times 59 \\
81\end{array}$ & $\begin{array}{c}131 \times 67 \\
88,33\end{array}$ \\
\hline 6 & $A$ & $\begin{array}{c}103 \times 56 \\
71,66\end{array}$ & $\begin{array}{c}101 \times 50 \\
67\end{array}$ & $\begin{array}{c}112 \times 56 \\
74,66\end{array}$ & $\begin{array}{c}102 \times 69 \\
80\end{array}$ & $\begin{array}{c}105 \times 69 \\
81\end{array}$ & $\begin{array}{c}121 \times 63 \\
82,33\end{array}$ \\
\hline 7 & $A$ & $\begin{array}{c}118 \times 51 \\
73,33\end{array}$ & $\begin{array}{l}93 \times 40 \\
57,66\end{array}$ & $\begin{array}{c}115 \times 66 \\
82,33\end{array}$ & $\begin{array}{c}120 \times 64 \\
82,66\end{array}$ & $\begin{array}{c}123 \times 72 \\
89\end{array}$ & $\begin{array}{c}130 \times 68 \\
88,66\end{array}$ \\
\hline 8 & $A$ & $\begin{array}{c}117 \times 71 \\
86,33\end{array}$ & $\begin{array}{c}116 \times 69 \\
84,66\end{array}$ & $\begin{array}{l}80 \times 45 \\
56,66\end{array}$ & $\begin{array}{l}98 \times 51 \\
66,66\end{array}$ & $\begin{array}{c}101 \times 54 \\
69,66\end{array}$ & $\begin{array}{c}100 \times 56 \\
70,66\end{array}$ \\
\hline 9 & $A$ & $\begin{array}{c}120 \times 71 \\
87,33\end{array}$ & $\begin{array}{c}120 \times 70 \\
86,66\end{array}$ & $\begin{array}{l}134 \times 99 \\
110,67\end{array}$ & $\begin{array}{c}161 \times 120 \\
133,67\end{array}$ & $\begin{array}{c}152 \times 109 \\
123,33\end{array}$ & $\begin{array}{c}158 \times 114 \\
128,67\end{array}$ \\
\hline 10 & $A$ & $\begin{array}{l}99 \times 53 \\
68,33\end{array}$ & $\begin{array}{l}98 \times 58 \\
71,33\end{array}$ & $\begin{array}{l}98 \times 51 \\
66,67\end{array}$ & $\begin{array}{c}103 \times 51 \\
68,33\end{array}$ & $\begin{array}{c}102 \times 55 \\
70,66\end{array}$ & $\begin{array}{c}103 \times 57 \\
72,33\end{array}$ \\
\hline 11 & $B$ & $\begin{array}{c}113 \times 56 \\
75\end{array}$ & $\begin{array}{c}127 \times 64 \\
85\end{array}$ & $\begin{array}{c}148 \times 85 \\
106\end{array}$ & $\begin{array}{l}161 \times 84 \\
109,67\end{array}$ & $\begin{array}{c}134 \times 58 \\
83,33\end{array}$ & $\begin{array}{c}106 \times 50 \\
68,67\end{array}$ \\
\hline 12 & $B$ & $\begin{array}{c}155 \times 92 \\
113\end{array}$ & $\begin{array}{c}148 \times 85 \\
106\end{array}$ & $\begin{array}{l}151 \times 84 \\
106,33\end{array}$ & $\begin{array}{l}148 \times 87 \\
107,33\end{array}$ & $\begin{array}{c}140 \times 78 \\
98,67\end{array}$ & $\begin{array}{c}141 \times 78 \\
99\end{array}$ \\
\hline 13 & $B$ & $\begin{array}{c}100 \times 54 \\
69,33\end{array}$ & $\begin{array}{c}106 \times 58 \\
74\end{array}$ & $\begin{array}{c}107 \times 56 \\
73\end{array}$ & $\begin{array}{c}103 \times 61 \\
75\end{array}$ & $\begin{array}{c}117 \times 64 \\
81,67\end{array}$ & $\begin{array}{c}109 \times 58 \\
75\end{array}$ \\
\hline 14 & $B$ & $\begin{array}{c}117 \times 77 \\
90,33\end{array}$ & $\begin{array}{c}138 \times 95 \\
109,33\end{array}$ & $\begin{array}{c}170 \times 118 \\
135,33\end{array}$ & $\begin{array}{c}174 \times 124 \\
140,67\end{array}$ & $\begin{array}{c}142 \times 108 \\
119,33\end{array}$ & $\begin{array}{c}166 \times 123 \\
137,33\end{array}$ \\
\hline 15 & $B$ & $\begin{array}{c}108 \times 57 \\
74\end{array}$ & $\begin{array}{c}124 \times 106 \\
112\end{array}$ & $\begin{array}{l}74 \times 52 \\
59,33\end{array}$ & $\begin{array}{l}74 \times 51 \\
58,67\end{array}$ & $\begin{array}{l}80 \times 55 \\
63,33\end{array}$ & $\begin{array}{l}75 \times 35 \\
48,33\end{array}$ \\
\hline 16 & $B$ & $\begin{array}{l}99 \times 62 \\
74,33\end{array}$ & $\begin{array}{c}115 \times 68 \\
83,67\end{array}$ & $\begin{array}{l}56 \times 30 \\
38,67\end{array}$ & $\begin{array}{l}51 \times 25 \\
33,67\end{array}$ & $\begin{array}{l}41 \times 21 \\
27,67\end{array}$ & $\begin{array}{l}63 \times 31 \\
41,67\end{array}$ \\
\hline 17 & $B$ & $\begin{array}{c}110 \times 52 \\
71,33\end{array}$ & $\begin{array}{c}102 \times 58 \\
72,67\end{array}$ & $\begin{array}{c}109 \times 58 \\
75\end{array}$ & $\begin{array}{c}105 \times 63 \\
77\end{array}$ & $\begin{array}{c}119 \times 62 \\
81\end{array}$ & $\begin{array}{c}108 \times 55 \\
72,66\end{array}$ \\
\hline 18 & B & $\begin{array}{c}92 \times 59 \\
70\end{array}$ & $\begin{array}{c}131 \times 61 \\
84,33\end{array}$ & $\begin{array}{c}149 \times 110 \\
123\end{array}$ & $\begin{array}{c}170 \times 120 \\
136,67\end{array}$ & $\begin{array}{c}155 \times 104 \\
121\end{array}$ & $\begin{array}{c}159 \times 114 \\
129\end{array}$ \\
\hline 19 & B & $\begin{array}{l}109 \times 96 \\
100,33\end{array}$ & $\begin{array}{c}123 \times 82 \\
95,67\end{array}$ & $\begin{array}{c}124 \times 91 \\
102\end{array}$ & $\begin{array}{l}128 \times 94 \\
105,33\end{array}$ & $\begin{array}{l}132 \times 95 \\
107,33\end{array}$ & $\begin{array}{c}140 \times 100 \\
113,33\end{array}$ \\
\hline
\end{tabular}

PAD: Pressão arterial diastólica; PAM: Pressão arterial média; PAS: Pressão arterial sistólica; SH: Solução salina hipertônica 
A Tabela 2 descreve as médias e desvios padrão observados para as medidas da PIC, coletadas da monitoração intraparenquimatosa, e das variáveis VS, VD, VM e IP, coletadas através do USNG com Doppler craniano conforme descrito nos métodos. Estes valores são apresentados apenas de forma descritiva. Observa-se moderada elevação da PIC após insuflação do balão no grupo A e importante elevação da mesma no grupo B. Nos dois grupos há estabilidade dos valores da PIC entre os momento pré-SH e pré-desinsuflação, ou seja, não houve alteração da PIC após infusão da SH. 
Tabela 2 - Distribuição dos valores médios e desvios padrão dos parâmetros mensurados por Grupo e por Momento de avaliação. São Paulo, 2013

\begin{tabular}{|c|c|c|c|c|}
\hline Parâmetro & Momento & $\begin{array}{c}\text { Grupo A } \\
(n=10)\end{array}$ & $\begin{array}{c}\text { Grupo B } \\
(n=9)\end{array}$ & Total $(n=19)$ \\
\hline \multirow{6}{*}{$\begin{array}{l}\text { PIC } \\
(\mathrm{mmHG})\end{array}$} & Basal & $7,26 \pm 5,87$ & $7,28 \pm 4,2$ & $7,27 \pm 5,01$ \\
\hline & Pós-insuflação & $23,12 \pm 10,86$ & $50,81 \pm 27,21$ & $36,24 \pm 24,28$ \\
\hline & Pré-SH & $16,69 \pm 6,6$ & $31,96 \pm 15,31$ & $23,92 \pm 13,69$ \\
\hline & Pós-SH & $15,17 \pm 6,26$ & $29,21 \pm 16,42$ & $21,82 \pm 13,83$ \\
\hline & Pré-desinsuflação & $16,65 \pm 7,96$ & $31,01 \pm 19,47$ & $23,45 \pm 15,95$ \\
\hline & Pós- desinsuflação & $7,16 \pm 6,1$ & $4,69 \pm 4,96$ & $5,99 \pm 5,58$ \\
\hline \multirow{6}{*}{$\begin{array}{l}\text { VS } \\
(\mathrm{cm} / \mathrm{s})\end{array}$} & Basal & $75,32 \pm 48,05$ & $67,93 \pm 29,45$ & $71,82 \pm 39,43$ \\
\hline & Pós-insuflação & $80,32 \pm 53,33$ & $59,42 \pm 27,84$ & $70,42 \pm 43,37$ \\
\hline & Pré-SH & $89,88 \pm 46,06$ & $57,81 \pm 26,04$ & $74,69 \pm 40,41$ \\
\hline & Pós-SH & $89,17 \pm 55,09$ & $79,91 \pm 39,05$ & $84,78 \pm 47,09$ \\
\hline & Pré- desinsuflação & $89,76 \pm 41,75$ & $71,31 \pm 27,27$ & $81,02 \pm 35,94$ \\
\hline & Pós- desinsuflação & $94,99 \pm 49,08$ & $93,76 \pm 35,36$ & $94,41 \pm 41,96$ \\
\hline \multirow{6}{*}{$\begin{array}{l}\text { VD } \\
(\mathrm{cm} / \mathrm{s})\end{array}$} & Basal & $39,62 \pm 24,53$ & $33,64 \pm 12,27$ & $36,79 \pm 19,42$ \\
\hline & Pós-insuflação & $30,72 \pm 16,79$ & $17,69 \pm 9,17$ & $24,55 \pm 14,93$ \\
\hline & Pré-SH & $42,23 \pm 22,31$ & $21,75 \pm 23,08$ & $32,53 \pm 24,42$ \\
\hline & Pós-SH & $45,39 \pm 24,76$ & $27,55 \pm 36,62$ & $36,94 \pm 31,41$ \\
\hline & Pré- desinsuflação & $46,01 \pm 20,61$ & $29,58 \pm 24,17$ & $38,23 \pm 23,3$ \\
\hline & Pós- desinsuflação & $53,14 \pm 27,27$ & $48,02 \pm 28,17$ & $50,71 \pm 27,04$ \\
\hline \multirow{6}{*}{$\begin{array}{l}\text { VM } \\
(\mathrm{cm} / \mathrm{s})\end{array}$} & Basal & $51,52 \pm 32,21$ & $45,07 \pm 17,72$ & $48,47 \pm 25,87$ \\
\hline & Pós-insuflação & $47,25 \pm 27,97$ & $31,6 \pm 14,07$ & $39,84 \pm 23,32$ \\
\hline & Pré-SH & $58,11 \pm 28,13$ & $33,77 \pm 22,69$ & $46,58 \pm 27,94$ \\
\hline & Pós-SH & $59,98 \pm 33,89$ & $45 \pm 32,02$ & $52,89 \pm 33$ \\
\hline & Pré- desinsuflação & $60,59 \pm 26,82$ & $40,45 \pm 23,01$ & $51,05 \pm 26,49$ \\
\hline & Pós desinsuflação & $67,09 \pm 33,65$ & $63,26 \pm 29,07$ & $65,27 \pm 30,75$ \\
\hline \multirow{6}{*}{ IP } & Basal & $0,69 \pm 0,15$ & $0,74 \pm 0,19$ & $0,71 \pm 0,17$ \\
\hline & Pós-insuflação & $1,02 \pm 0,31$ & $1,3 \pm 0,39$ & $1,15 \pm 0,37$ \\
\hline & Pré-SH & $0,82 \pm 0,3$ & $2,54 \pm 3,68$ & $1,63 \pm 2,62$ \\
\hline & Pós-SH & $0,71 \pm 0,22$ & $6,59 \pm 15,83$ & $3,5 \pm 10,98$ \\
\hline & Pré- desinsuflação & $0,73 \pm 0,2$ & $11,73 \pm 31,31$ & $5,94 \pm 21,62$ \\
\hline & Pós- desinsuflação & $0,63 \pm 0,19$ & $0,87 \pm 0,65$ & $0,75 \pm 0,47$ \\
\hline
\end{tabular}

IP: Índice de pulsatilidade; PIC: Pressão intracraniana; SH: Solução salina hipertônica; VD: Velocidades do fluxo sanguíneo cerebral diastólica; VM: Velocidade média do fluxo sanguíneo cerebral; VS: Velocidades do fluxo sanguíneo cerebral sistólica 
Os Gráficos 1 e 2 apresentam a distribuição do perfil individual de cada suíno e do perfil médio por grupo para a PIC. No Gráfico 2 é possível notar que os desvios observados nas medidas do grupo B (insuflação de 7 $\mathrm{mL}$ ) são superiores aos do grupo A (insuflação de $4 \mathrm{~mL}$ ). Essa variabilidade foi considerada no modelo misto com efeito aleatório do intercepto ajustado para essa medida.

\section{Gráfico 1 - Distribuição do perfil individual de PIC para cada suíno}

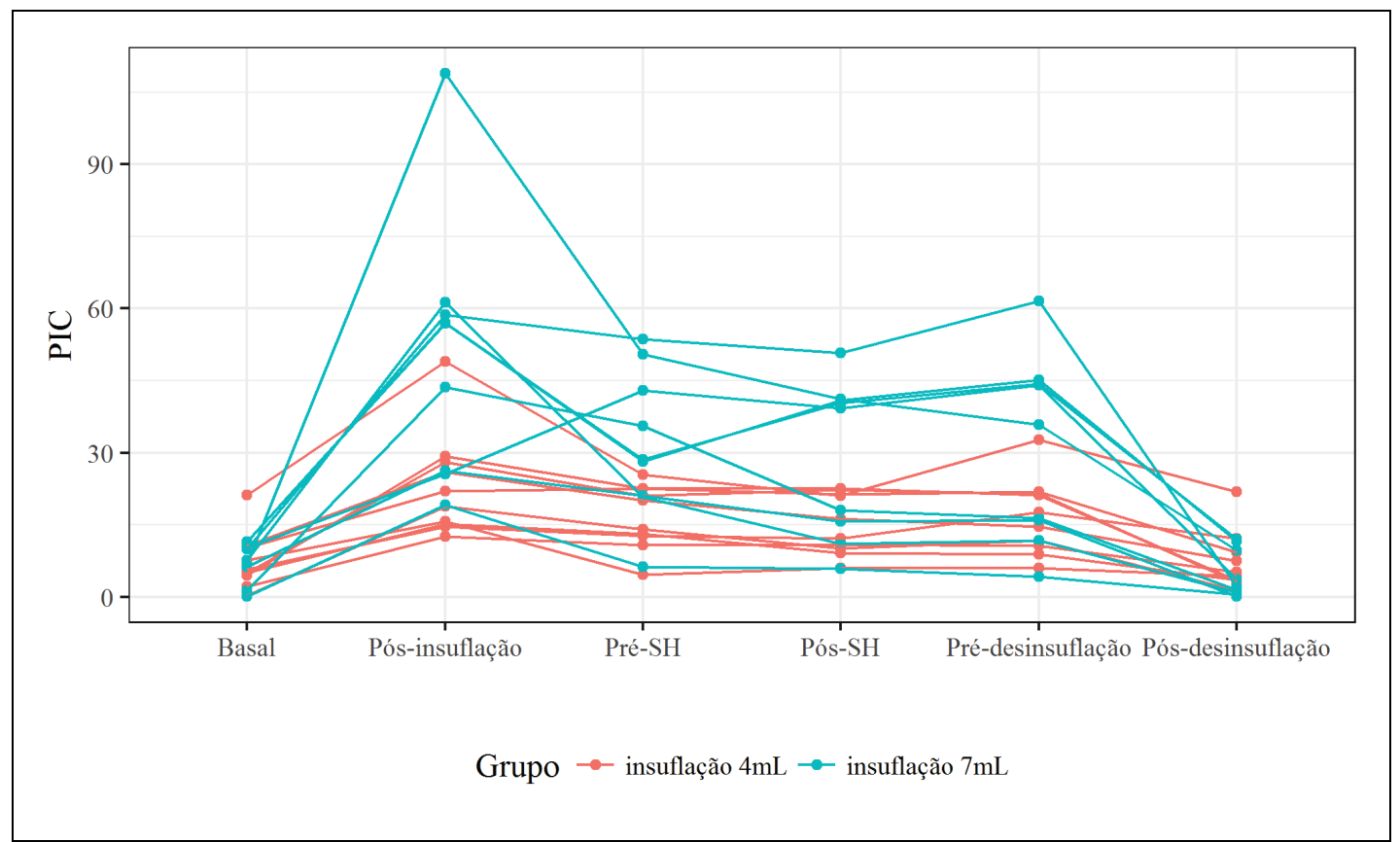

PIC: Pressão intracraniana; SH: Solução salina hipertônica 


\section{Gráfico 2 - Distribuição do perfil médio de PIC por Grupo}

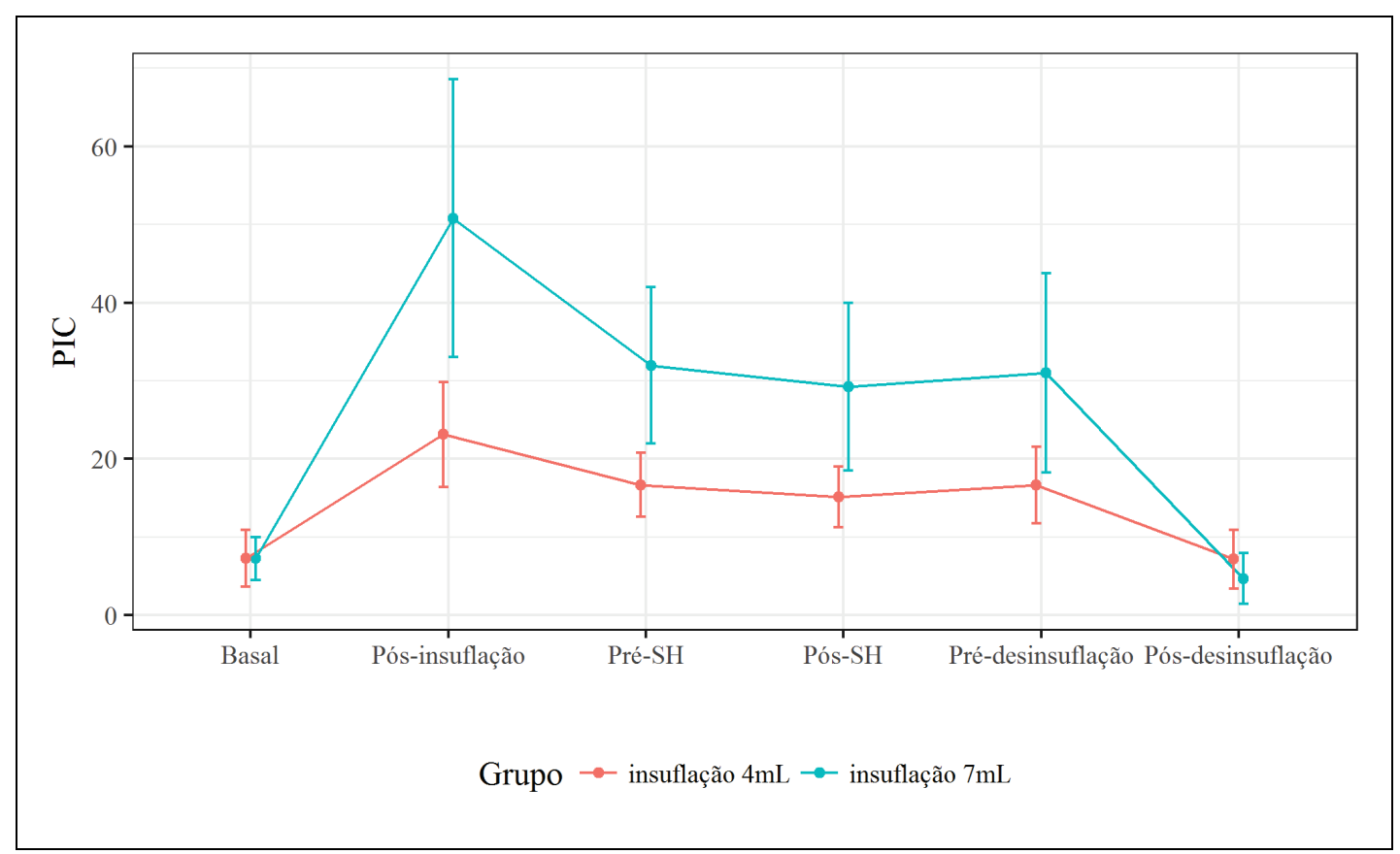

PIC: Pressão intracraniana; SH: Solução salina hipertônica

A partir do modelo ajustado, construiu-se a Tabela 3, com as comparações entre os grupos para cada momento e das diferenças observadas entre os grupos para cada momento avaliado (Basal, pósinsuflação, pré-SH, Pós-SH, Pré-desinsuflação e pós-desinsuflação). Notase que a PIC é muito similar entre os grupos no momento basal e no pósdesinsuflação, o que mostra que não havia diferença estatisticamente significante da PIC nos dois grupos antes e após o término do experimento. Os valores da PIC no grupo B são superiores nos momentos logo após a insuflação, Pré-SH, Pós-SH e Pré-desinsuflação. 
Tabela 3 - Comparações múltiplas da diferença da PIC entre os grupos B e A nos diferentes momentos do experimento. São Paulo, 2013

\begin{tabular}{|c|c|c|}
\hline Comparações múltiplas & IC $(95 \%)$ & $P$ \\
\hline 7 mL - 4 mL (Basal) & $0,02[-11,33 ; 11,37]$ & 0,998 \\
\hline 7 mL - 4 mL (Pós-insuflação) & $27,69[16,34 ; 39,04]$ & $<0,001$ \\
\hline 7 mL - 4 mL (Pré-SH) & $15,27[3,91 ; 26,62]$ & 0,008 \\
\hline 7 mL - 4 mL (Pós-SH) & $14,04[2,69 ; 25,39]$ & 0,015 \\
\hline 7 mL - 4 mL (Pré-desinsuflação) & $14,36[3,01 ; 25,71]$ & 0,013 \\
\hline 7 mL - 4 mL (Pós-desinsuflação) & $-2,47[-13,82 ; 8,88]$ & 0,670 \\
\hline
\end{tabular}

Os parâmetros VS, VD e VM são apresentados nos Gráficos de 3 a 8 e nas Tabelas de 4 a 6 , ajustadas pelo mesmo método empregado para PIC. Nota-se que, para essas medidas, não é possível assumir que exista diferença entre os grupos. Embora as médias sejam consistentemente superiores para o grupo A (insuflação $4 \mathrm{~mL}$ ), não há evidência suficiente que negue a hipótese de igualdade entre os grupos ao nível de significância de $5 \%$. Isto mostra que, estatisticamente, não houve diferença das variáveis VS, VD, e VM entre os grupos $A$ e $B$, em nenhum momento do experimento. 


\section{Gráfico 3 - Distribuição do perfil individual de VS para cada suíno}

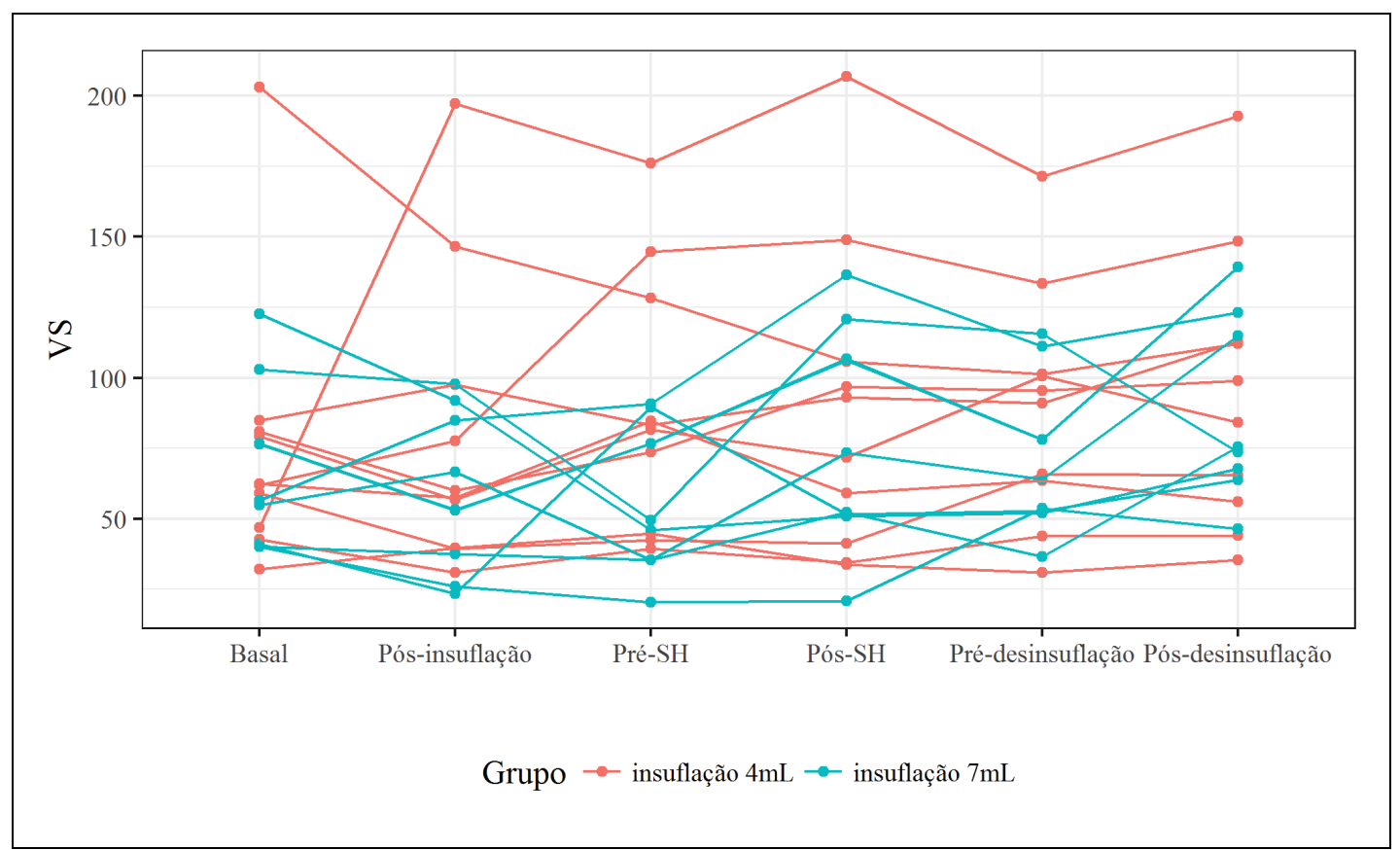

SH: Solução salina hipertônica; VS: Velocidades do fluxo sanguíneo cerebral sistólica

\section{Gráfico 4 - Distribuição do perfil médio de VS por Grupo}

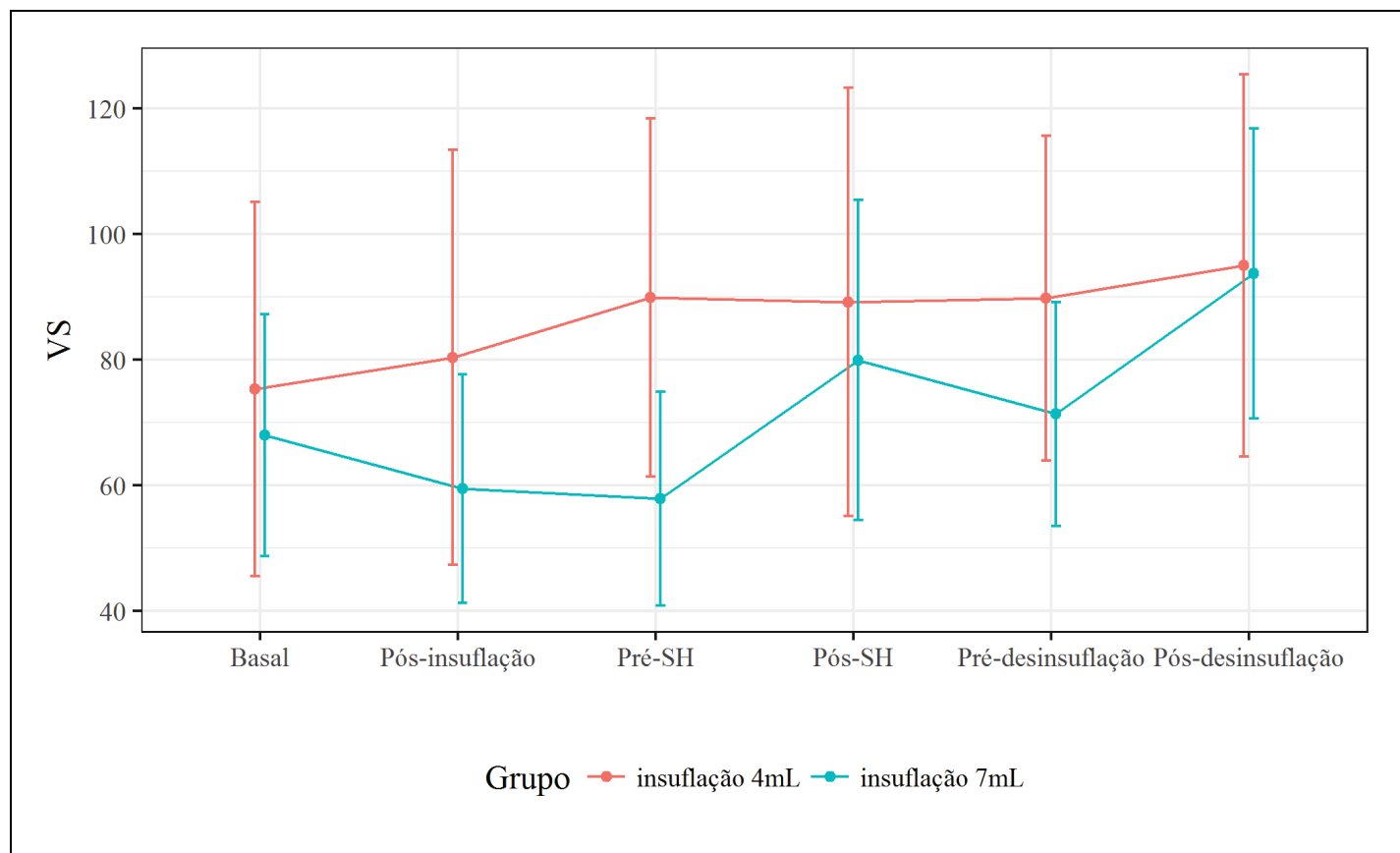

SH: Solução salina hipertônica; VS: Velocidades do fluxo sanguíneo cerebral sistólica 
Tabela 4 - Comparações múltiplas da diferença de VS entre os grupos B e A nos diferentes momentos do experimento. São Paulo, 2013

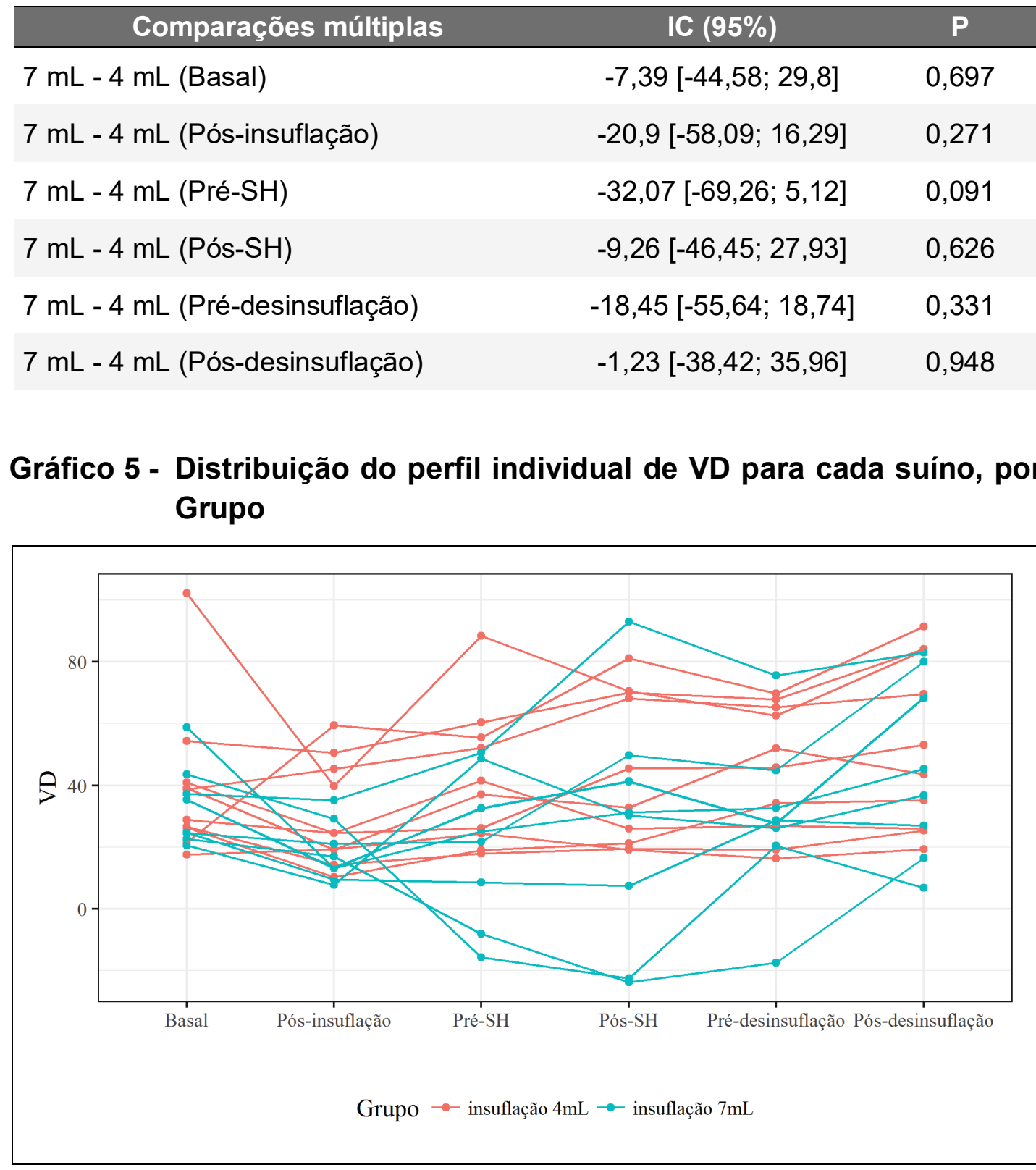

SH: Solução salina hipertônica; VD: Velocidades do fluxo sanguíneo cerebral diastólica 


\section{Gráfico 6 - Distribuição do perfil médio de VD por Grupo}

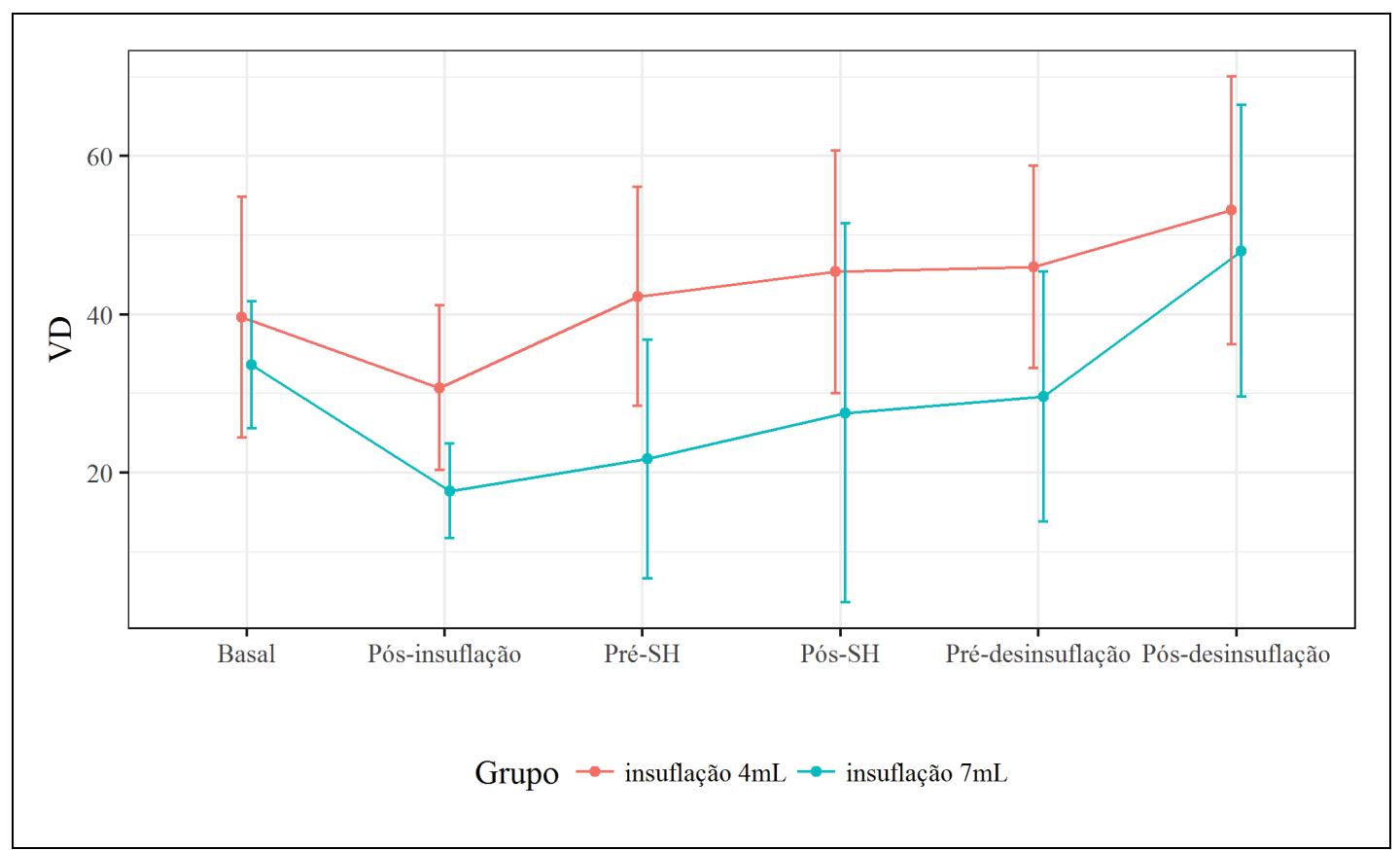

SH: Solução salina hipertônica; VD: Velocidades do fluxo sanguíneo cerebral diastólica

Tabela 5 - Comparações múltiplas da diferença de VD entre os grupos B e A nos diferentes momentos do experimento. São Paulo, 2013

\section{Comparações múltiplas}

$7 \mathrm{~mL}-4 \mathrm{~mL}$ (Basal)

$7 \mathrm{~mL}$ - $4 \mathrm{~mL}$ (Pós-insuflação)

$7 \mathrm{~mL}-4 \mathrm{~mL}$ (Pré-SH)

$7 \mathrm{~mL}-4 \mathrm{~mL}$ (Pós-SH)

$7 \mathrm{~mL}$ - $4 \mathrm{~mL}$ (Pré-desinsuflação)

$7 \mathrm{~mL}$ - 4 mL (Pós-desinsuflação)

\section{IC $(95 \%)$}

$-5,98[-27,38 ; 15,43]$

$-13,03[-34,44 ; 8,37]$

$-20,48[-41,89 ; 0,92] \quad 0,061$

$-17,84[-39,25 ; 3,56]$

0,102

$-16,43[-37,84 ; 4,97]$

$-5,12[-26,53 ; 16,28]$
0,132

\section{$\mathrm{P}$}

0,584

0,233

0,639 


\section{Gráfico 7 - Distribuição do perfil individual de VM para cada suíno, por Grupo}

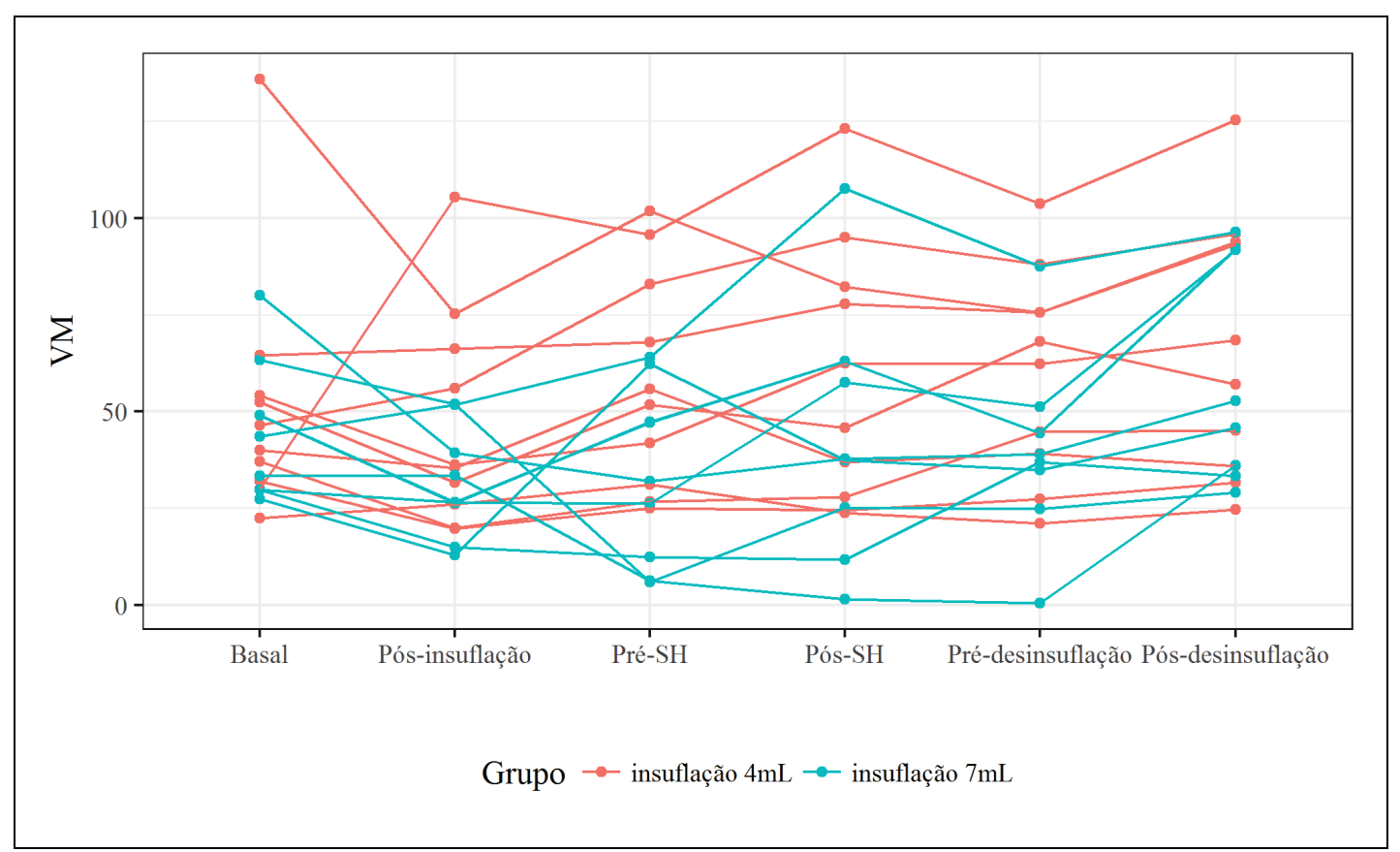

SH: Solução salina hipertônica; VM: Velocidade média do fluxo sanguíneo cerebral

\section{Gráfico 8 - Distribuição do perfil médio de VM por Grupo}

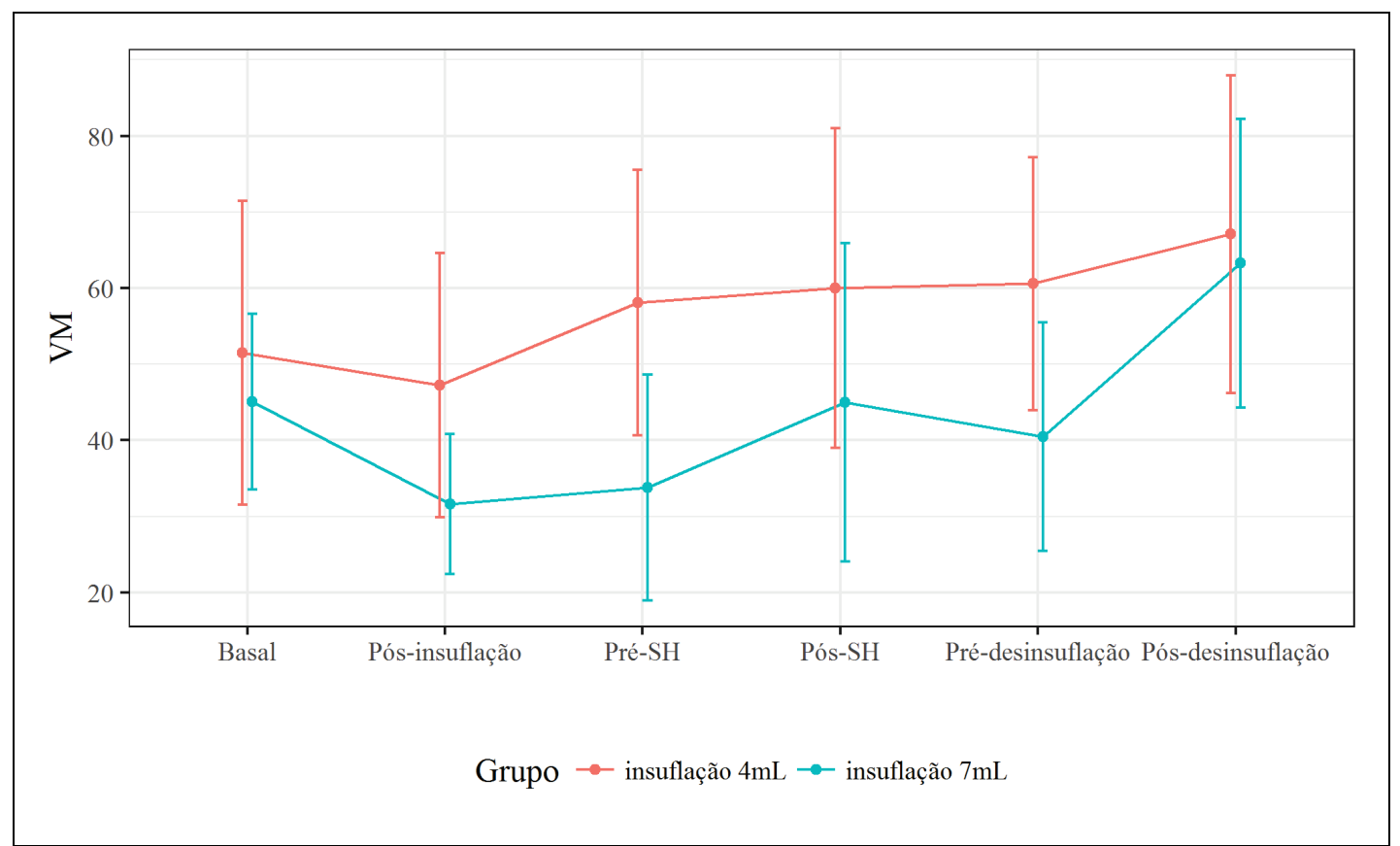

SH: Solução salina hipertônica; VM: Velocidade média do fluxo sanguíneo cerebral 
Tabela 6 - Comparações múltiplas da diferença de VM entre os grupos B e A nos diferentes momentos do experimento. São Paulo, 2013

\begin{tabular}{lcc}
\hline \multicolumn{1}{c}{ Comparações múltiplas } & IC (95\%) & P \\
\hline $7 \mathrm{~mL}$ - $4 \mathrm{~mL}$ (Basal) & $-6,45[-31,45 ; 18,56]$ & 0,613 \\
$7 \mathrm{~mL}$ - $4 \mathrm{~mL}$ (Pós-insuflação) & $-15,65[-40,66 ; 9,35]$ & 0,22 \\
$7 \mathrm{~mL}$ - $4 \mathrm{~mL}$ (Pré-SH) & $-24,34[-49,35 ; 0,67]$ & 0,056 \\
$7 \mathrm{~mL}$ - $4 \mathrm{~mL}$ (Pós-SH) & $-14,98[-39,99 ; 10,02]$ & 0,24 \\
$7 \mathrm{~mL}$ - $4 \mathrm{~mL}$ (Pré-desinsuflação) & $-20,14[-45,15 ; 4,87]$ & 0,114 \\
$7 \mathrm{~mL}$ - 4 mL (Pós-desinsuflação) & $-3,82[-28,83 ; 21,18]$ & 0,764
\end{tabular}

Os Gráficos de 9 a 11 e a Tabela 7 apresentam os resultados para a medida IP. O gráfico 9 está em escala logarítmica. Nota-se que dois suínos apresentam valores a partir do instante Pré-SH muito superiores aos demais. Esses valores fogem da distribuição padrão dos outros indivíduos e dificulta a modelagem. Esses dois animais apresentaram, durante o experimento, fluxo sanguíneo cerebral oscilatório não positivo, devido à grande elevação da PIC e queda da pressão arterial nesses momentos, o que influenciou os valores de IP. Portanto, inicialmente, considerando o log da variável para reduzir o efeito de alavanca dos dois valores de IP muito acima da média (outliers) fez-se o Gráfico 9. 


\section{Gráfico 9 - Distribuição do perfil individual de IP (em escala logarítmica) dos suínos, por grupo}

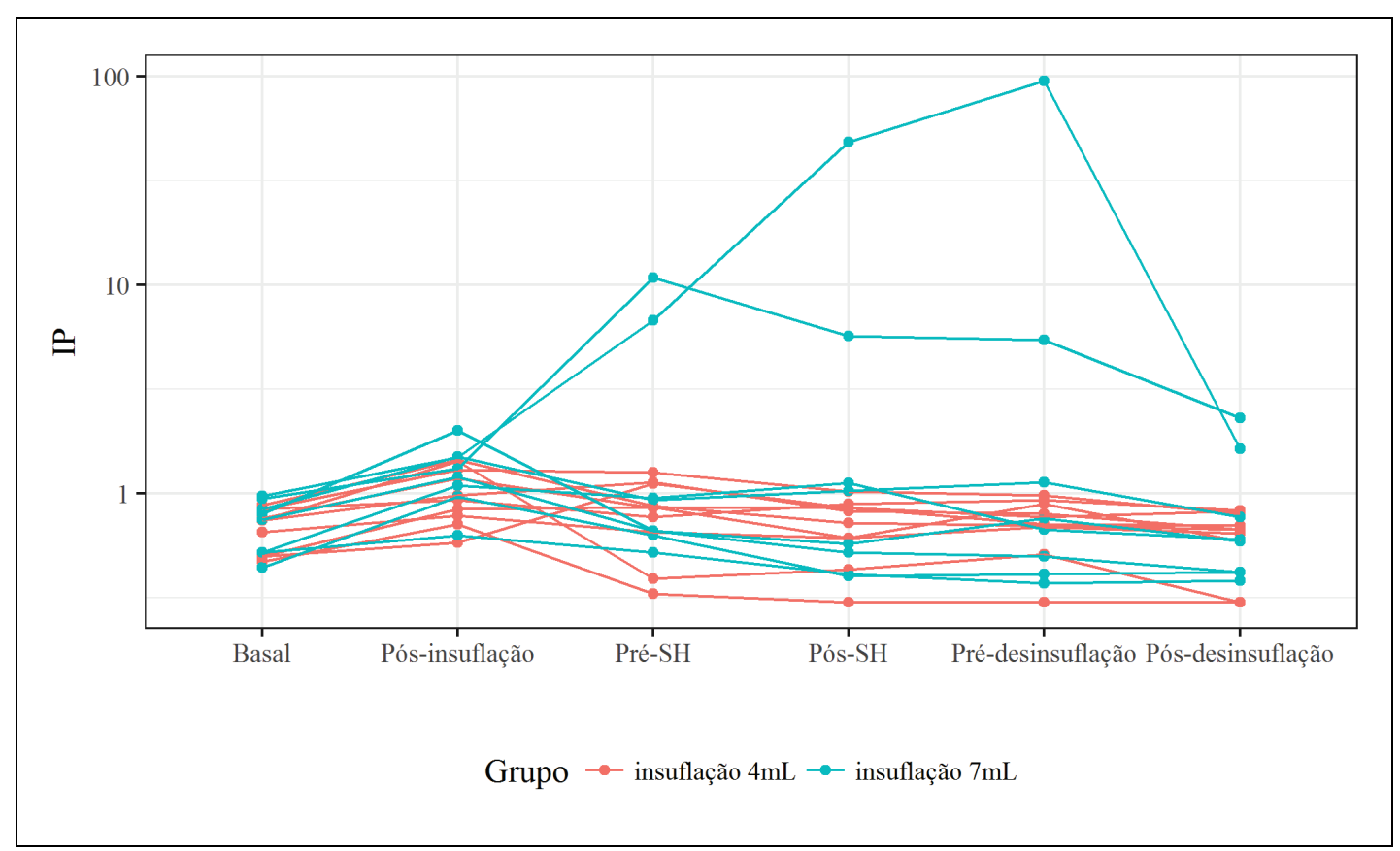

IP: Índice de pulsatilidade; SH: Solução salina hipertônica

Optou-se por excluir, para o estudo do IP, os dois animais fora do padrão. Retirando os indivíduos 15 e 16, a distribuição do perfil de cada animal é mais parecida e o modelo com o log não faz mais sentido. Ao retirar esses dois casos o modelo indica que o IP é superior no Grupo B apenas logo após a insuflação e é similar nos outros momentos, mesmo a PIC sendo maior no grupo B (Tabela 7). 
Gráfico 10 -Distribuição do perfil individual de IP dos suínos, por grupo (excluindo-se os suínos 15 e 16)

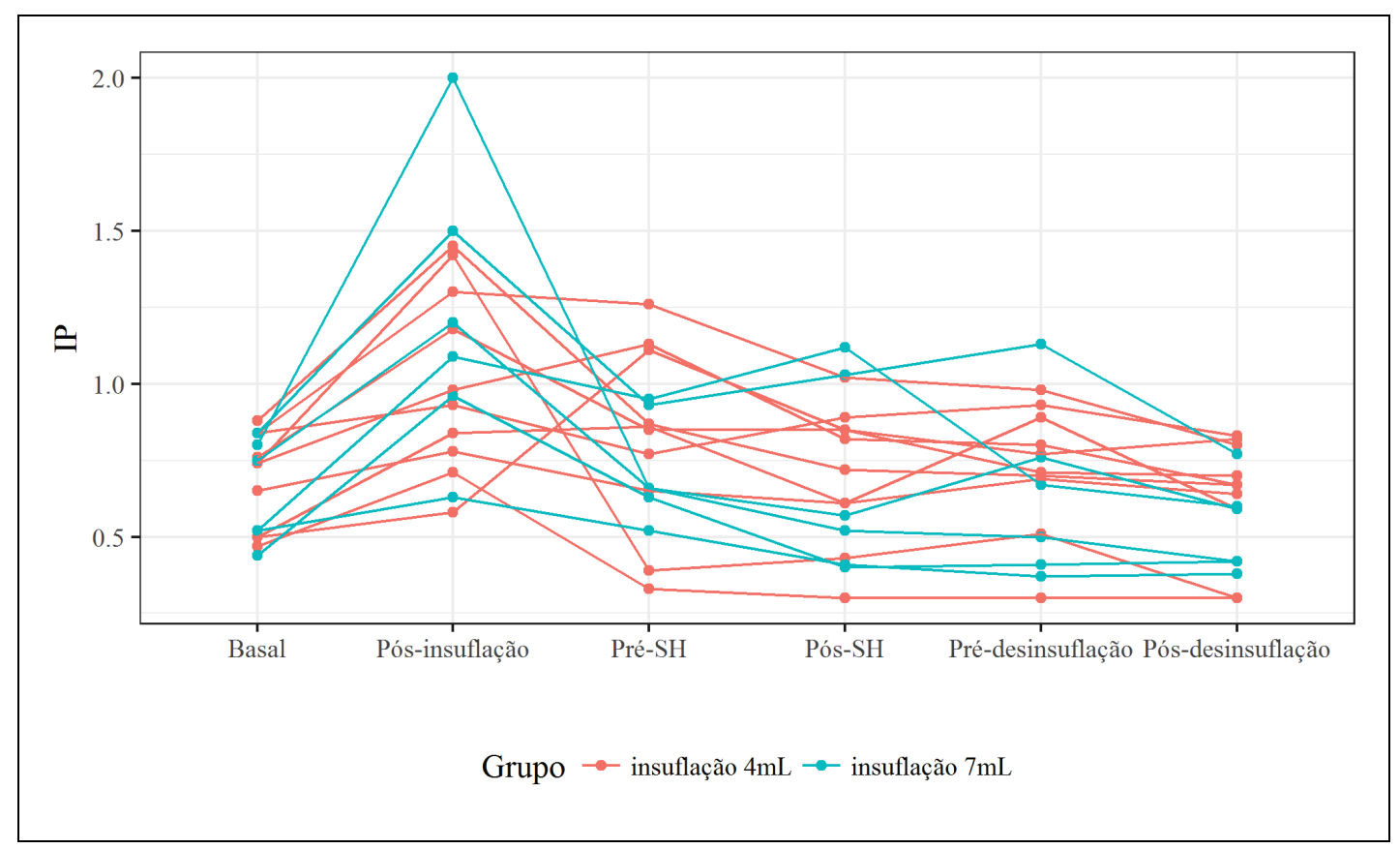

IP: Índice de pulsatilidade; SH: Solução salina hipertônica

Gráfico 11 -Distribuição do perfil médio de IP por grupo (eccluindo-se os suínos 15 e 16)

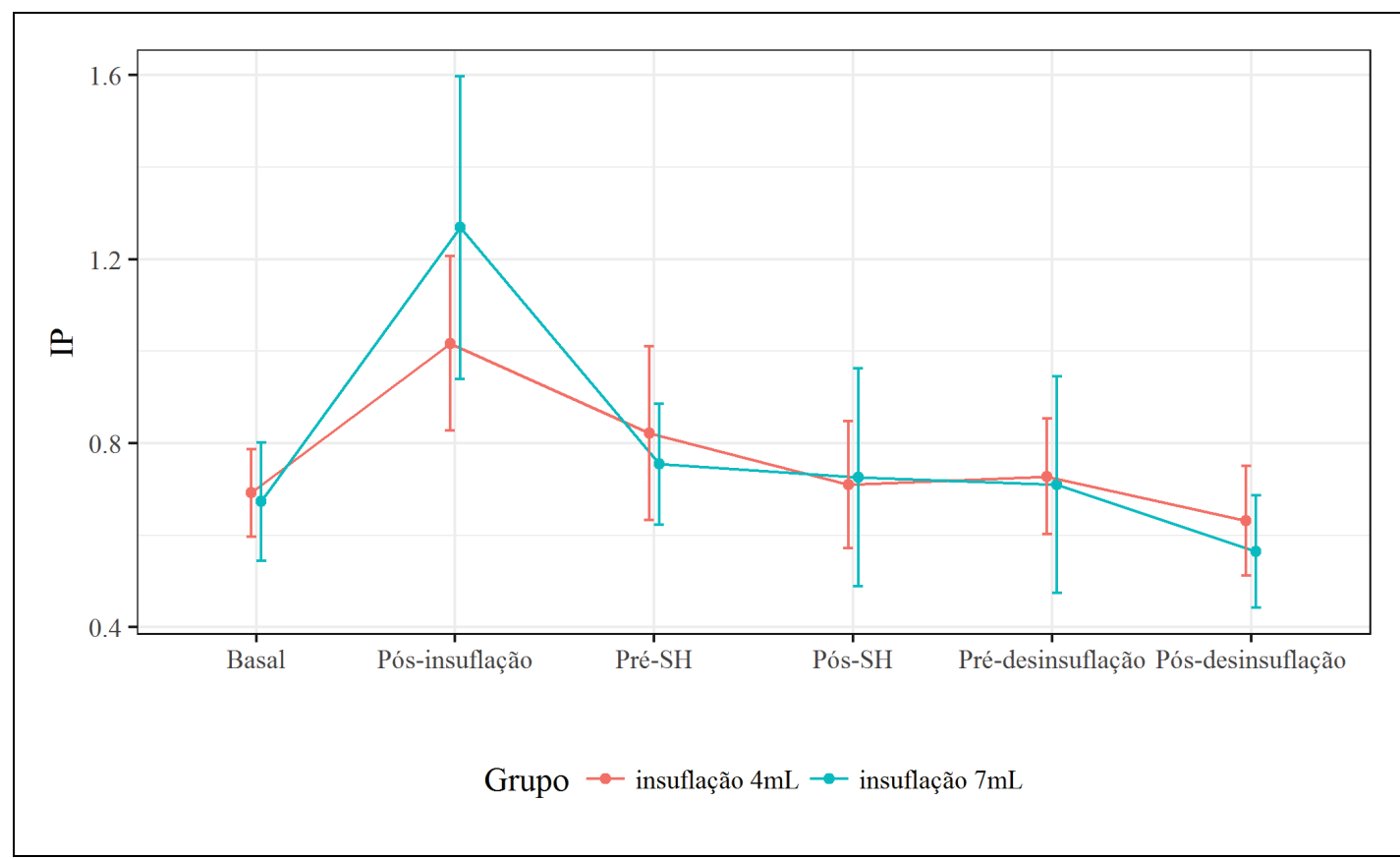

IP: Índice de pulsatilidade; SH: Solução salina hipertônica 
Tabela 7 - Comparações múltiplas da diferença do IP entre os grupos $B$ e A nos diferentes momentos do experimento (excluindose os suínos 15 e 16). São Paulo, 2013

\begin{tabular}{lcc}
\hline \multicolumn{1}{c}{ Comparações múltiplas } & IC (95\%) & P \\
\hline $7 \mathrm{~mL}$ - $4 \mathrm{~mL}$ (Basal) & $-0,02[-0,27 ; 0,23]$ & 0,882 \\
$7 \mathrm{~mL}$ - $4 \mathrm{~mL}$ (Pós-insuflação) & $\mathbf{0 , 2 5}[\mathbf{0 , 0 0 ; 0 , 5 0 ]}$ & $\mathbf{0 , 0 5 0}$ \\
$7 \mathrm{~mL}$ - $4 \mathrm{~mL}$ (Pré-SH) & $-0,07[-0,32 ; 0,18]$ & 0,598 \\
$7 \mathrm{~mL}$ - $4 \mathrm{~mL}$ (Pós-SH) & $0,02[-0,24 ; 0,27]$ & 0,903 \\
$7 \mathrm{~mL}$ - $4 \mathrm{~mL}$ (Pré-desinsuflação) & $-0,02[-0,27 ; 0,23]$ & 0,889 \\
$7 \mathrm{~mL}-4 \mathrm{~mL}$ (Pós-desinsuflação) & $-0,07[-0,32 ; 0,18]$ & 0,598
\end{tabular}

O objetivo principal desse estudo consiste em avaliar o quanto a medida da PIC está associada às medidas de IP, VS, VD e VM. Para tanto, construíram-se gráficos de distribuição entre essas medidas em cada um dos momentos e foram apreesentados coeficientes de correlação de Spearman entre as medidas para cada uma das suas relações e momentos, apresentadas nas Tabelas de 8 a 11 e Gráficos de 12 a 15.

As correlações apresentadas nas diagonais da Tabela 8 (PIC x IP, sem suínos 15 e 16) se referem às comparações apresentadas no Gráfico 12. Evidencia-se que a correlação da PIC com o IP no basal e logo após a insuflação é maior do que a correlação existente entre a PIC e os outros valores de IP ao longo do tempo. Ou seja, as medidas da IP no momento basal, quando PIC ainda é normal, e também no pós-insuflação, quando há uma elevação abrupta da PIC, estão mais correlacionadas à PIC do que no decorrer do experimento. Os valores de PIC logo após a desinsuflação voltam a ser correlacionados aos valores do IP. 
Tabela 8 - Correlação de Spearman entre PIC e IP em todos os momentos (excluindo-se os suínos 15 e 16). São Paulo, 2013

\begin{tabular}{|c|c|c|c|c|c|}
\hline \multirow{3}{*}{ PIC } & \multicolumn{5}{|c|}{ IP (sem suínos 15 e 16) } \\
\hline & & & & & Desinsuflação \\
\hline & Basal & Pós-insuflação & Pré & Pós & Pré Pós \\
\hline Basal & $0,661^{*}$ & & & & \\
\hline
\end{tabular}

Pós-insuflação

$0,543^{*}$

Pré-SH

0,022

Pós-SH

0,347

Pré-desinsuflação

0,368

Pós-desinsuflação

$0,578^{*}$

$\left(^{*}\right) p<0,05$

IP: Índice de pulsatilidade; PIC: Pressão intracraniana;SH: Solução salina hipertônica

Gráfico 12 -Dispersão entre PIC e IP em cada momento, sem os suínos 15 e 16

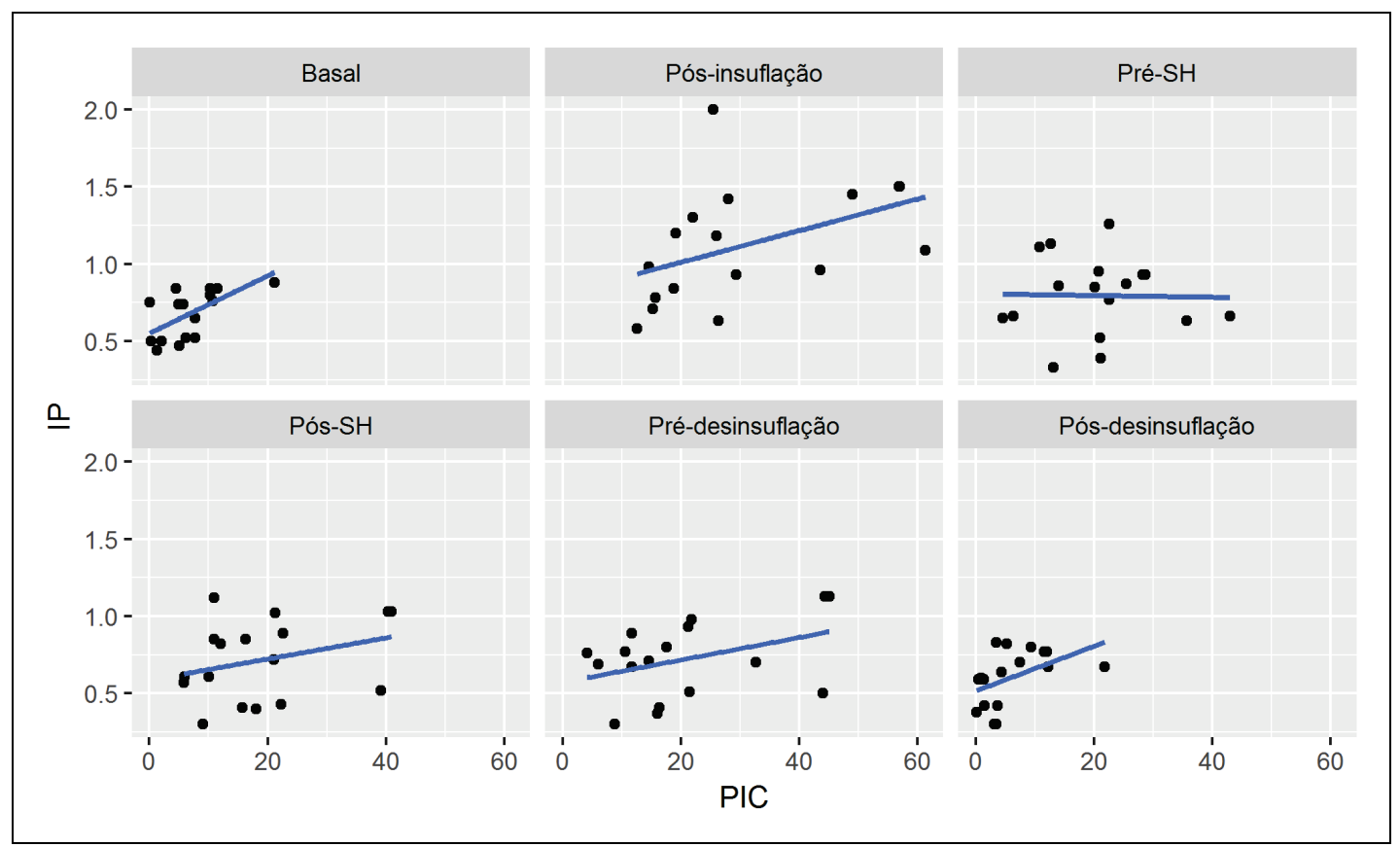

IP: Índice de pulsatilidade; PIC: Pressão intracraniana;SH: Solução salina hipertônica

As correlações da PIC com VD, VM e VS, apresentadas respectivamente nas diagonais das Tabelas de 9 a 11, se referem às comparações apresentadas nos Gráficos de 13 a 15. Os gráficos e as 
Tabela 10 -Correlação de Spearman entre PIC e VM em todos os momentos. São Paulo, 2013

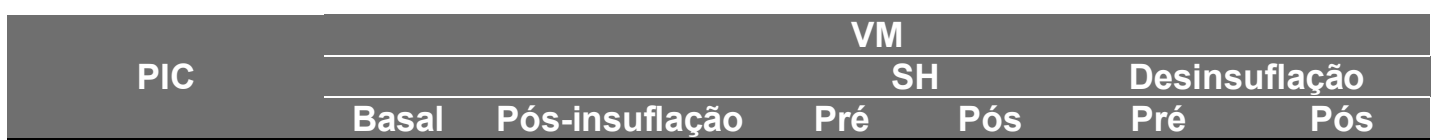

Basal

0,12

Pós-insuflação

$-0,184$

Pré-SH

Pós-SH

0,007

Pré-desinsuflação

$-0,109$

Pós-desinsuflação

0,132

$\left.{ }^{*}\right) p<0,05$

PIC: Pressão intracraniana; SH: Solução salina hipertônica; VM: Velocidade média do fluxo sanguíneo cerebral

\section{Gráfico 14 -Dispersão entre PIC e VM em cada momento}

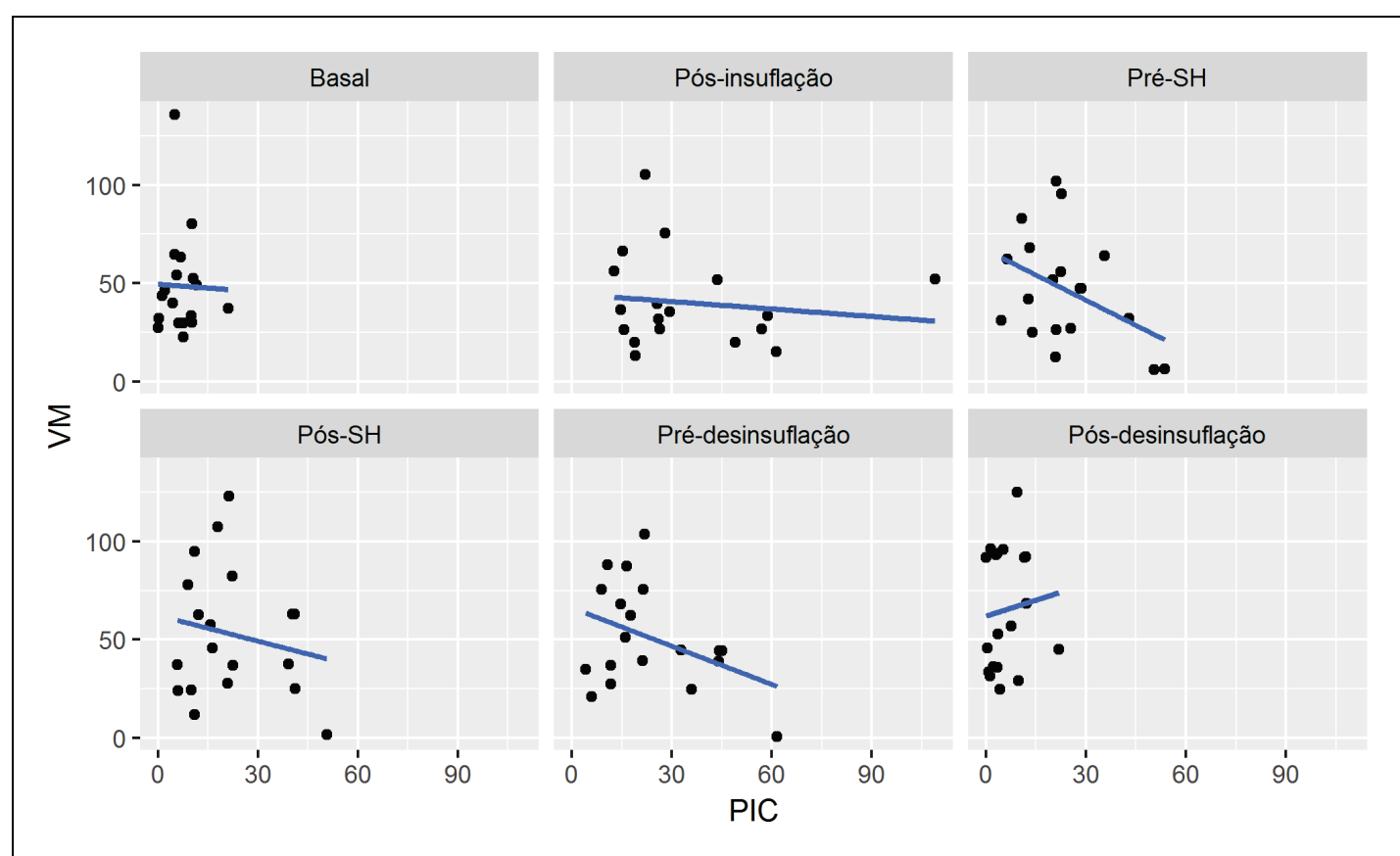

PIC: Pressão intracraniana; SH: Solução salina hipertônica; VM: Velocidades média do fluxo sanguíneo cerebral 
Tabela 11 -Correlação de Spearman entre PIC e VS em todos os momentos

\begin{tabular}{llllll}
\multirow{2}{*}{ PIC } & \multicolumn{4}{c}{ VS } \\
\cline { 2 - 6 } & Basal & Pós-insuflação & Pré & Pós & Pesinsuflação \\
\hline \multirow{2}{*}{ Basal } & 0,146 & & & &
\end{tabular}

Pós-insuflação

$-0,058$

Pré-SH

$-0,135$

Pós-SH

0,34

Pré-desinsuflação

0,096

Pós-desinsuflação

0,304

$\left.{ }^{*}\right) p<0,05$

PIC: Pressão intracraniana; SH: Solução salina hipertônica; VS: Velocidades do fluxo sanguíneo cerebral sistólica

\section{Gráfico 15 -Dispersão entre PIC e VS em cada momento}

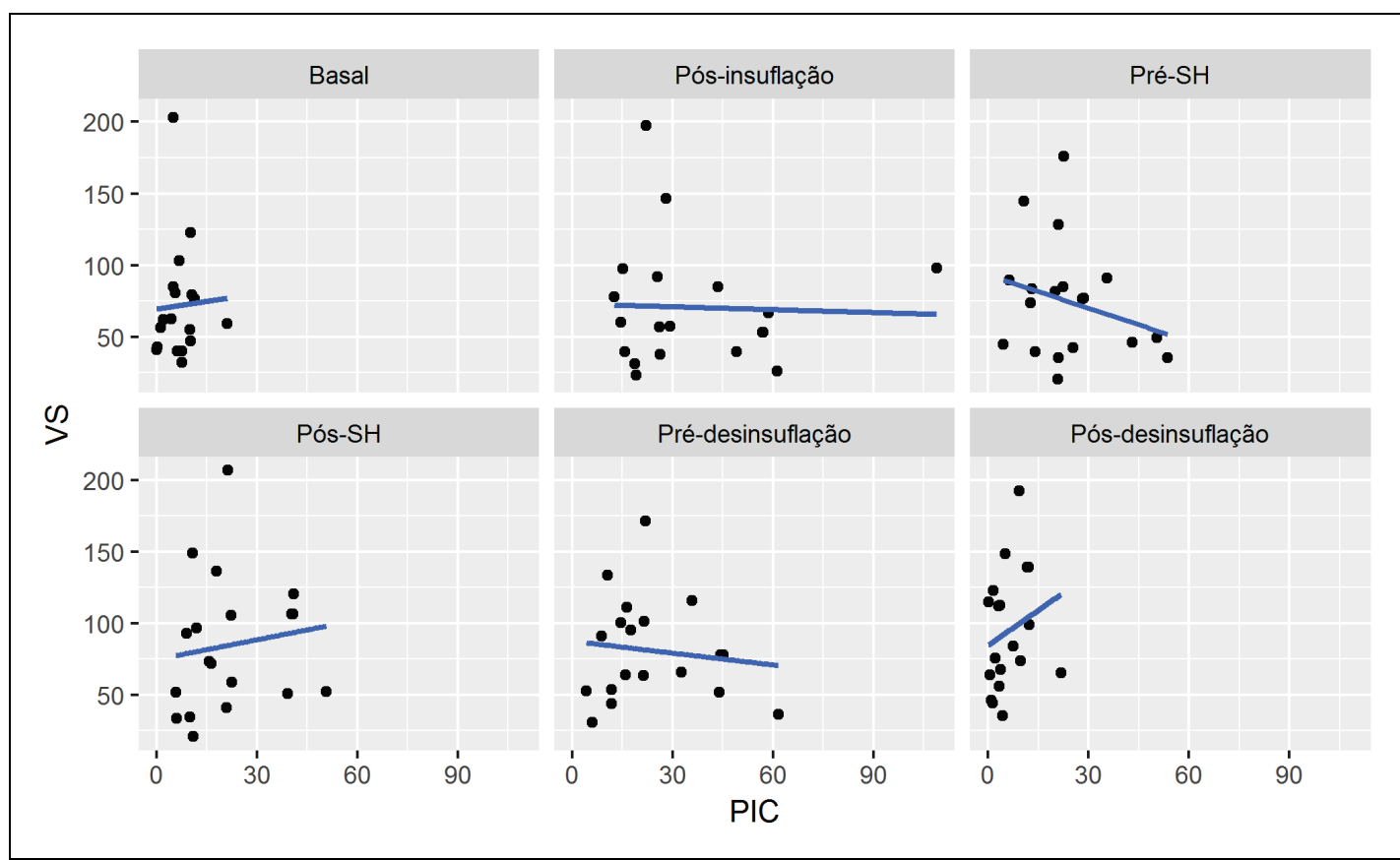

PIC: Pressão intracraniana; SH: Solução salina hipertônica; VS: Velocidades do fluxo sanguíneo cerebral sistólica 


\section{DiscussÃo}




\subsection{Considerações sobre o Modelo Animal de HIC}

O presente estudo se utilizou do modelo animal de HIC desenvolvido no LIM 26 da FMUSP (Andrade et al., 2013), que utiliza a insuflação, com soro fisiológico, de um balão na substância branca do lobo frontal de suínos para induzir a HIC. Balão este que pode ser desinsuflado para reverter a HIC, conforme descrito nos métodos. Os resultados mostraram que os grupos A e B não apresentavam diferenças em relação a PIC no momento basal, ou seja, antes de se induzir a HIC. Após a insuflação do balão (4 mL no grupo A e $7 \mathrm{~mL}$ no grupo B), houve produção de HIC nos dois grupos, sendo que no grupo B a média da PIC se manteve superior à média do grupo A por todo o experimento, voltando a se normalizarem e se igualarem após a desinsuflação. Os dados confirmam este modelo suíno de insuflação de balão intraparenquimatoso como eficaz na produção de HIC sustentada durante o experimento, e também demonstra a capacidade de se reverter a HIC com a desinsuflação do balão.

$\mathrm{Na}$ literatura há descrições de alguns modelos de hipertensão intracraniana experimentais em animais, porém com grande variação da metodologia empregada e dos parâmetros avaliados. Dentre eles, há os de injeção direta de sangue autólogo do animal no parênquima cerebral, o que provoca a HIC (Bullock et al., 1984; Takasugi et al., 1985; Yang et al., 1994; Wagner et al., 1996; Pourcyrous et al., 1997; Xi et al., 1998 e 2001; Hua et 
al., 2000; Nakamura et al., 2003; Rohde et al., 2002). Porém a desvantagem em relação ao modelo do presente estudo, de insuflação de balão, é a incapacidade de reversão da HIC induzida naqueles modelos, o que limita o estudo pós-tratamento. A vantagem é que o contato do sangue com o tecido cerebral desencadeia resposta inflamatória e lesões cerebrais secundárias, semelhante a um hematoma verdadeiro. Este último efeito está ausente no modelo de balão empregado no atual estudo.

Outro modelo clássico de HIC em animais é o da colagenase bacteriana. Esta protease é injetada nos gânglios da base do animal e promove lesão gradual nas paredes dos capilares cerebrais. Assim há formação lenta de um hematoma cerebral (Rosenberg et al., 1990; Clark et al., 1998; Mun-Bryce et al., 2001; Lei et al., 2014). A desvantagem em relação ao modelo de balão também é a irreversibilidade da lesão, além do que, a colagenase pode causar um importante efeito inflamatório no tecido cerebral, interferindo nos resultados. Também os hematomas formados não são uniformes.

O modelo de avulsão de vasos, também descrito na literatura, consiste em expor estes vasos por craniotomia e lesioná-los, provocando um hematoma cerebral (Funnell et a.l, 1990; Xue e Del Bigio, 2003). A desvantagem em relação ao modelo de balão é também a irreversibilidade da HIC, e ainda há uma variabilidade no tamanho do hematoma formado.

Modelos animais de HIC por insuflação de balão intracraniano vêm sendo desenvolvidos há décadas em animais de pequeno porte, como camundongos (Sinar et al., 1987), gatos (Nagai et al. 1997) e coelhos (Kasapas et al., 2014). 
A vantagem do modelo de balão é que ele reproduz o efeito de massa do hematoma de forma similar aos sangramentos agudos no ser humano. A desvantagem é que ele não consegue criar os potenciais efeitos bioquímicos e celulares da presença de sangue e substâncias decorrentes da formação de coágulos. Isso poderia ser a razão pela qual há um menor grau de isquemia neste modelo do que se esperaria com um volume equivalente de sangue (Rojas et al., 2008).

Em 2010, Shi et al. desenvolveram um modelo, em suínos, em que se insuflava um balão intraparenquimatoso para abrir espaço para posterior injeção de sangue autólogo. Assim, obviamente, o modelo se enquadra melhor neste grupo, pois perde as vantagens de um modelo de HIC induzida exclusivamente por insuflação de balão.

Portanto o modelo suíno desenvolvido no projeto piloto de Andrade et al. (2013), e de eficácia na produção de HIC reafirmada neste presente estudo, é um modelo inédito de HIC induzida por insuflação de balão no parênquima cerebral de um animal de grande porte. O cérebro do suíno apresenta giros corticais, além de substância branca bem desenvolvida, estado de saúde mais uniforme nesta idade e um custo relativamente baixo, tornando-o um excelente modelo animal para estudos de hipertensão intracraniana e de hematoma cerebral. A utilização de balão na substância branca subcortical, ao invés de sangue injetado na massa cinzenta dos gânglios basais, resulta em volumes de hematoma mais reprodutíveis e uniformes, além de possibilitar a desinsuflação do balão, e consequente reversão da HIC. 


\subsection{Considerações sobre as Correlações da PIC com os Parâmetros do DTC}

A monitoração invasiva da PIC por dispositivos intracranianos, intraparenquimatosos ou intraventriculares, se desenvolveu ao longo do Século $\mathrm{XX}$, e se tornou o método padrão ouro pra este fim. Apesar de alguns trabalhos questionarem o real benefício da monitoração invasiva da PIC (Cremer et al., 2005; Chesnut et al., 2012), a recomendação atual dos consensos norteamericano e europeu coloca esta monitoração como ponto central no manejo de pacientes neurocríticos tratados em UTI (Le Roux et al., 2014; Carney et al., 2017), conforme explicitado na revisão bibliográfica desta tese.

Apesar da boa acurácia e da vasta experiência histórica das técnicas de monitoração invasiva da PIC, estas podem trazer riscos e complicações, como infecções, hematomas e mau posicionamento ou mau funcionamento dos dispositivos (Steiner e Andrews, 2006; Andrade et al., 2011). Por isso, nos últimos anos, há um grande número de estudos que visam a desenvolver diversas técnicas não invasivas para estimação da PIC (Bellner et al., 2004; Cardim et al., 2016c; Robba et al., 2017; Roh e Park 2016).

Dentre estas técnicas se destaca o estudo do DTC, com ênfase no IP como parâmetro de estimação não invasiva da PIC (Bellner et al., 2004; Bouzat et al., 2016; Cardim et al., 2016a e 2016b). Tornam o DTC um método interessante a sua disponibilidade nos hospitais, sua portabilidade, a facilidade em realizar repetidos exames não invasivos na beira do leito. A limitação técnica básica que é medir a velocidade do fluxo sangüíneo cerebral e não o fluxo de volume verdadeiro, estimulou mais ainda o estudo e o desenvolvimento na utilização do dados adquiridos pelo DTC (Bellner et al., 2004). 
No presente estudo os resultados mostraram que os grupos $A$ e B não apresentavam diferenças em relação aos parâmetros do Doppler no momento basal, ou seja, antes de se induzir a HIC os grupos eram semelhantes em relação aos parâmetros do USNG com Doppler craniano. Após a insuflação do balão e conseqüente produção de HIC nos dois grupos, as variáveis VS, VD e VM tiveram comportamento semelhante nos dois grupos, não evidenciando diferença estatística dos valores. Já o IP foi estatisticamente mais elevado no grupo B, de PIC mais elevada, no momento imediatamente após a insuflação do balão. Nos demais momentos do experimento não houve diferença estatisticamente significante dos valores da média do IP entre os dois grupos (excluídos os animais 15 e 16).

Foram calculadas também as correlações entre a PIC e as variáveis VS,VD, VM e IP. Encontrou-se correlação do IP com a PIC em três momentos do experimento (coeficientes de correlação de Spearman). No basal (r: 0,661), no pós- insuflação (r: 0,543 ) e no pós-desinsuflação (r: $0,578)$, todos com $p<0,05$. Do momento pré-SH ao pré-desinsuflação não houve correlação estatisticamente significante. Já as variáveis VS, VD e VM não tiveram correlação com a PIC em nenhum dos momentos do experimento. Os dados obtidos são consonantes com os de alguns trabalhos da literatura e contrários aos de outros, conforme discutido a seguir.

Bellner et al. realizaram em 2004 um estudo prospectivo para investigar a relação da PIC com o IP, obtido por DTC. Foram estudados 81 pacientes com lesões cerebrais diversas (hemorragia subaracnoidea, TCE, HIE, entre outros) que receberam cateter intraventricular para monitorar a PIC. Encontrou-se 
relação direta da PIC com IP, obtendo-se elevado coeficiente de correlação de 0,938. Estes resultados foram confirmados por outro estudo prospectivo de um centro hospitalar em Istambul (Gura et al., 2011). Neste, foram avaliados 58 pacientes com TCE grave, tratados em UTI conforme o guideline da Brain Trauma Foundation. Foi realizado DTC diariamente para comparação do IP com a monitoração invasiva da PIC (cateteres intraparenquimatosos ou intraventriculares). Encontrou-se forte correlação entre IP e PIC, sendo o coeficiente de correlação no quinto dia de 0,779.

Já em 2016, Cardim et al. (2016a) realizaram um estudo retrospectivo em Cambridge - Reino Unido, onde 53 pacientes passaram por um teste de infusão (infusão de solução salina no espaço liquórico, por punção lombar, para estudo de distúrbios de circulação liquórica). Foram medidos os valores de PIC (pela agulha lombar), e velocidades de fluxo sanguineo na artéria cerebral média por DTC. Um dos parâmetros estudados para mensuração não invasiva da PIC foi o IP obtido pelo DTC. Houve significância estatística na correlação direta entre esses dois parâmetros $(r: 0,45)$ evidenciando bom potencial do IP para estimação não invasiva da PIC. Uma importante limitação do trabalho é o fato de se tratar de estudo retrospectivo, além de os dados terem sido coletados em períodos diferentes.

Outros trabalhos também obtiveram resultados positivos referentes à correlação da PIC com o IP em pacientes com lesões cerebrais (Czosnyka et al., 1998; Voulgaris et al., 2005; Melo et al., 2011; de Riva et al., 2012; Wang et al., 2014; Wakerley et al., 2014; O'Brien et al., 2015). Estes trabalhos são condizentes com os resultados do presente experimento em 
que se encontrou forte correlação entre o IP e a PIC em três importantes momentos. Ressalta-se o coeficiente de correlação de 0,543 logo após a insuflação do balão, que é o momento em que ocorre a elevação da PIC. Nos demais momentos, em que a PIC se mantém elevada, porém estável, o IP perdeu a correlação com a PIC. Pode-se inferir daí que o IP talvez seja importante na monitoração da piora da PIC, podendo ser indicado em pacientes com esta suspeita de deterioração.

Bouzat et al. realizaram, em 2016, um estudo prospectivo francês multicêntrico. Foram estudados 356 pacientes com TCE leve e moderado (Glasgow entre 9 e 15). Realizou-se o DTC bilateral até 8 horas após o trauma. O objetivo era avaliar DTC como preditor de deterioração neurológica secundária nestes pacientes (ocorreu em 6\% dos pacientes do estudo), no sétimo dia pós trauma. O parâmetro DTC normal considerado foi IP menor que 1,25 e VD maior que $25 \mathrm{~cm} / \mathrm{s}$. Este parâmetro teve sensibilidade de $80 \%$ e especificidade de $79 \%$ para predizer piora neurológica. $O$ valor preditivo negativo foi de $98 \%$ e o valor preditivo positivo foi de $18 \%$, sugerindo que o resultado normal do DTC seja mais importante na predição de prognóstico do que o DTC anormal. Também este estudo mostrou que o IP e a VD estão relacionadas ao prognóstico dos pacientes com TCE leve a moderado. Uma limitação do estudo foi a baixa taxa de pacientes com deterioração neurológica, que era o foco do estudo, o que pode ter causado viés nos resultados. Este trabalho, apesar de não estudar a correlação dos parâmetros do DTC com a PIC, reforça a possível utilidade do IP e VD como triadores de pacientes potencialmente em risco de piora neurológica. 
Outro estudo prospectivo, de Martí-Fàbregas et al. (2015, avaliou 51 pacientes com HIE, comparando o volume destes hematomas na TC inicial com parâmetros do DTC. Quanto maior o volume do HIE maior foi o IP e menor foi o VD, encontrando correlação estatisticamente significante, com coeficientes de correlação de 0,59 (forte) e -0,32 (fraca) respectivamente. Não houve correlação entre o volume do HIE na TC com VM ou VS. As limitações deste estudo incluem a ausência de monitoração invasiva da PIC, e a utilização para a análise apenas de TC iniciais, sem acompanhamento da evolução do volume do HIE e dos parâmetros do DTC. Porém o resultado reforça a possível indicação de se usar o IP na triagem inicial de pacientes com lesões agudas cerebrais.

A despeito destes resultados, encontra-se na literatura muitos trabalhos que contradizem os resultados positivos de correlação entre PIC e IP. Em 2016, Cardim et al.,(2016c) em estudo prospectivo incluíram 40 pacientes vítimas de TCE que foram tratados em UTI de um hospital, e que receberam um cateter intraparenquimatoso para monitorar a PIC. Foram coletados os dados de PIC e DTC. Um dos parâmetros analisados para avaliação não invasiva da PIC foi o IP. Não se observou correlação estatisticamente significante entre IP e PIC. Os resultados foram concordantes aos de Figaji et al. (2009), outro estudo prospectivo que avaliou 34 crianças com TCE grave, que tiveram a PIC monitorada. DTC foi realizado na artéria cerebral média ipsilateral ao cateter de PIC. Tentou-se determinar neste estudo correlação entre o IP maior que 1 e a PIC superior a $20 \mathrm{mmHG}$, assim como o IP menor que 1 com a PIC menor que 20 mmHG. Porém não houve correlação do IP 
com PIC em nenhuma dessas situações. A conclusão deste estudo foi que o IP não é um bom parâmetro para avaliação nao invasiva da PIC em crianças com TCE. Estes resultados são condizentes com outros estudos já publicados (Hanlo et al., 1995; Zweifel et al., 2012; Cardim et al., 2016c; Morgalla e Magunia, 2016; Robba et al., 2017).

\subsection{Efeito da Infusão de Solução Salina Hipertônica no Presente Modelo Experimental}

Como descrito na revisão bibliográfica, a terapia hiperosmolar é usada para tratar edema cerebral e HIC de diversas etiologias, sendo o manitol a 20\% a solução padrão ouro. Porém a SH, em diferentes concentrações, vem sendo muito estudada para tal finalidade (Fink, 2012; Diringer, 2013; Stocchetti e Maas, 2014). As soluções hipertônicas agem através da desidratação do tecido cerebral e diminuição da resposta inflamatória do cérebro à lesão, além de causar efeitos positivos na homeostase e hemodinâmica cardiovascular (Suarez, 2004; Li et al., 2015). Apesar de não haver consenso sobre a melhor concentração de SH para controle da HIC, neste trabalho foi utilizada a concentração de $3 \%$, por ser equiosmolar ao manitol $20 \%$, e também por haver trabalhos relatando sua boa eficácia em relaxamento cerebral intraoperatório e também em controlar HIC de variadas causas, além de boa segurança com poucos efeitos colaterais (Khanna et al., 2000; Prabhakar et al., 2014, Sokhal et al., 2017).

No atual estudo, os grupos A e B mantiveram a PIC estável após a infusão da $\mathrm{SH}$, conforme descrito nos resultados, sem apresentar o efeito de 
redução da PIC demonstrado em outros trabalhos. Talvez o presente modelo animal de HIC não seja adequado para avaliar efeitos da SH. A dilatação do balão simula um efeito de massa aguda com um material que não responde às mudanças na osmolaridade do sangue. Os benefícios da $\mathrm{SH}$ são postulados como resultado de um efeito osmolar, o que não afetaria o balão. Outros efeitos da SH como aumento do débito cardíaco e inibição de alterações inflamatórias também não são aplicáveis neste modelo. Isso justifica os resultados obtidos neste experimento, em que não houve alteração da PIC após infusão da SH. Portanto o modelo de HIC por insuflação de balão simula um processo de doença que só é passível de ser tratado por intervenção cirúrgica.

\subsection{Limitações do Estudo}

O presente estudo experimental tem em sua metodologia e resultados importantes contribuições em relação ao desenvolvimento de um modelo animal de HIC induzida e reversível, inédito na literatura. Também contribui com o estudo dos parâmetros obtidos por USNG com Doppler craniana em vigência de HIC. Porém apresenta algumas limitações, descritas a seguir.

Avaliações por ultrassonografia ou Doppler sempre são dependentes do operador, o que se tentou minimizar neste trabalho com a realização do exame sempre pelo mesmo neurossonologista, com vasta experiência.

Os parâmetros VS, VD, VM e IP são influenciáveis não apenas pela PIC. Também sofrem influência da pressão arterial e da viscosidade sanguínea do indivíduo estudado. Neste estudo dois animais apresentaram 
instabilidade hemodinâmica, refratária às tentativas de estabilização realizadas pelos pesquisadores. Assim o IP dos animais 15 e 16 tiveram que ser excluídos da estatística final. Desta forma, salienta-se a importância da estabilidade hemodinâmica dos indivíduos estudados com as técnicas de Doppler.

Outra limitação deste modelo animal é a ausência de contato de sangue com o tecido cerebral. Portanto ele induz a HIC com a insuflação do balão, mas estão ausentes as reações inflamatórias causadas por um hematoma verdadeiro.

Por fim, em relação ao estudo de soluções hipertônicas endovenosas é interessante avaliar seriadamente o sódio sérico durante o experimento, que pode ser alterada pela infusão da soluções, o que não foi feito no presente estudo. Também já foi discutida a limitação deste modelo para estudar essas soluções, pois o balão insuflado não sofre influência das mesmas. 
7 CONCLUSÕES 
O IP calculado a partir dos dados obtidos através da técnica de ultrassonografia Doppler, mostrou correlação com a PIC monitorada por cateter intraparenquimatoso, principalmente no momento de elevação abrupta da PIC. Este resultado demonstra o potencial do IP como bom parâmetro de avaliação de pacientes com suspeita de elevação hiperaguda e recente da PIC. Não se conseguiu demonstrar os mesmos resultados de correlação entre a PIC e as demais variáveis VS, VD e VM. Diante dos achados deste estudo e dos dados conflitantes da literatura disponível até o momento, não se recomenda, por enquanto, a utilização desses parâmetros isoladamente como substitutos da monitoração invasiva da PIC, evidenciando a necessidade de mais estudos clínicos e experimentais acerca do assunto.

Conseguiu-se reafirmar a viabilidade deste modelo experimental de HIC em suínos induzida por insuflação de balão no parênquima cerebral do animal.

Por último, demonstrou-se que o modelo animal utilizado neste estudo não parece adequado para se estudar efeitos de infusão endovenosa de soluções hipertônicas no tratamento da HIC. 


\section{ANEXOS}




\section{Anexo A - Aprovação do projeto pela Comissão de Ética para Análise de Projetos do Hospital da Clínicas da Faculdade de Medicina da Universidade de São Paulo}

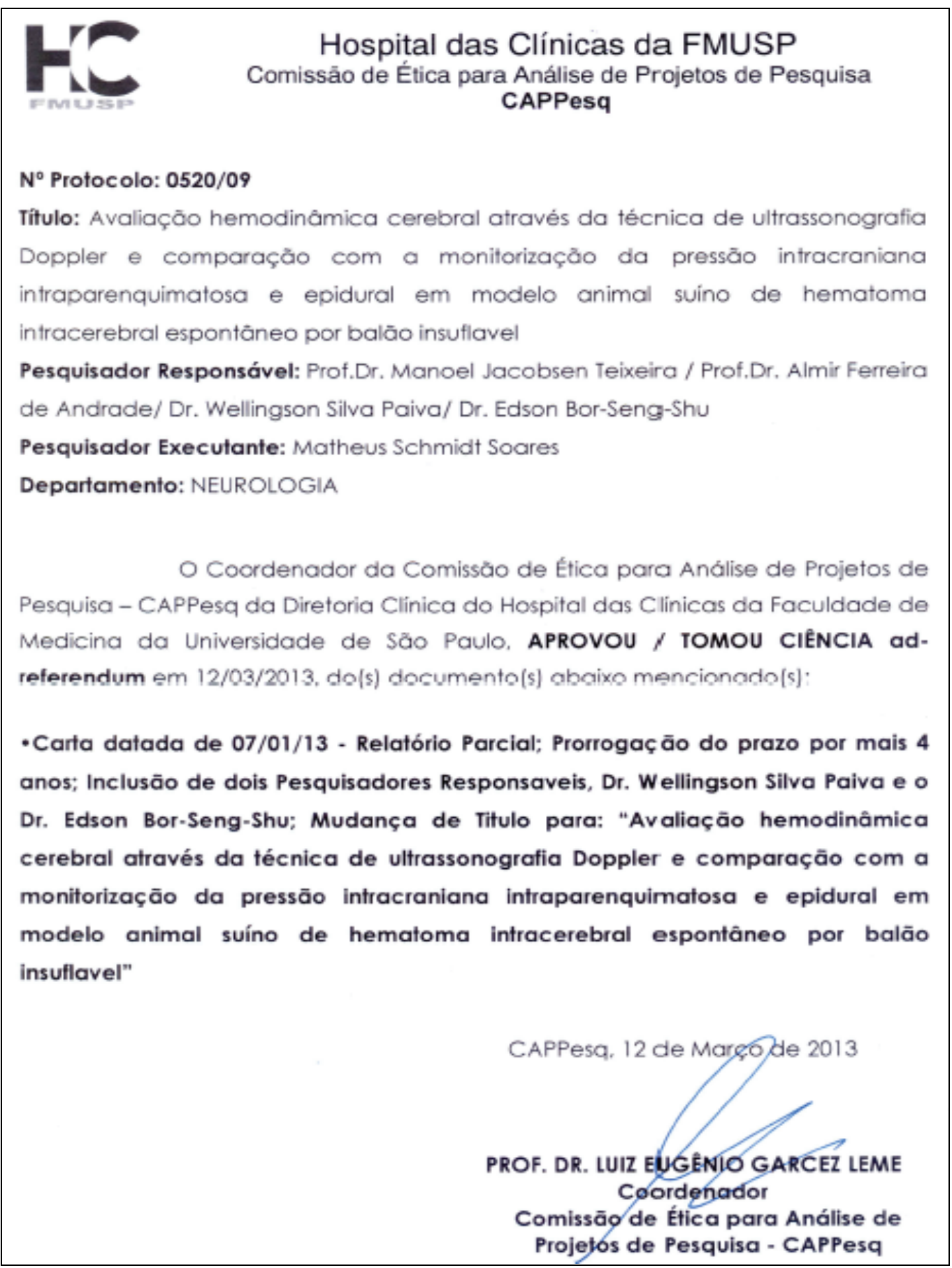


Anexo B - Instrumento de coleta de dados. Para cada variável estudada (VS, VD, VM, IP e PIC) e para cada dado da monitoração clínica e anestésica foi utilizado um formulário deste

\begin{tabular}{|c|c|c|c|c|c|c|c|c|c|}
\hline Animal & Grupo & Basal & $\begin{array}{c}\text { Pó- } \\
\text { insuflar }\end{array}$ & $\begin{array}{c}\text { Pré } \\
\text { salina }\end{array}$ & $\begin{array}{c}\text { Pós } \\
\text { salina }\end{array}$ & $\begin{array}{c}\text { Pré } \\
\text { desinsuflar }\end{array}$ & $\begin{array}{c}\text { Pós } \\
\text { desinsuflar }\end{array}$ & Peso & Gênero \\
\hline 1 & A & & & & & & & & \\
\hline 2 & A & & & & & & & & \\
\hline 3 & A & & & & & & & & \\
\hline 4 & A & & & & & & & & \\
\hline 5 & A & & & & & & & & \\
\hline 6 & A & & & & & & & & \\
\hline 7 & A & & & & & & & & \\
\hline 8 & A & & & & & & & \\
\hline 9 & A & & & & & & & & \\
\hline 10 & A & & & & & & & & \\
\hline 11 & B & & & & & & & & \\
\hline 12 & B & & & & & & & & \\
\hline 13 & B & & & & & & & & \\
\hline 14 & B & & & & & & & & \\
\hline 15 & B & & & & & & & & \\
\hline 16 & B & & & & & & & & \\
\hline 17 & B & & & & & & & & \\
\hline 18 & B & & & & & & & & \\
\hline 19 & B & & & & & & & & \\
\hline
\end{tabular}




\section{REFERÊNCIAS}


Aaslid R, Huber P, Nornes $H$. Evaluation of cerebrovascular spasm with transcranial Doppler ultrasound. J Neurosurg. 1984;60:37-41.

Aaslid R, Markwalder TM, Nornes H. Noninvasive transcranial Doppler ultrasound recording of flow velocity in basal cerebral arteries. $J$ Neurosurg. $1982 ; 57: 769-74$.

Andrade AF, Paiva WS, Amorim RL, Figueiredo EG, Almeida AN, Brock RS, Bor-Seng-Shu E, Teixeira MJ. Continuous ventricular cerebrospinal fluid drainage with intracranial pressure monitoring for management of posttraumatic diffuse brain swelling. Arq Neuropsiquiatr. 2011;69(1):79-84.

Andrade AF, Paiva WS, Neville IS, Noleto GS, Alves Junior A, Sandon LH, Bor-Seng-Shu E, Amorim RL, Teixeira MJ. Intracranial pressure monitoring in traumatic brain injury: techniques and clinical applications. Panamerican $J$ Trauma. 2009; 16(1): 26-32.

Andrade AF, Paiva WS, Neville IS, Noleto GS, Alves Junior A, Sandon LH, Bor-Seng-Shu E, Amorim RL, Teixeira MJ. Monoblock external ventricular drainage system in the treatment of patients with acute hydrocephalus: a pilot study. Med Sci Monit. 2014; 20:227-32. 
Andrade AF, Soares MS, Patriota GC, Belon AR, Paiva WS, Bor-Seng-Shu E, Oliveira M de L, Nascimento CN, Noleto GS, Alves Junior AC, Figueiredo EG, Otoch JP, Teixeira MJ. Experimental model of intracranial hypertension with continuous multiparametric monitoring in swine. Arq Neuropsiquiatr. 2013;71(10):802-6.

Andrews PJ, Citerio G. Intracranial pressure. Part one: historical overview and basic concepts. Intensive Care Med. 2004;30:1730-3.

Ariesen MJ, Calus SP, Rinkel GJ, Algra A. Risck factors for intracerebral hemorrhage in the general population: a systematic review. Stroke. 2003, $34: 2060-5$.

Badri S, Chen J, Barber J, Temkin NR, Dikmen SS, Chesnut RM, Deem S, Yanez ND, Treggiari MM. Mortality and long-term functional outcome associated with intracranial pressure after traumatic brain injury. Intensive Care Med. 2012; 38(11):1800-9.

Bauer DF, Razdan SN, Bartolucci AA, Markert JM. Meta-analysis of hemorrhagic complications from ventriculostomy placement by neurosurgeons. Neurosurgery. 2011;69:255-60.

Becker DP, Miller JD, Ward JD, Greenberg RP, Young HF, Sakalas R. The outcome from severe head injury with early diagnosis and intensive management. J Neurosurg. 1977;47(4): 491-502. 
Behrens A, Lenfedt N, Ambarki K, Malm J, Eklund A, Koskinem LO. Transcranial Doppler pulsatility index: not an accurate method to assess intracranial pressure. Neurosurgery. 2010;66(6):1050-7.

Bellner J, Romner B, Reinstrup P, Kristiansson KA, Ryding E, Brandt L. Transcranial Doppler sonography pulsatility index $(\mathrm{PI})$ reflects intracranial pressure (ICP). Surg Neurol. 2004;62(1):45-51

Bhatia A, Gupta AK. Neuromonitoring in the intensive care unit. I. Intracranial pressure and cerebral blood flow monitoring. Intensive Care Med. 2007; 33(7):1263-71.

Boone MD, Oren-Grinberg A, Robinson TM, Chen CC, Kasper EM. Mannitol or hypertonic saline in the setting of traumatic brain injury: what have we learned? Surg Neurol Int. 2015;6:177.

Bor-Seng-Shu E, Kita WS, Figueiredo EG, Paiva WS, Fonoff ET, Teixeira MJ, Panerai RB. Cerebral hemodynamics: concepts of clinical importance. Arq Neuropsiquiatr. 2012;70(5):352-6.

Bouzat P, Almeras L, Manhes P, Sanders L, Levrat A, David JS, Cinotti R, Chabanne R, Gloaguen A, Bobbia X, Thoret S, Oujamaa L, Bosson JL, Payen JF, Asehnoune K, Pes P, Lefrant JY, Mirek S, Albasini F, Scrimgeour C, Thouret JM, Chartier F, Ginet M; TBI-TCD Study Investigators. Transcranial Doppler to Predict Neurologic Outcome after Mild to Moderate Traumatic Brain Injury. Anesthesiology. 2016;125(2):346-54. 
Broderick JP, Brott TG, Duldner JE, Tomsick T, Huster G. Volume of intracerebral hemorrhage. A powerful and easy-to-use predictor of 30-day mortality. Stroke. 1993;24:987-93.

Broderick JP, Diringer MN, Hill MD, Brun NC, Mayer SA, Steiner T, Skolnick BE, Davis SM. Determinants of intracerebral hemorrhage growth: an exploratory analysis. Stroke. 2007;38:1072-5.

Brott T, Broderick J, Kothari R, Barsan W, Tomsick T, Sauerbeck L, Spilker J, Duldner J, Khoury J. Early hemorrhage growth in patients with intracerebral hemorrhage. Stroke 1997;28:1-5.

Bullock R, Mendelow AD, Teasdale GM, Graham DI. Intracranial haemorrhage induced at arterial pressure in the rat. Part 1: Description of technique, ICP changes and neuropathological findings. Neurol Res. 1984;6:184-8.

Burgess S, Abu-Laban RB, Slavik RS, Vu EN, Zed PJ. A Systematic Review of Randomized Controlled Trials Comparing Hypertonic Sodium Solutions and Mannitol for Traumatic Brain Injury: Implications for Emergency Department Management. Ann Pharmacother. 2016;50(4):291-300.

Cardim D, Czosnyka M, Donnelly J, Robba C, Cabella BC, Liu X, Cabeleira MT, Smielewsky P, Haubrich C, Garnett MR, Pickard JD, Czosnyka Z. Assessment of non-invasive ICP during CSF infusion test: an approach with transcranial Doppler. Acta Neurochir (Wien). 2016a;158(2):279-87. 
Cardim D, Robba C, Bohdanowicz M, Donnelly J, Cabella B, Liu X, Cabeleira M, Smielewski P, Schmidt B, Czosnyka M. Non-invasive Monitoring of Intracranial Pressure Using Transcranial Doppler Ultrasonography: Is It Possible? Neurocrit Care. 2016b;25: 473-91.

Cardim D, Robba C, Donnelly J, Bohdanowicz M, Schmidt B, Damian M, Varsos GV, Liu X, Cabeleira M, Frigieri G, Cabella B, Smielewski P, Mascarenhas S, Czosnyka M. Prospective Study on Noninvasive Assessment of Intracranial Pressure in Traumatic Brain-Injured Patients: Comparison of Four Methods. J Neurotrauma. 2016c;33(8):792-802.

Cardim D, Schmidt B, Robba C, Donnelly J, Puppo C, Czosnyka M, Smielewski P. Transcranial Doppler Monitoring of Intracranial Pressure Plateau Waves. Neurocrit Care. 2017; 26(3):330-8.

Carney N, Totten AM, O'Reilly C, Ullman JS, Hawryluk GW, Bell MJ, Bratton SL, Chesnut R, Harris OA, Kissoon N, Rubiano AM, Shutter L, Tasker RC, Vavilala MS, Wilberger J, Wright DW, Ghajar J. Guidelines for the management of severe traumatic brain injury, Fourth Edition. Neurosurgery. 2017;80(1):6-15

Chesnut RM, Temkin N, Carney N, Dikmen S, Rondina C, Videtta W, Petroni G, Lujan S, Pridgeon J, Barber J, Machamer J, Chaddock K, Celix JM, Cherner M, Hendrix T; Global Neurotrauma Research Group. A trial of intracranial-pressure monitoring in traumatic brain injury. $N$ Engl $J$ Med. 2012;367(26):2471-81. 
Clark W, Gunion-Rinker L, Lessov N, Hazel K, Macdonald RL. Citicoline treatment for experimental intracerebral hemorrhage in mice editorial comment. Stroke. 1998;29:2136-40.

Cremer OL, van Dijk GW, van Wensen E, Brekelmans GJ, Moons KG, Leenen LP, Kalkman CJ. Effect of intracranial pressure monitoring and targeted intensive care on functional outcome after severe head injury. Crit Care Med. 2005; 33:2207-13.

Cremer OL. Does ICP monitoring make a difference in neurocritical care? Eur J Anaesthesiol Suppl. 2008;42:87-93.

Cushing $\mathrm{H}$. The blood pressure reaction of acute cerebral compression, illustrated by cases of intracranial hemorrhage. Am J Sci. 1903;125:1017-44.

Czosnyka M, Brady K, Reinhard M, Smielewski P, Steiner LA. Monitoring of cerebrovascular autoregulation: facts, myths, and missing links. Neurocrit Care. 2009;10(3):373-86.

Czosnyka M, Matta BF, Smilewski P, Kirkpatrick PJ, Pickard JD. Cerebral perfusion pressure in head-injured patients: a noninvasive assessment using transcranial Doppler ultrasonography. J Neurosurg. 1998;88:802-8.

Czosnyka M, Pickard JD. Monitoring and interpretation of intracranial pressure. J Neurol Neurosurg Psychiatry. 2004; 5(6):813-21. 
de Riva N, Budohoski KP, Smielewski P, Kasprowicz M, Zweifel C, Steiner LA, Reinhard M, Fábregas N, Pickard JD, Czosnyka M. Transcranial Doppler pulsatility index: what it is and what it isn't. Neurocrit Care. 2012;17(1):58-66.

Diringer MN. New trends in hyperosmolar therapy? Curr Opin Crit Care. 2013;19:77-82.

Dunn LT. Raised intracranial pressure. J Neurol Neurosurg Psychiatry. 2002;73(Suppl. 1):i23-7.

Eriksson EA, Barletta JF, Figueroa BE, Bonnell BW, Vanderkolk WE, McAllen KJ, Ott MM. Cerebral perfusion pressure and intracranial pressure are not surrogates for brain tissue oxygenation in traumatic brain injury. Clin Neurophysiol. 2012;123(6):1255-60.

Fang MC, Go AS, Chanf Y, Hylek EM, Henault LE, Jensvold NG, Singer DE. Death and disability from warfarin-associated intracranial and extracranial hemorrhages. Am J Med. 2007;120:700-5.

Feldmann E, Broderick JP, Kernan WN, Viscoli CM, Brass LM, Brott T, Morgenstern LB, Wilterdink JL, Horwitz RI. Major risk factors for intracerebral hemorrhage in the young are modifiable. Stroke. 2005;36:1881-5.

Figaji AA, Zwane E, Fieggen AG, Siesjo P, Peter JC. Transcranial Doppler pulsatility index is not a reliable indicator of intracranial pressure in children with severe traumatic brain injury. Surg Neurol. 2009;72(4):389-94. 
Fink ME. Osmotherapy for intracranial hypertension: mannitol versus hypertonic saline. Continuum (Minneap Minn). 2012;18:640-54.

Fogelholm R, Murros K, Rissanen A, Avikainen S. Long term survival after primary intracerebral hemorrhage: a retrospective population based study. $J$ Neurol Neurosurg Psychiatry. 2005,76:1534-8.

Francony G, Fauvage B, Falcon D, Canet C, Dilou H, Lavagne P, Jacquot C, Payen JF. Equimolar doses of mannitol and hypertonic saline in the treatment of increased intracranial pressure. Crit Care Med. 2008; 6(3):795800.

Friess SH, Ralston J, Eucker SA, Helfaer MA, Smith C, Margulies SS. Neurocritical care monitoring correlates with neuropathology in a swine model of pediatric traumatic brain injury. Neurosugery. 2011,69(5):1139-47.

Funnell WR, Maysinger D, Cuello AC. Three-dimensional reconstruction and quantitative evaluation of devascularizing cortical lesions in the rat. $J$ Neurosci Methods. 1990;35:147-56.

Goldstein LB, Simel DL. Is this patient having a stroke? JAMA. $2005 ; 293: 2391-402$.

Gorelick PB, Weisman SM. Risck of hemorrhagic stroke with aspirin use: an update. Stroke. 2005;36:1801-7.

Gosling RG, King DH. Arterial assessment by Doppler shift ultrasound. Proc R Soc Med. 1974;67:447-9. 
Gu Y, Hua Y, Keep RF, Morgenstern LB, Xi G. Deferoxamine reduces intracerebral hematoma-induced iron accumulation and neuronal death in piglets. Stroke. 2009;40(6):2241-3.

Guillaume J, Janny P. Continuous intracranial manometry, physiopathologic and clinical significance of the method. Press Med. 1951;59:953-5.

Gura M, Elmaci I, Sari R, Coskun N. Correlation of pulsatility index with intracranial pressure in traumatic brain injury. Turk Neurosurg. $2011 ; 21(2): 210-5$.

Hanlo PW, Gooskens RH, Nijhuis IJ, Faber JA, Peters RJ, van Huffelen AC, Tulleken CA, Willemse J. Value of transcranial Doppler indices in predicting raised ICP in infantile hydrocephalus. A study with review of the literature. Childs Nerv Syst. 1995;11(10):595-603.

Hartl R, Bardt TF, Kiening KL, Sarrafzadeh AS, Schneider GH, Unterberg AW. Mannitol decreases ICP but does not improve brain-tissue $\mathrm{pO} 2$ in severely head-injured patients with intracranial hypertension. Acta Neurochir Suppl. 1997;70:40-2.

Harukuni I, Kirsch JR, Bhardwaj A. Cerebral resuscitation: role of osmotherapy. J Anesth. 2002;16:229-37.

Harutjunyan L, Holz C, Rieger A, Menzel M, Grond S, Soukup J. Efficiency of $7.2 \%$ hypertonic saline hydroxyethyl starch $200 / 0.5$ versus mannitol $15 \%$ in the treatment of increased intracranial pressure in neurosurgical patients - a randomized clinical trial. Crit Care. 2005;9(5):R530-40. 
Hemphill JC 3rd, Greenberg SM, Anderson CS, Becker K, Bendok BR, Cushman M, Fung GL, Goldstein JN, Macdonald RL, Mitchell PH, Scott PA, Selim MH, Woo D; American Heart Association Stroke Council; Council on Cardiovascular and Stroke Nursing; Council on Clinical Cardiology. Guidelines for the Management of Spontaneous Intracerebral Hemorrhage: A Guideline for Healthcare Professionals From the American Heart Association/American Stroke Association. Stroke. 2015;46(7):2032-60.

Hemphill JCIII, Bonovich DC, Besmertis L, Manley GT, Johnston SC. The $\mathrm{ICH}$ score: a simple, reliable grading scale for intracerebral hemorrhage. Stroke. 2001;32:891-7.

Hua Y, Keep RF, Hoff JT, Xi G. Brain injury after intracerebral hemorrhage: the role of trombin and iron. Stroke. 2007;38:759-62.

Hua Y, Xi G, Keep RF, Hoff JT. Complement activation in the brain after experimental intracerebral hemorrhage. J Neurosurg. 2000;92(6):1016-22.

Ichai C, Armando G, Orban JC, Berthier F, Rami L, Samat-Long C, Grimaud D, Leverve X. Sodium lactate versus mannitol in the treatment of intracranial hypertensive episodes in severe traumatic brain-injured patients. Intensive Care Med. 2009;35(3):471-9.

Juvela S, Heiskanen O, Poranen A, Valtronen S, Kuurne T, Kaste M,Troupp $\mathrm{H}$. The treatment of spontaneous intracerebral hemorrhage. A prospective randomized trial of surgical and conservative treatment. $J$ Neurosurg. $1989 ; 70: 755-8$ 
Kasapas K, Diamantopoulou A, Pentilas N, Papalois A, Douzinas E, Kouraklis G, Slama M, Terkawi AS, Blaivas M, Sargsyan AE, Karakitsos D. Invasive and ultrasound based monitoring of the intracranial pressure in an experimental model of epidural hematoma progressing towards brain tamponade on rabbits. ScientificWorldJournal. 2014;2014:504248.

Khanna S, Davis D, Peterson B, Fisher B, Tung H, O'Quigley J, Deutsch R. Use of hypertonic saline in the treatment of severe refractory posttraumatic intracranial hypertension in pediatric traumatic brain injury. Crit Care Med. 2000;28(4):1144-51.

Kidwell CS, Chalela JA, Saver JL, Starkman S, Hill MD, Demchuk AM, Butman JA, Patronas N, Alger JR, Latour LL, Luby ML, Baird AE, Leary MC, Tremwel M, Ovbiagele B, Fredieu A, Suzuki S, Villablanca JP, Davis S, Dunn B, Todd JW, Ezzeddine MA, Haymore J, Lynch JK, Davis L, Warach S. Comparison of MRI and CT for detection of acute intracerebral hemorrhage. JAMA. 2004,292:1823-30.

Kirkman MA, Allan SM, Parry-Jones AR. Experimental intracerebral hemorrhage: avoiding pitfalls in translational research. J Cereb Blood Flow Metab. 2011;31(11):2135-51.

Ko SB. Multimodality monitoring in the neurointensive care unit: a special perspective for patients with stroke. J Stroke. 2013;15(2):99-108. 
Kosty JA, Leroux PD, Levine J, Park S, Kumar MA, Frangos S, MaloneyWilensky E, Kofke WA. Brief report: a comparison of clinical and research practices in measuring cerebral perfusion pressure: a literature review and practitioner survey. Anesth Analg. 2013;117(3):694-8.

Langfitt TW, Weinstein JD, Kassell NF, Simeone FA. Transmission of increased intracranial pressure. I. Within the craniospinal axis. J Neurosurg. $1964 ; 21: 989-97$.

Le Roux P, Menon DK, Citerio G, Vespa P, Bader MK, Brophy G, Diringer MN, Stocchetti N, Videtta W, Armonda R, Badjatia N, Bösel J, Chesnut R, Chou S, Claassen J, Czosnyka M, De Georgia M, Figaji A, Fugate J, Helbok R, Horowitz D, Hutchinson P, Kumar M, McNett M, Miller C, Naidech A, Oddo M, Olson D, O'Phelan K, Provencio JJ, Puppo C, Riker R, Roberson C, Schmidt M, Taccone F. The International Multidisciplinary Consensus Conference on Multimodality Monitoring in Neurocritical Care: a list of recommendations and additional conclusions: a statement for healthcare professionals from the Neurocritical Care Society and the European Society of Intensive Care Medicine. Neurocrit Care. 2014; 21 Suppl 2:S282-96.

Lei B, Sheng H, Wang H, Lascola CD, Warner DS, Laskowitz DT, James ML. Intrastriatal injection of autologous blood or clostridial collagenase as murine models of intracerebral hemorrhage. J Vis Exp. 2014 Jul 3;(89).

Lescot T, Reina V, Le Manach Y, Boroli F, Chauvet D, Boch AL, Puybasset L. In vivo accuracy of two intraparenchymal intracranial pressure monitors. Intensive Care Med. 2011;37(5):875-9. 
Li M, Chen T, Chen S, Cai J, Hu YH. Comparison of Equimolar Doses of Mannitol and Hypertonic Saline for the Treatment of Elevated Intracranial Pressure After Traumatic Brain Injury A Systematic Review and MetaAnalysis. Medicine (Baltimore). 2015;94(17):e736.

Lundberg N. Continuous recording and control of ventricular fluid pressure in neurosurgical practice. Acta Psychiatr Scand Suppl. 1960;36(149):1-193.

Magalhães MN, Lima ACP. Noções de probabilidade e estatística. São Paulo: IME-USP, 2000.

Martí-Fàbregas J, Belvís R, Guàrdia E, Cocho D, Martí-Vilaltaand JL. Relationship between transcranial doppler and ct data in acute intracerebral hemorrhage. Am J Neuroradiol . 2015;26:113-8.

Mayer SA, Ligneli A, Fink ME, Kessler DB, Thomas CE, Swarup R, Van Heertum RL. Perilesional blood flow and edema formation in acute intracerebral hemorrhage: a SPECT study. Stroke. 1998;29:1791-8.

Mayer SA, Rincon F. Treatment of intracerebral haemorrhage. Lancet Neurol. 2005;4:662-72.

Melo JR, Di Rocco F, Blanot S, Cuttaree H, Sainte-Rose C, Oliveira-Filho J, Zerah M, Meyer PG. Transcranial Doppler can predict intracranial hypertension in children with severe traumatic brain injuries. Childs Nerv Syst. 2011;27:979-84. 
Mendelow AD, Gregson BA, Fernandes HM, Murray GD, Teasdale GM, Hope DT, Karimi A, Shaw MD, Barer DH. Early surgery versus initial conservative treatment in patients with spontaneous supratentorial intracerebral hematomas in the International Surgical Trial in Intracerebral Hemorrhage (STICH): a randomized trial. Lancet. 2005,365:387-97.

Mendelow AD, Gregson BA, Rowan EN, Murray GD, Gholkar A, Mitchell PM; STICH II Investigators. Early surgery versus initial conservative treatment in patients with spontaneous supratentorial lobar intracerebral haematomas (STICH II): a randomised trial. Lancet. 2013;382:397-408.

Misra UK, Kalita J, Vajpayee A, Phadke RV, Hadique A, Savlani V.Effect of single mannitol bolus in intracerebral hemorrhage. Eur $J$ Neurol. 2007;14:1118-23.

Mokri B. The Monro-Kellie hypothesis: applications in CSF volume depletion. Neurology. 2001;56(12):1746-8.

Morgalla $\mathrm{MH}$, Magunia $\mathrm{H}$. Noninvasive measurement of intracranial pressure via the pulsatility index on transcranial doppler sonography: Is improvement possible? J Clin Ultrasound. 2016;44(1):40-5. 
Morgenstern LB, Hemphill JC 3rd, Anderson C, Becker K, Broderick JP, Connolly ES Jr, Greenberg SM, Huang JN, MacDonald RL, Messé SR, Mitchell PH, Selim M, Tamargo RJ; American Heart Association Stroke Council and Council on Cardiovascular Nursing. Guidelines for the management of spontaneous intracerebral hemorrhage: a guideline for healthcare professionals from the American Heart Association/American Stroke Association. Stroke. 2010;41(9):2108-29.

Muizelaar JP, Lutz HA 3rd, Becker DP. Effect of mannitol on ICP and CBF and correlation with pressure autoregulation in severely head-injured patients. J Neurosurg. 1984;61:700-6.

Muizelaar JP, Shahlaie K. Hypertonic saline in neurocritical care: Iscontinuous infusion appropriate? Crit Care Med. 2009,37:1521-3.

Mun-Bryce S, Wilkerson AC, Papuashvili N, Okada YC. Recurring episodes of spreading depression are spontaneously elicited by an intracerebral hemorrhage in the swine. Brain Res. 2001;888(2):248-55.

Murai Y, Ikeda Y, Teramoto A, Godstein JN, Greenberg SM, Smith EE, Lev $\mathrm{MH}$, Rosand J. Contrast extravasation on CT angiography predicts hematoma expansion in intracerebral hemorrhage. Neurology. 2007,69:617.

Nagai H, Moritake K, Takaya M. Correlation between transcranial Doppler ultrasonography and regional cerebral blood flow in experimental intracranial hypertension. Stroke. 1997; 28(3): 603-7. 
Nakagawa K , Serrador J, LaRose S, Sorond F. Dynamic cerebral autoregulation after intracerebral hemorrhage: A case-control study. BMC Neurology. 2011,11:108.

Nakamura T, Keep RF, Hua Y, Schallert T, Hoff JT, Xi G. Deferoxamineinduced attenuation of brain edema and neurological deficits in a rat model of intracerebral hemorrhage. Neurosurg Focus. 2003; 15(4):ECP4.

Narayan RK, Kishore PR, Becker DP, Ward JD, Enas GG, Greenberg RP, Domingues Da Silva A, Lipper MH, Choi SC, Mayhall CG, Lutz HA 3rd, Young HF. Intracranial pressure: to monitor or not to monitor? A review of our experience with severe head injury. J Neurosurg. 1982;56(5):650-9.

O'Brien NF, Maa T, Reuter-Rice K. Noninvasive screening for intracranial hypertension in children with acute, severe traumatic brain injury. $J$ Neurosurg Pediatr. 2015;16(4):420-5.

Oddo M, Levine JM, Frangos S, Carrera E, Maloney-Wilensky E, Pascual JL, Kofke WA, Mayer SA, LeRoux PD. Effect of mannitol and hypertonic saline on cerebral oxygenation in patients severe traumatic brain injury and refractory intracranial hypertension. J Neurol Neurosurg Psychiatry. 2009;80(8):916-20.

Paiva WS. Considerações sobre o modelo experimental de hipertensão intracraniana e avaliação do sistema de microchip para monitoração de pressão epidural [tese]. São Paulo: Faculdade de Medicina, Universidade de São Paulo; 2014. 
Pérez ES, Delgado-Mederos R, Rubiera M, Delgado P, Ribó M, Maisterra O, Ortega G, Álvarez-Sabin J, Molina CA. Transcranial Duplex Sonography for Monitoring Hyperacute Intracerebral Hemorrhage. Stroke. 2009;40:987-990.

Pinheiro JC, Bates DM. Mixed-Effects Models in $S$ and S-PLUS. U.S.A. Springer, 2000. 528 p.

Pourcyrous M, Parfenova H, Shibata M, Bada HS, Korones SB, Leffler CW. The effects of intraventricular/periventricular blood on cerebral 3',5'-cyclic adenosine monophosphate concentration and cerebrovascular reactivity in newborn pigs. Pediatr Res. 1997,42(3):305-10.

Prabhakar H, Singh GP, Anand V, Kalaivani M. Mannitol versus hypertonic saline for brain relaxation in patients undergoing craniotomy. Cochrane Database Syst Rev. 2014 Jul 16;(7):CD010026.

Querish Al, Tuhrim S, Broderick JP, Batjer HH, Hondo H, Hanley DF. Spontaneous intracerebral hemorrhage. N Engl J Med. 2001;344:1450-60.

Rajamani K, Gorman M. Transcranial Doppler in stroke. Biomed Pharmacother. 2001;55(5): 247-57.

Rangel-Castillo L, Robertson CS. Management of intracranial hypertension. Crit Care Clin. 2006;22:713-32.

Rincon F, Mayer SA. Novel therapies for intracerebral hemorrhage. Curr Opin Crit Care. 2004;10:94-100. 
Robba C, Bacigaluppi S, Cardim D, Donnelly J, Bertuccio A, Czosnyka M. Non-invasive assessment of intracranial pressure. Acta Neurol Scand. 2016;134(1):4-21.

Robba C, Cardim D, Tajsic T, Pietersen J, Bulman M, Donnelly J, Lavinio A, Gupta A, Menon DK, Hutchinson PJA, Czosnyka M. Ultrasound non-invasive measurement of intracranial pressure in neurointensive care: a prospective observational study. PLoS Med. 2017;14(7): e1002356.

Roh D, Park S. Brain Multimodality Monitoring: Updated Perspectives. Curr Neurol Neurosci Rep. 2016;16(6):56.

Rohde V, Rohde I, Thiex R, Ince A, Jung A, Dückers G, Gröschel K, Röttger C, Küker W, Müller HD, Gilsbach JM. Fibrinolysis therapy achieved with tissue plasminogen activator and aspiration of the liquefied clot after experimental intracerebral hemorrhage: rapid reduction in hematoma volume but intensification of delayed edema formation. J Neurosurg. 2002;97(4):954-62.

Rojas $\mathrm{H}$, Zhang $\mathrm{JH}$. Animal models of spontaneous intracerebral hemorrhage. In: Zhang JH (ed.). Advancements in neurological research. Research SignPost. 2008. p. 39-89.

Rosand J, Eckman MH, Knudsen KA, Singer DE, Greenberg SM. The effect of warfarin and intensity of anticoagulation on outcome of intracerebral hemorrhage. Arch Intern Med. 2004,164:880-4.

Rosenberg GA, Mun-Bryce S, Wesley M, Kornfeld M. Collagenase-induced intracerebral hemorrhage in rats. Stroke. 1990;21:801-7. 
Sagher $O$. Treatment guidelines from the Brain Trauma Foundation. $J$ Neurosurg. 2013;119:1246-7.

Sahuquillo J, Gregson B; BrainlT group. Multicenter clinical assessment of the Raumedic Neurovent-P intracranial pressure sensor: a report by the BrainlT group. Neurosurgery. 2008;63(6):1152-8.

Saloheimo P, Ahonen M, Juvela S, Pythinen J, Savolainen ER, Hillbom M. Regular aspirin use preceding the onset of primary intracerebral hemorrhage is an idependent predictor for death. Stroke. 2006; 37:129-33.

Schmidt B, Klingelho"fer J, Schwarze JJ, Sander D, Wittich I. Noninvasive prediction of intracranial pressure curves using transcranial Doppler ultrasonography and blood pressure curves. Stroke. 1997,28:2465-72.

Schmidt EA, Czosnyka M, Gooskens I. Preliminary experience of the estimation of cerebral perfusion pressure using transcranial Doppler ultrasonography. J Neurol Neurosurg Psychiatry. 2001,70:198-204.

Schreckinger M, Marion DW. Contemporary management of traumatic intracranial hypertension: is there a role for therapeutic hypothermia? Neurocrit Care. 2009;11(3):427-36.

Segal AZ, Chiu RI, Eggleston-Sexton PM, Beiser A, Greenberg SM. Low cholesterol as risk factor for primary intracerebral hemorrhage: a case control study. Neuroepidemiology. 1999,18:185-93. 
Shi Y, Li Z, Zhang S, Xie M, Meng X, Xu J, Liu N, Tang Z. Establishing a model of supratentorial hemorrhage in the piglet. Tohoku $J$ Exp Med. 2010,220(1):33-40.

Sinar EJ, Mendelow AD, Graham DI, Teasdale GM. Experimental intracerebral hemorrhage: effects of a temporary mass lesion. $J$ Neurosurg. 1987;66(4):568-76.

Skidmore CT, Andrefsky J. Spontaneous intracerebral hemorrhage: epidemiology, pathophisiology, and medical management. Neurosurg Clin N Am. 2002; 3:281-8.

Sokhal N, Rath GP, Chaturvedi A, Singh M, Dash HH. Comparison of $20 \%$ mannitol and $3 \%$ hypertonic saline on intracranial pressure and systemic hemodynamics. J Clin Neurosci. 2017;42:148-54.

Sorani MD, Morabito D, Rosenthal G, Giacomini KM, Manley GT. Characterizing the dose-response relationship between mannitol and intracranial pressure in traumatic brain injury patients using a high-frequency physiological data collection system. J Neurotrauma. 2008;25:291-8.

Steiner LA, Andrews PJ. Monitoring the injured brain: ICP and CBF. $\mathrm{Br} J$ Anaesth. 2006;97(1):26-38.

Stocchetti N, Maas Al. Traumatic intracranial hypertension. $N$ Engl J Med. 2014;370:2121-30. 
Sturgeon JD, Folsom AR, Longstreth WT Jr, Shahar E, Rosamond WD, Cushman M. Risk factors for intracerebral hemorrhage in a pooled prospective study. Stroke. 2007,38:2718-25.

Suarez Jl. Hypertonic saline for cerebral edema and elevated intracranial pressure. Clev Clin J Med. 2004;71(1):9-13.

Sussman BJ, Barber JB, Goald H. Experimental intracerebral hematoma. Reduction of oxygen tension in brain and cerebrospinal fluid. J Neurosurg. 1974;41(2):177-86.

Sutherland GR, Auer RN. Primary intracerebral hemorrhage. J Clin Neurosci. 2006;13(5):511-7.

Takasugi S, Ueda S, Matsumoto K. Chronological changes in spontaneous intracerebral hematoma--an experimental and clinical study. Stroke. $1985 ; 16(4): 651-8$.

Talving P, Karamanos E, Teixeira PG, Skiada D, Lam L, Belz- berg H, Inaba K, Demetriades D. Intracranial pressure monitoring in severe head injury: compliance with Brain Trauma Foundation guidelines and effect on outcomes: a prospective study. Clinical article. J Neurosurg. 2013;119:12481254.

Thrift AG, Dewey HM, MacDonell RA, McNeil JJ, Donnan GA. Incidence of the major stroke subtypes: initial findings from the North East Melbourne stroke incidency study (NEMESIS). Stroke. 2001;32:1732-8. 
Torack RM. Historical aspects of normal and abnormal brain fluids. I. Cerebrospinal fluid. Arch Neurol. 1982;39(4):197-201.

Toyada K, Okada Y, Minematsu K, Kamouchi M, Fujimoto S, Ibayashi S, Inoue T. Antiplatelet therapy contributes to acute deterioration of intracerebral hemorrhage. Neurology. 2005,65:1000-4.

Treggiari MM, Schutz N, Yanez ND, Romand J-A. Role of intracranial pressure values and patterns in predicting outcome in traumatic brain injury: a systematic review. Neurocrit Care. 2007;6:104-12.

Ursino M, Giulioni M, Lodi CA. Relationship among cerebral perfusion pressure, autoregulation, and transcranial Doppler waveform: a modeling study. J Neurosurg. 1998,89:255-66.

van Asch CJ, Luitse MJ, Rinkel GJ, van der Tweel I, Algra A, Klijn CJ.. Incidence, case fatality, and functional outcome of intracerebral haemorrhage, over time according to age, sex and ethnic origin: a systematic review and meta-analisys. Lancet Neurol. 2010,9(2):167-76.

Voulgaris SG, Partheni M, Kaliora H, Haftouras N, Pessach IS, Polyzoidis KS. Early cerebral monitoring using the transcranial Doppler pulsatility index in patients with severe brain trauma. Med Sci Monit. 2005;11(2):CR49-52.

Wagner K, Broderick J. Hemorrhagic stroke: pathophysiological mechanisms and neuroprotective treatments. In: Lo EH, Marwah J (eds.). Neurprotection. 2001. p. 471-508. 
Wagner KR, Hua Y, de Courten-Myers GM, Broderick JP, Nishimura RN, Lu SY, Dwyer BE. Tin-mesoporphyrin, a potent heme oxygenase inhibitor, for treatment of intracerebral hemorrhage: in vivo and in vitro studies. Cell Mol Biol (Noisy-le-grand). 2000;46(3):597-608.

Wagner KR, Packard BA, Hall CL, Smulian AG, Linke MJ, De Courten-Myers GM, Packard LM, Hall NC. Protein oxidation and heme oxygenase-1 induction in porcine white matter following intracerebral infusions of whole blood or plasma. Dev Neurosci. 2002;24(2-3):154-60.

Wagner KR, Sharp FR, Ardizzone TD, Lu A, Clark JF. Heme and iron metabolism: role in cerebral hemorrhage. J Cereb Blood Flow Metab. 2003;23(6):629-52.

Wagner KR, Xi G, Hua Y, Kleinholz M, de Courten-Myers GM, Myers RE. Early metabolic alterations in edematous perihematomal brain regions following experimental intracerebral hemorrhage. $J$ Neurosurg. 1998;88(6):1058-65.

Wagner KR, Xi G, Hua Y, Kleinholz M, de Courten-Myers GM, Myers RE, Broderick JP, Brott TG. Lobar intracerebral hemorrhage model in pigs: rapid edema development in perihematomal white matter. Stroke. 1996,27(3):490-7.

Wagner KR, Xi G, Hua Y, Zuccarello M, de Courten-Myers GM, Broderick JP, Brott TG. Ultra-early clot aspiration after lysis with tissue plasminogen activator in a porcine model of intracerebral hemorrhage: edema reduction and blood-brain barrier protection. J Neurosurg. 1999;90(3):491-8. 
Wagner KR. Modeling intracerebral hemorrhage: glutamate, nuclear factorkappa B signaling and cytokines. Stroke. 2007;38(2 Suppl):753-8.

Wakerley BR, Kusuma Y, Yeo LL, Liang S, Kumar K, Sharma AK, Sharma VK. Usefulness of transcranial Doppler-derived cerebral hemodynamic parameters in the noninvasive assessment of intracranial pressure. $J$ Neuroimaging. 2015;25(1):111-6.

Wang Y, Duan YY, Zhou HY, Yuan LJ, Zhang L, Wang W, Li LH, Li L. Middle cerebral arterial flow changes on transcranial color and spectral Doppler sonography in patients with increased intracranial pressure. J Ultrasound Med. 2014;33(12):2131-6.

Wartenberg KE, Schmidt JM, Mayer SA. Multimodality monitoring in neurocritical care. Crit Care Clin. 2007;23(3):507-38.

Whisnant JP, Sayer GP, Millikan CH. Experimental intracerebral hematoma. Arch Neurol. 1963; 9:586-92.

Woo D, Haverbusch M, Sekar P, Kissela B, Khoury J, Schneider A, et al. Effect of Untreated hypertension on hemorrhagic stroke. Stroke. 2004; $35: 1703-8$.

Xi G, Fewel ME, Hua Y, Thompson BG Jr, Hoff JT, Keep RF. Intracerebral hemorrhage: pathophysiology and therapy. Neurocrit Care. 2004,1:5-18. 
Xi G, Hua Y, Bhasin RR, Ennis SR, Keep RF, Hoff JT. Mechanisms of edema formation after intracerebral hemorrhage: effects of extravasated red blood cells on blood flow and blood-brain barrier integrity. Stroke. $2001 ; 32(12): 2932-8$.

Xi G, Keep RF, Hoff JT. Erythrocytes and delayed brain edema formation following intracerebral hemorrhage in rats. J Neurosurg. 1998a;89(6):991-6.

Xi G, Wagner KR, Keep RF, Hua Y, de Courten-Myers GM, Broderick JP, Brott TG, Hoff JT. Role of blood clot formation on early edema development after experimental intracerebral hemorrhage. Stroke. 1998b;29(12):2580-6.

Xiao M, Li Q, Feng H, Zhang L, Chen Y. Neural vascular mechanism for the cerebral blood flow autoregulation after hemorrhagic stroke. Neural Plast. 2017:5819514

Xue M, Del Bigio MR. Comparison of brain cell death and inflammatory reaction in three models of intracerebral hemorrhage in adult rats. J Stroke Cerebrovasc Dis. 2003;12(3):152-9.

Yang GY, Betz AL, Chenevert TL, Brunberg JA, Hoff JT. Experimental intracerebral hemorrhage: relationship between brain edema, blood flow, and blood-brain barrier permeability in rats. J Neurosurg. 1994;81(1):93-102.

Zuccarello M, Andaluz N, Wagner KR. Minimally invasive therapy for intracerebral hematomas. Neurosurg Clin N Am. 2002;13(3):349-54. 
Zweifel C, Czosnyka M, Carrera E, Deriva N, Pickard JD, Smielewski P. Reliability of the blood flow velocity pulsatility index for assessment of intracranial and cerebral perfusion pressures in head-injured patients. Neurosurgery. 2012;71(4):853-61. 